\title{
Alternative Splicing in Vertebrate Photoreceptors and Mechanisms Underlying Retinitis Pigmentosa
}

Jesse C. Sundar

West Virginia University, jcsundar@mix.wvu.edu

Follow this and additional works at: https://researchrepository.wvu.edu/etd

Part of the Genetic Phenomena Commons, and the Genetic Processes Commons

\section{Recommended Citation}

Sundar, Jesse C., "Alternative Splicing in Vertebrate Photoreceptors and Mechanisms Underlying Retinitis Pigmentosa" (2019). Graduate Theses, Dissertations, and Problem Reports. 7661.

https://researchrepository.wvu.edu/etd/7661

This Dissertation is protected by copyright and/or related rights. It has been brought to you by the The Research Repository @ WVU with permission from the rights-holder(s). You are free to use this Dissertation in any way that is permitted by the copyright and related rights legislation that applies to your use. For other uses you must obtain permission from the rights-holder(s) directly, unless additional rights are indicated by a Creative Commons license in the record and/ or on the work itself. This Dissertation has been accepted for inclusion in WVU Graduate Theses, Dissertations, and Problem Reports collection by an authorized administrator of The Research Repository @ WVU.

For more information, please contact researchrepository@mail.wvu.edu. 
Alternative Splicing in Vertebrate Photoreceptors and Mechanisms Underlying Retinitis Pigmentosa

\author{
Jesse Sundar \\ Dissertation submitted \\ to the School of Medicine \\ at West Virginia University
}

in partial fulfillment of the requirements for the degree of

Doctor of Philosophy in

Biochemistry and Molecular Biology

Visvanathan Ramamurthy, Ph.D., Chair

Ronald Gross, M.D.

Maxim Sokolov, Ph.D.

John Hollander, Ph.D.

Peter Stoilov, Ph.D.

Department of Biochemistry and Molecular Biology

West Virginia University School of Medicine

Morgantown, West Virginia

2019

Keywords: Alternative Splicing, Musashi, RNA Binding Protein, BBS8, Retina, Photoreceptor, Outer Segment, Rhodopsin, Transducin, Retinitis Pigmentosa. 


\begin{abstract}
Alternative splicing in vertebrate photoreceptors and mechanisms underlying retinitis pigmentosa
\end{abstract}

Jesse Sundar

RNA binding proteins (RBPs) have emerged as important regulators of gene expression. RBPs typically contain RNA binding domains that recognize a specific sequence and/or structural motifs within the RNA. This allows them to modulate metabolism of RNAs in several possible ways including regulation of alternative splicing and processing, polyadenylation, translocation, localization, modification, stability, or translation. Previous studies have shown the Musashi (MSI) RBP family to be highly expressed in the retina, and more specifically, photoreceptors, but the importance of this expression remains largely unknown. We identified the MSI proteins as potential regulators of alternative exon splicing in murine photoreceptors. We hypothesized that the MSI proteins are essential splicing factors needed to produce photoreceptor-specific transcripts and that inactivation of the Msi genes would lead to decreased photoreceptor function and survival subsequent to aberrant splicing. We also predicted that the MSI proteins were regulating splicing of transcripts involved in ciliogenesis and outer segment morphogenesis.

To test our hypothesis, I generated Cre-LoxP conditional knockout mice to inactivate the Msi genes either in the entire retina and ventral forebrain or specifically rod photoreceptors. I found that both rod and cone photoreceptor function was completely absent after pan-retinal inactivation of both Msi genes. I also discovered alterations in retinal progenitor cell proliferation and decreased retinal cell survival at later ages in the absence of the MSI proteins. When analyzing the morphology of the outer segment and connecting cilium in the absence of MSI, I found defects only in outer segment morphology. Furthermore, I found that the MSI proteins regulate the photoreceptor-specific splicing of several outer segment and cilia-related transcripts including Bbs8, Cc2d2a, Cep290, and Prom1. Lastly, we found that deletion of these photoreceptor-specific exons in C57BL6/J mice did not significantly affect photoreceptor function. 


\section{Acknowledgements}

The work presented in my dissertation is not an individual achievement, but a culmination of support that I have received from my advisor, committee members, family, friends, and colleagues. I would like to thank my advisor Dr. Visvanathan Ramamurthy for training me for the past 4.5 years, and his instruction has allowed me to develop as a scientist in addition to preparing me for my next phase of my training. I would also like to thank my dissertation committee members Dr. John Hollander, Dr. Maxim Sokolov, Dr. Ronald Gross, and Dr. Peter Stoilov for their careful guidance on my projects during my PhD training.

The support and encouragement from my Dad, Mom, Brother, Sister, and extended family has also been invaluable to me during my $\mathrm{PhD}$ training, and without them, I would not be where I am today. I am also grateful to my fellow lab members for their feedback during my time in lab. 


\section{$\underline{\text { Table of Contents }}$}

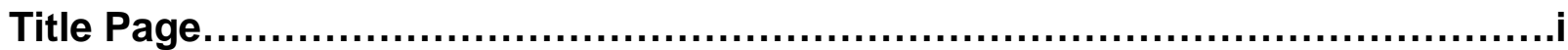

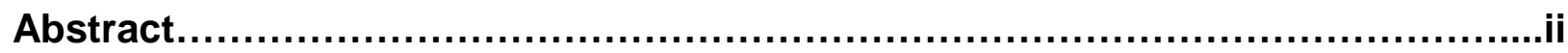

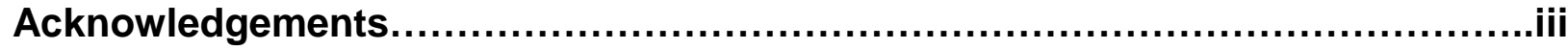

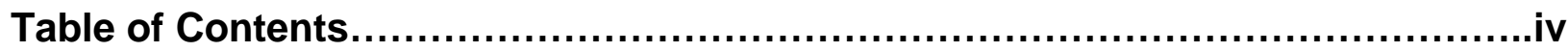

Chapter 1: Background, Introduction, and Hypotheses.................................

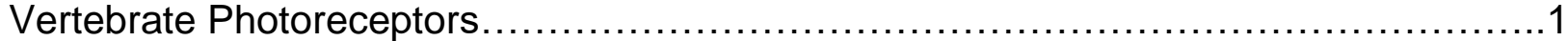

Vertebrate Phototransduction in Rod Photoreceptors.................................. 2

Photoreceptor Development............................................................... 3

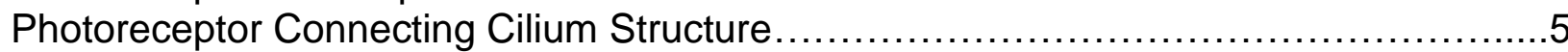

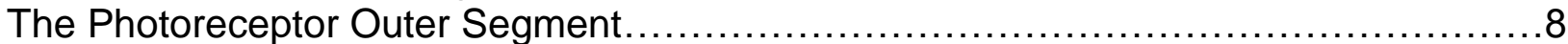

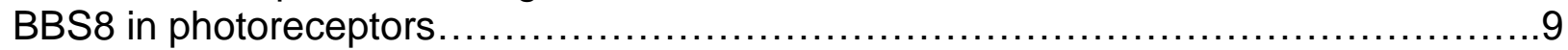

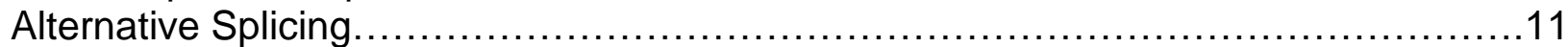

The Musashi (MSI) RNA binding protein family ...................................... 14

Alternative Splicing and Retinal Degeneration....................................... 15

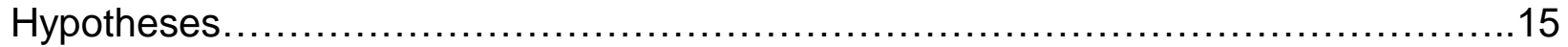

Chapter 2: A critical role for MSI1 and MSI2 in photoreceptor morphogenesis

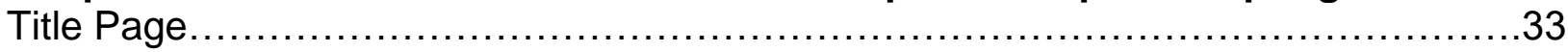

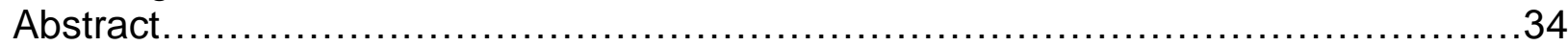

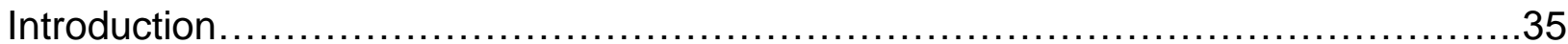

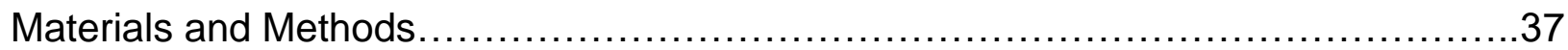

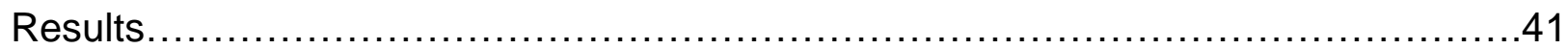

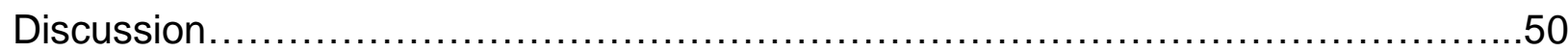

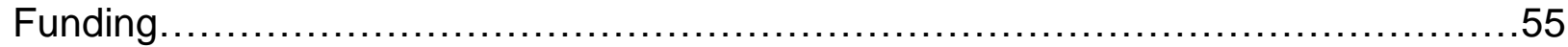

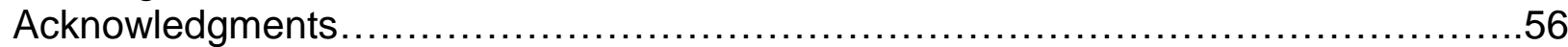

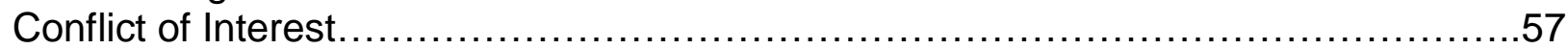

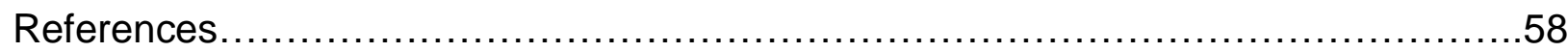

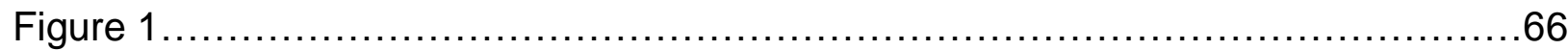

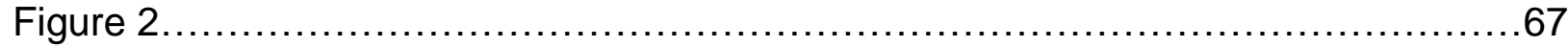

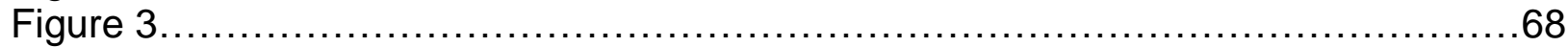

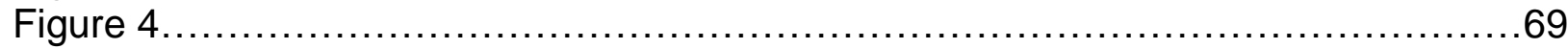

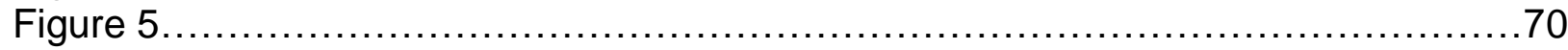

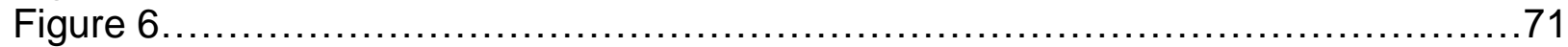

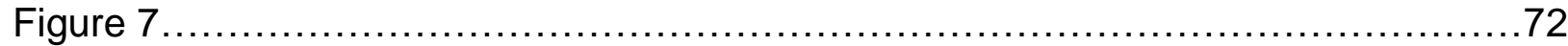

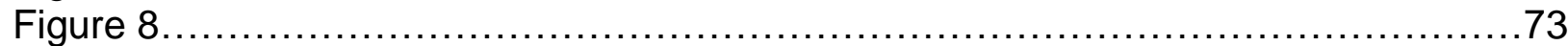

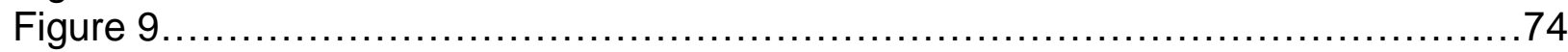

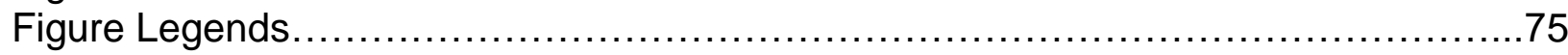

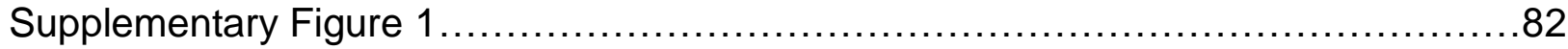

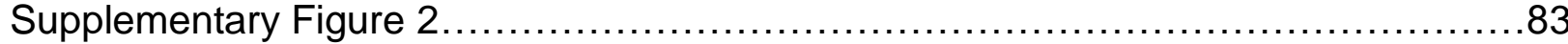

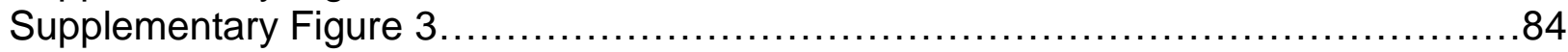




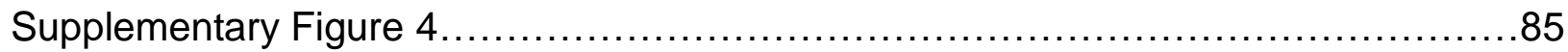

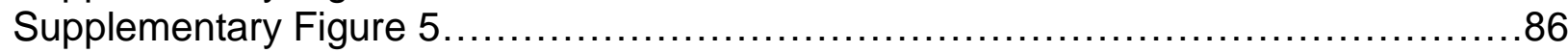

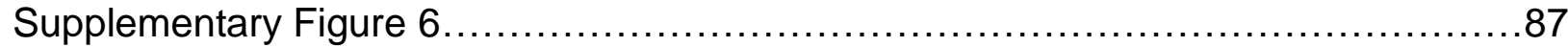

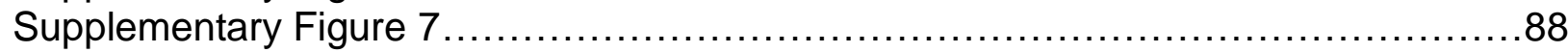

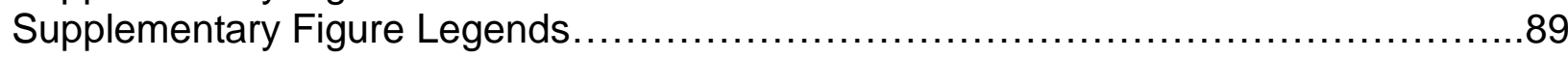

Chapter 3 Rhodopsin signaling mediates light induced photoreceptor cell death in rd10 mice through a transducin-independent mechanism

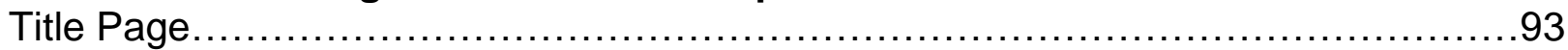

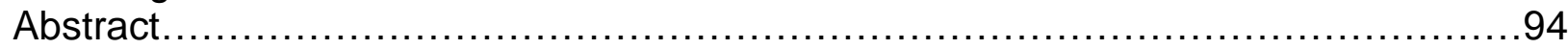

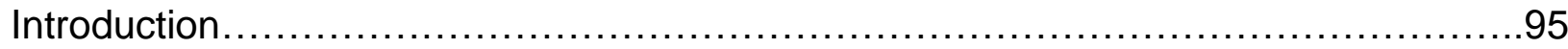

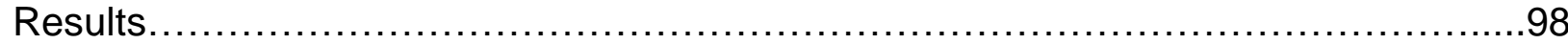

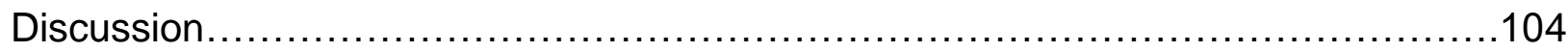

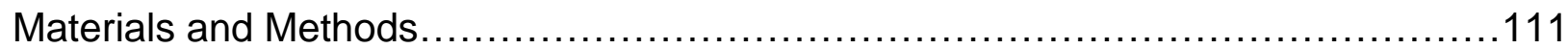

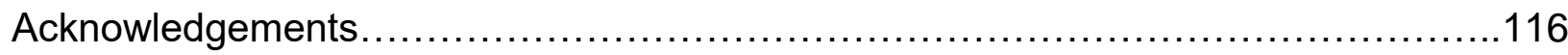

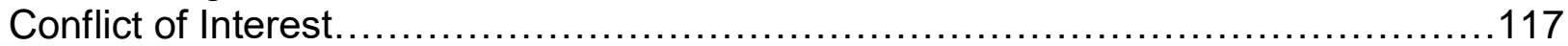

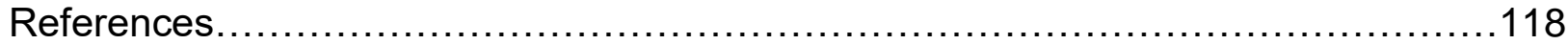

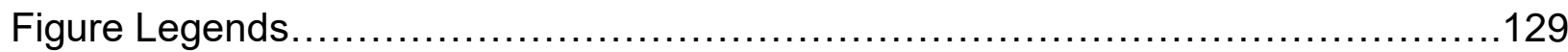

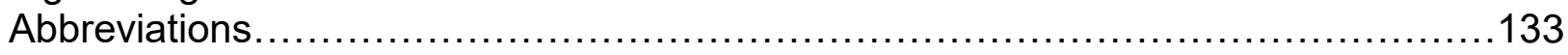

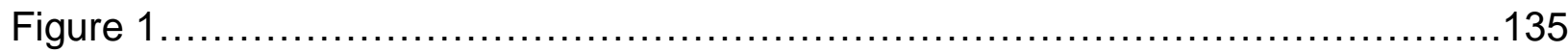

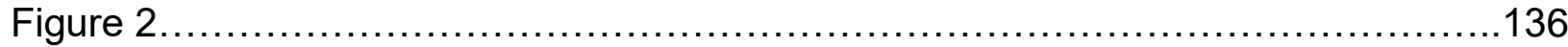

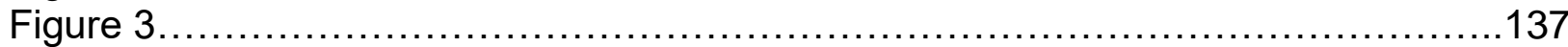

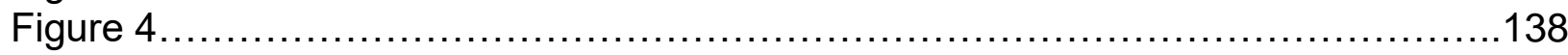

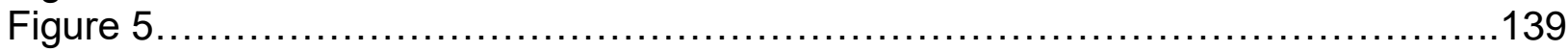

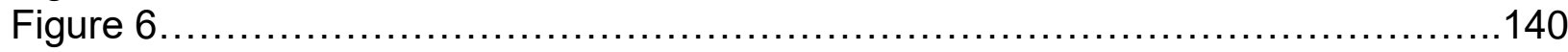

Chapter 4: Discussion and Future Directions......................................141

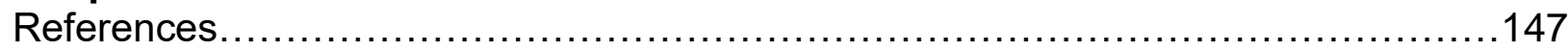




\section{Chapter 1: Literature Review}

\section{Introduction, Background, and Hypotheses}

\section{Vertebrate Photoreceptors}

Visual sensation begins with phototransduction when visible wavelength photons are absorbed and lead to a biochemical signaling cascade in the neural retina, which is located within the back of the eye ${ }^{1}$. Photoreceptors are retinal neurons specialized to detect these photons ${ }^{1}$. Photoreceptors are highly compartmentalized cells, and the phototransduction cascade occurs at the most distal end of the cell within a stacked membranous structure termed the outer segment ${ }^{1}$. Immediately proximal to the outer segment is the metabolic compartment of the photoreceptor termed the inner segment where energy production occurs, and cellular proteins are synthesized ${ }^{1}$. The outer segment is connected to the inner segment through a small "highway" called the connecting cilium which allows for transport of phototransduction proteins and various metabolites from the inner segment to the outer segment ${ }^{1}$. Proximal to the inner segment is the photoreceptor cell body where the nucleus resides ${ }^{1}$. On the other side of the cell body is the photoreceptor axon where signal propagation occurs and more distally the photoreceptor ribbon synapse is located and allows for electrochemical signal transmission to second-order neurons for further signal processing ${ }^{1,2}$.

There are two different types of photoreceptors adapted for operation in different environmental conditions ${ }^{1}$. When illuminance is low, visual function is maintained by rod photoreceptors when can reliably detect single photons ${ }^{1,3}$. At higher levels of illuminance, visual function is replaced by cone photoreceptors which are less sensitive after rods have become saturated ${ }^{1,4}$. Cones can be further classified into two or more types based on their optimal spectral sensitivity ${ }^{1,4}$. This allows for color discrimination 
where the output of each type of cone can be compared to the other types ${ }^{1,5}$. Intriguingly, cone photoreceptors do not saturate even at very high levels of illuminance ${ }^{1,4}$.

\section{Vertebrate Phototransduction in Rod Photoreceptors}

Detection of light begins with the photon-induced isomerization of a chromophore called 11-cis retinal which is bound to a G-protein-coupled receptor called rhodopsin through a covalent linkage ${ }^{1,6}$. Photon absorption by 11 -cis retinal leads to its conversion to all-trans retinal ${ }^{1,6}$. This isomerization ultimately causes a switch in conformation of the cytoplasmic domain of rhodopsin which allows it to interact with transducin, which is a heterotrimeric G-protein ${ }^{1,6}$. Transducin's $\alpha$-subunit then swaps GDP for GTP which results in its dissociation from the $\beta$ and $\gamma$ subunits of transducin ${ }^{1,6}$. Transducin's activated $\alpha$-subunit then binds the phosphodiesterase-6 (PDE6) holoenzyme which leads to the relief of inhibition caused by PDE6's $\gamma$ subunits to allow hydrolysis of the photoreceptor's intracellular second messenger cyclic guanosine monophosphate $(\text { cGMP })^{1,6}$. The hydrolysis of cytoplasmic cGMP results in closure of membrane cation channels which were kept open through cGMP gating ${ }^{1,6}$. The closure of these cGMP gated channels causes a reduced influx of cations such as $\mathrm{Na}^{+}$and $\mathrm{Ca}^{2+}$, which leads to hyperpolarization of the photoreceptor cell ${ }^{1,6}$.

Once the cascade has been activated, it must be reset. This begins when activated rhodopsin is phosphorylated by rhodopsin kinase (GRK1) $)^{1,7}$. In darkness, GRK1 is normally inhibited by a protein called recoverin which acts as a calcium sensor and inhibits GRK1 when calcium levels are high ${ }^{1,7}$. When calcium levels drop after phototransduction signaling, recoverin's inhibition of GRK1 is relieved, and GRK1 goes 
on to phosphorylate activated rhodopsin ${ }^{1,7}$. Another protein called arrestin binds phosphorylated rhodopsin to abrogate activation of transducin ${ }^{1,7}$. Transducin- $\alpha$ must also be inactivated and this occurs through intrinsic GTPase activity which is regulated by a complex composed of G 35 , PDE6 $\gamma$, RGS9, and R9AP ${ }^{1,8}$. PDE6 becomes inactivated again when PDE6 $\gamma$ rebinds to block entry to the active site ${ }^{1,9}$. In addition, guanylate cyclase is activated to normalize cGMP concentrations ${ }^{1,6}$. This occurs when guanylate cyclase activating proteins (GCAPs) sense a decrease in calcium levels and subsequently interact with and stimulate guanylate cyclase to produce cGMP ${ }^{1,10}$.

\section{Photoreceptor Development}

Eye morphogenesis begins relatively early during the third week of embryonic development ${ }^{11}$. After blastulation and morulation of the zygote, the neural plate forms from the ectoderm during gastrulation ${ }^{12}$. The neural plate is organized into distinct regions including the forebrain, midbrain, hindbrain, and spinal cord ${ }^{12}$. The forebrain is further subdivided into the telencephalon, eye, and diencephalon ${ }^{12}$. The eye field is specified in the anterior forebrain and contains all the progenitors of the neural-derived eye structures ${ }^{13}$. Bilateral indentations called optic sulci form in the eye field ${ }^{14}$. The eye field then splits into two optic vesicles ${ }^{15}$. All neuroectoderm-derived cells within the eye arise from retinal stem cells from the optic vesicles ${ }^{14}$. The optic cup is formed after the optic vesicles bend around the lens placode, which is derived from surface ectoderm $^{16,17}$. The optic cup consists of three regions which are the retinal pigment epithelium, neural retina, and optic stalk ${ }^{15}$. The inner layer of the optic cup will eventually become the neural retina whereas the outer layer of the optic cup will become the RPE ${ }^{15}$. 
Fully differentiated cells in neural retina of the vertebrate eye arise from cells called retinal progenitor cells (RPCs) ${ }^{18}$. These RPCs can give rise to either rods, cones, bipolar cells, horizontal cells, amacrine cells, Muller glia, or ganglion cells ${ }^{18}$. The cones, horizontal cells, amacrine cells, and ganglion cells are born early in retinal development whereas the rods, Muller glia, and bipolar cells are born late in retinal development ${ }^{18}$. Intrinsic factors within the RPCs regulate their differentiation and the time at which they differentiate will influence the cell type that they give rise to ${ }^{18}$. Cells expressing the transcription factor Ikaros can become amacrine, horizontal, and ganglion cells, which are born early in retinal development ${ }^{18,19}$. Contrarily, cells expressing the transcription factor Casz1 can become rods and bipolar cells which are born late in retinal development ${ }^{18,20}$.

Interestingly, cells expressing Olig2 early in retinal morphogenesis can give rise to cones whereas cells expressing Olig2 postnatally give rise to rods ${ }^{18,21}$. RPCs undergo cell division before some eventually commit to becoming a post-mitotic photoreceptor precursor as a result of a signaling cascade that is not well understood $^{18,22}$. A subset of photoreceptor precursors will express Nrl transcription factor which is necessary for the formation of fully differentiated rod photoreceptors ${ }^{18,23}$. The photoreceptor precursors lacking Nrl expression will become fully differentiated cone photoreceptors ${ }^{18,23-26}$. Nrl also allows for rods to express a nuclear receptor called Nr2e3 which inhibits cone gene expression ${ }^{18,27}$. Additionally, immature cones express a nuclear hormone receptor called thrb ${ }^{18,28}$. Moreover, when the transcription factor Onecut 1 is expressed in precursors also expressing the transcription factor Otx2, these cells can develop into cones ${ }^{18,29}$. When precursors only express Onecut1, these cells 
differentiate into horizontal cells ${ }^{18}$. Furthermore, the transcription factor PRDM8 is necessary for the development of bipolar cells ${ }^{30}$. Lastly, the expression of the transcription factors Isl1 and Pou4f2 are sufficient for differentiation of cells to the ganglion cell lineage ${ }^{31}$.

\section{Photoreceptor Connecting Cilium Structure}

The photoreceptor outer segment is connected to the inner segment by a small intracellular bridge termed the connecting cilium through which all exchanges between the inner segment and outer segment occur ${ }^{32-33}$. The continuous phagocytosis of the photoreceptor outer segment distal end by the retinal pigment epithelium requires an enormous unidirectional trafficking of all outer segment proteins ${ }^{32,34}$. These proteins undergo nascent synthesis and final modification by the translation machinery and posttranslational modification machinery respectively before being transported from their site of synthesis in the inner segment through the connecting cilium and into the outer segment $^{32,34}$.

Cilia are often described as cellular protrusions which are specialized to detect and convert extracellular signals into an intracellular response ${ }^{32,35}$. The extension of the cilia starts at the basal body located in the apical cytoplasm immediately underneath the cell's plasma membrane ${ }^{32}$. The basal body has centriole microtubules with a $9 \times 3+0$ arrangement ${ }^{32,36}$. Immediately distal to the basal body is the transition zone consisting of a $9 \times 2+0$ microtubule arrangement ${ }^{32,36}$. Distal to the transition zone is the axoneme consisting of a $9 \times 2+2$ microtubule arrangement ${ }^{32}$. Distal to the axoneme is the end cap of the cilia where microtubules from the axoneme are attached to the apical ciliary membrane ${ }^{32}$. 
The photoreceptor connecting cilium and outer segment can be thought of as a specialized type of immotile cilium ${ }^{32}$. Immediately underneath the apical inner segment membrane is the basal body of photoreceptors. Medial to the basal body are cilia rootlets which traverse into the photoreceptor cell body and terminate in the synaptic termina| ${ }^{32,37}$. This lengthy structure provides rigid architectural support for the basal body ${ }^{32}$. The microtubule organizing center at the basal body is where microtubule nucleation occurs and allows for projection from the plus-end ${ }^{32}$. The connecting cilium of photoreceptors corresponds to the primary cilium transition zone ${ }^{32,38}$. The transition zone is thought to be a regulatory center where transport and interchange of proteins across this zone is modulated and has a distinct composition from proteins in the cytoplasm ${ }^{32}$. The connecting cilium is approximately $1 \mu \mathrm{m}$ in length and has a $9 \times 2+0$ microtubule arrangement ${ }^{32}$. In addition, the connecting cilium in photoreceptors has a unique structure with Y-shaped cross-linkers emerging from each doublet between the A- and B-tubules and extend to the plasma membrane ${ }^{32,39}$. The plasma membrane surrounding the medial end of the connecting cilium is connected to the distal inner segment membrane and forms the periciliary ridge complex ${ }^{32,40}$. Opsin containing vesicles from the inner segment reach the periciliary ridge complex and dock while awaiting transport by the cilia trafficking complexes ${ }^{32,41}$. The distal inner segment membrane also contains small protrusions that resemble microvilli and are called calycal processes and might provide structural reinforcement for the outer segment ${ }^{32,42}$. When the axoneme extends into the outer segment, its microtubule arrangement changes from a $9 \times 2+0$ structure to a $9+0$ structure $^{32,43}$. Calcium binding proteins called Centrins are found in the connecting cilium and at the basal body. Centrins 1-3 are 
found in the connecting cilium; the basal body centrioles also contain Centrin-2 and Centrin-3 while Centrin-4 is unique to the basal body ${ }^{32,44}$.

Important cilia associated protein complexes include the IFT-A and IFT-B complexes which are necessary for ciliogenesis and ciliary sustentation in eukaryotes ${ }^{32,45}$. These complexes allow for anterograde and retrograde transport of nonmembrane bound cargo throughout the cilium ${ }^{32,46}$. The IFT-A complex consists of primarily four high molecular weight proteins ranging from $120 \mathrm{kDa}$ to $150 \mathrm{kDa}$ whereas the IFT-B complex consists primarily of low molecular weight proteins less than $100 \mathrm{kDa}$ 32,47. Kinesin-2 is responsible for anterograde transport of IFT complex along the axoneme after its formation adjacent to the basal body 32,48 . Contrarily, dynein is responsible for retrograde transport of IFT complex from the distal end of the axoneme toward the basal body ${ }^{32,49}$.

Another important cilium associated protein complex is the BBSome ${ }^{50}$. The BBSome is a protein complex formed from eight different proteins, which are BBS1, BBS2, BBS4, BBS5, BBS7, BBS8, BBS9 and BBS18 to create an octamer ${ }^{51}$. Interestingly, the BBSome can interact with Arl6 if Arl6 has bound GTP52,74. BBS proteins_have been shown to be important for the development of planar cell polarity, lipid homeostasis, IFT transport regulation, and centrosome-related functions ${ }^{32,53}$. Interestingly, BBS7 and BBS8 have been implicated in IFT complex assembly ${ }^{54}$. This suggests a crucial role for BBSome in ciliary transport ${ }^{55}$.

Other important ciliary proteins whose defects can cause either retinitis pigmentosa or Leber congenital amaurosis include two interactors which are RPGR (retinitis pigmentosa GTPase regulator) and RPGRIP1 (RPGR-interacting protein-1) 
32,56. RPGR is found at the basal body and axoneme in photoreceptors whereas RPGRIP1 anchors RPGR to the connecting cilium ${ }^{32,57,58}$. RPGRIP1 is thought to be important for outer segment disc morphogenesis since knockout leads to disruption in disc production ${ }^{32,59}$. Lastly, RP1 is a microtubule associated protein thought to be necessary for the organized disc stacking within the photoreceptor outer segment, and its deficiency results in retinitis pigmentosa ${ }^{32,60}$. RP1 interacts with the axonemal microtubules that are localized in the photoreceptor outer segment ${ }^{32,60}$.

\section{The Photoreceptor Outer Segment}

The location in which light detection and signal transduction occurs in photoreceptor sensory neurons is known as the outer segment ${ }^{61}$. This structure is often described as part of a highly specialized primary cilium which extends from the distal end of the connecting cilium ${ }^{61}$. The outer segment has a structure termed the axoneme which is connected to an ordered stack of disc membranes that is fully encased by the cell membrane in rods ${ }^{61}$. The base of the outer segment axoneme is composed of an arrangement of $9 \times 2+0$ microtubules, but more distally, the axoneme arrangement changes to $9+0$ singlet microtubules ${ }^{61}$. There are also linkages between neighboring discs and between discs and the cell membrane which are not well understood ${ }^{61,62}$.

The G-protein-coupled receptor of the phototransduction cascade is rhodopsin, and its density within the outer segment disc membranes is exceptionally high at $25,000 u^{-261}$. This contributes to almost half the mass of outer segment disc membranes, with cholesterol and phospholipids making up the remainder and is thought to be an important structural component in the outer segment in addition to contributing directly to phototransduction ${ }^{61}$. Rom-1 and Peripherin-2 (Rds) are proteins found at disc 
rims and contain transmembrane domains along with extracellular domains, and these proteins have been suggested to aid in membrane fusion during disc formation ${ }^{61,63}$. Prominin-1 is a cholesterol binding protein found at the base of the outer segment and has been implicated to aid in membrane bending ${ }^{61,64}$. Cep290 is found at the basal body in photoreceptors and studies have suggested that it is involved in the formation of the Y-shaped crosslinkers ${ }^{61,65}$. Interestingly, Cep290 has been shown to interact with RPGR, RGRIP1, Cc2d2a, PCM-1 and $\gamma$-tubulin ${ }^{66-69}$.

\section{BBS8 in photoreceptors}

Bardet-Biedl Syndrome Protein-8 (BBS8) is a tetratricopeptide repeat domain protein with a solenoid structure ${ }^{70}$. Mutations in this protein usually lead to Bardet-Biedl Syndrome which is a ciliopathy characterized by retinitis pigmentosa, hypogonadism, kidney disease, obesity, and polydactyly ${ }^{71}$. BBS8 is thought to be an adaptor for transport of IFT cargoes ${ }^{72}$. In photoreceptors, previous studies have suggested that the BBSome is crucial for the retrograde transport of cytosolic proteins from the outer segment into the inner segment ${ }^{51}$. This is supported by our lab's previous work showing mislocalization of syntaxin-3 into the outer segment in the absence of BBS8, and we also observed that BBS8 is crucial for normal outer segment morphology ${ }^{51}$. Deletion of BBS8 also caused changes in BBSome subunit expression possibly allowing for compensation by other subunits due to the lack of BBS $8^{51}$.

Twelve tissues are known to express BBS8 including the cortex, cerebellum, heart, liver, lung, kidney, testes, muscle, pancreas, stomach, thymus, and retina ${ }^{73}$. Interestingly, a mutation was identified that causes only non-syndromic retinitis pigmentosa in contrast to most Bbs8 mutations which cause Bardet Biedl Syndrome ${ }^{73}$. 
The causative mutation was discovered to be a homozygous $A$ to $G$ substitution in intron 1 (IVS1-2 $A>G)^{73}$. This mutation alters the splicing of a previously unidentified 30 base pair exon called Exon 2A by disrupting the 3' splice acceptor site ${ }^{73,74}$. The inclusion of this microexon into mature BBS8 transcripts was found to occur only in photoreceptors $^{73,74}$. Therefore, the Bbs8 gene contains a photoreceptor-specific alternative exon encoding a 10 amino acid sequence that is only included in Bbs8 transcripts of photoreceptor cells ${ }^{73,74}$. All other tissues were found to express the shorter Bbs8 isoform with Exon 2A spliced out ${ }^{73,74}$. Remarkably, this splice site is invariant in 33 species $^{73}$. Interestingly, two other mutations have been identified in BBS proteins including BBS3 (ARL6) A89V and BBS1 M390R that also cause non-syndromic retinitis pigmentosa whereas most other mutations will cause classical Bardet Biedl Syndrome ${ }^{74-76}$. Moreover, ARL6 also contains a photoreceptor alternative exon and this longer ARL6 protein isoform is necessary for photoreceptor survival ${ }^{74,77-78}$.

Our laboratories previously delineated the likely mechanism underlying the missplicing of Bbs8 Exon $2 A^{74}$. We found that the IVS1-2 A>G mutation disrupts the normal 3' splice acceptor site and results in the activation of a cryptic 3' splice site seven nucleotides downstream from the normal 3' splice site within Exon $2 A$ itself $^{74}$. This missplicing results in the splicing out of the first part of Exon $2 \mathrm{~A}$ and the inclusion of only the latter part of the Exon $2 A^{74}$. The inclusion of the truncated Exon $2 A$ results in a frameshift mutation leading to the formation of premature stop codon in the downstream Exon $2^{74}$. In essence, the IVS1-2 A>G mutation leads to deletion of BBS8 protein specifically in photoreceptor cells while still allowing BBS8 expression in other cell types $^{74}$. The sequence elements located within exons such as exonic splicing 
enhancers are usually necessary for exon inclusion into the mRNA ${ }^{74,79}$. Contrarily, we found that the elements controlling splicing are intronic and exonic splicing enhancers or exonic splicing silencers do not exist within Exon $2 \mathrm{~A}^{74}$. Lastly, we found that intronic splicing enhancers exist between 150 nucleotides upstream and 120 nucleotides downstream of Exon 2A with the downstream intronic splicing enhancers being more important for Exon 2A recognition and inclusion ${ }^{74}$.

\section{Alternative Splicing}

Alternative splicing is an RNA processing mechanism found in almost all multicellular eukaryotic organisms ${ }^{80}$. Pre-mRNA splicing is more widely exploited in multicellular than unicellular eukaryotes ${ }^{81}$. Alternative splicing occurs in pre-mRNAs from approximately $\sim 95 \%$ of mammalian genes ${ }^{82}$. Even though human and chimpanzee genes are $>99 \%$ similar, $\sim 7 \%$ of their corresponding alternative exons are differentially spliced in the same tissues possibly implicating alternative splicing as one mechanism responsible for species identity ${ }^{82}$. Through alternative splicing, protein coding regions of pre-mRNA can be differentially combined to ultimately form unique protein isoforms from the same gene sequence ${ }^{82}$. This process expands upon the number of proteins that can be formed from the same gene and is a significant contributor to the protein diversity found in multicellular eukaryotes ${ }^{82}$. Alternative splicing has also emerged as an important mechanism of posttranscriptional regulation of gene expression ${ }^{83}$. Intriguingly, splicing is substantially exploited in mammalian neuronal tissues as shown by an abundance of alternatively spliced transcripts leading to unique protein isoforms ${ }^{84,85}$. Moreover, alternative splicing has been shown to be crucial for neurons during their development, and this process has been shown to be critical for axon guidance and 
synaptogenesis ${ }^{85}$. Interestingly, a specialized type of splicing leading to incorporation of small exons has been shown to be most abundant in neurons ${ }^{84}$. It is thought that the alternative exons which are only expressed in certain tissues either encode intrinsically disordered regions that may serve as sites for posttranslational modifications or be a binding motif which allows for protein-protein interaction ${ }^{82}$.

Alternative pre-mRNA splicing is catalyzed by a ribonucleoprotein complex called the spliceosome ${ }^{82,86}$. Spliceosome assembly requires only a 5' splice site, 3' splice site, and branch point sequence (usually near a polypyrimidine tract) as these are the only conserved sequence elements of introns ${ }^{82,86}$. The 5' splice site consists of a GU RNA sequence at the 5' end of the intron whereas the 3' splice site consists of an AG RNA sequence at the $3^{\prime}$ end of the intron ${ }^{82,86}$. Upstream from the 3 ' splice site is the polypyrimidine tract which is a region with high expression of the cytosine and uracil nucleobases ${ }^{82,86}$. Near the polypyrimidine tract is the branch point sequence consisting of an adenine nucleobase required for looping out of the intron ${ }^{82,86}$.

The reactions catalyzed by the spliceosome is transesterification occurring in two steps $^{82,86}$. In the first step, the phosphate of the 5 ' splice site guanine nucleotide undergoes nucleophilic attack by the 2 '- $\mathrm{OH}$ of the branch point sequence adenine ${ }^{82,86}$. In the second step, the phosphate of the first nucleotide in the downstream exon undergoes nucleophilic attack by the $3^{\prime}-\mathrm{OH}$ of the last nucleotide in the upstream exon 82,86 .

This process begins when the 5 ' splice site is recognized by the $U 1$ small nuclear ribonucleoprotein (snRNP) ${ }^{82,86}$. At the same time, U2AF binds the 3' splice site, and splicing factor 1 binds the branch point sequence ${ }^{82,86}$. After initial complex formation, 
splicing factor 1 is replaced by U2 snRNP to form a complex that then interacts with the U4/U5/U6 tri-snRNP to form the fully assembled spliceosome ${ }^{82,86}$. U1 and U4 snRNPs then leave before the transesterification reaction takes place and the excised intron lariat is removed from the pre-mRNA ${ }^{82,86}$.

The diversity of mature mRNAs coming from a single pre-mRNA can be increased through a number of possible splicing mechanisms ${ }^{82}$. Most notably, some exons can be skipped or spliced out in some cells but not others, and this exon is called an alternative cassette exon ${ }^{82}$. In addition, alternative 5' splice sites or alternative 3' splice sites can be utilized depending on cellular context ${ }^{82}$. Intriguingly, an intron can also be retained and not spliced out to generate a unique mature mRNA as well82. Lastly, there are cases of mutually exclusive exon inclusion where only one exon will be spliced in but not the other ${ }^{82}$. Altogether, these mechanisms increase mature mRNA diversity.

Alternative splicing can be further modulated through cis-regulatory sequences and trans-acting factors ${ }^{82}$. There are at least four major types of cis-regulatory sequences ${ }^{82}$. The first is an exonic splicing enhancer region which is a sequence located within an exon that acts to promote inclusion of an exon ${ }^{82}$. The second is an exonic splicing silencer region which is a sequence inside an exon that acts to promote exclusion of an exon ${ }^{82}$. The third is an intronic splicing enhancer which is a sequence within an intron that acts to promote inclusion of an exon ${ }^{82}$. The fourth is an intronic splicing silencer which is a sequence inside an intron that acts to promote exclusion of an exon ${ }^{82}$. These cis-regulatory sequences can be further modulated when an RNA adopts secondary structure which can act to hide or expose these regulatory regions ${ }^{82}$. 
Trans-acting factors including RNA binding proteins can bind to these cis-regulatory sequences to promote either inclusion or exclusion of an exon, and some factors are tissue-specific, and their expression levels or activity can be modulated by various signaling pathways ${ }^{82}$.

\section{The Musashi (MSI) RNA binding protein family}

The MSI RBP family consists of two paralogues in vertebrates, MSI1 and MSI287-

90. The MSI1 and MSI2 proteins have two highly conserved RNA binding domains (RBDs) in the $\mathrm{N}$-terminal region which show $\sim 90 \%$ sequence identity ${ }^{87}$. The first RBD of MSI1 was shown to interact with the GUAG RNA sequence while the second RBD is thought to interact with the UAG RNA sequence ${ }^{87}$. The high degree of sequence identity between the MSI1 and MSI2 RBDs suggests a target functional redundancy within the MSI protein family and this has been confirmed in previous studies ${ }^{88,91}$. The two RBDs of MSI1 and MSI2 are followed by a less conserved C-terminal region which shows approximately $70 \%$ sequence similarity ${ }^{92}$.

The MSI RBPs are well-studied regulators of mRNA translation in the cytoplasm ${ }^{93-94}$. Several reports have shown them to either repress or activate translation of target mRNAs depending on the cellular context ${ }^{95-100}$. Intriguingly, several studies have shown MSI1 to be localized inside the nuclei of some cell types ${ }^{101-104}$, and the nuclear localization signal for MSI1 lies within its first RBD ${ }^{105}$. However, the significance of this nuclear localization remains largely unknown. Our previous studies led to our hypothesis that the MSI proteins in the nucleus regulate the splicing of photoreceptorspecific exons into target mRNAs in vivo ${ }^{101}$. Only one other group has suggested that the MSI proteins could regulate alternative splicing of their target mRNAs ${ }^{106}$. 


\section{Alternative Splicing and Retinal Degeneration}

It has been estimated that $10 \%$ of disease-causing point mutations disturb core splice sites; in addition, another $25 \%$ of mutations are expected to alter regulation of mRNA splicing ${ }^{74,107,108}$. These mutations can disrupt cis-regulatory sequences of a gene or genes encoding trans-acting splicing factors ${ }^{109}$. Mutations affecting cis-regulatory sequences can lead to inappropriate exon skipping, intron inclusion, exon inclusion, or activation of cryptic splice sites ${ }^{109}$. This can lead to insertions, deletions, frameshifts, and/or premature termination ${ }^{109}$.

Interestingly, many mutations affecting splice sites have been found to cause retinitis pigmentosa and cone-rod dystrophies ${ }^{109}$. For example, alternative exon mutations in COL2A1 cause Stickler Syndrome ${ }^{109}$. Likewise, an intronic mutation affecting the splicing of an alternative exon in RPGR causes X-linked retinitis pigmentosa ${ }^{109}$. Moreover, mutations in ubiquitously expressed splicing factors including PRPF3, PRPF8, and PRPF31 can specifically cause autosomal dominant retinitis pigmentosa while not significantly affecting other tissues ${ }^{109}$. It is thought that these mutations affect photoreceptors since photoreceptors exploit splicing machinery to a much higher extent than other cells due to their high rate of protein synthesis which is required to replace the phagocytosed phototransduction proteins and outer segment membranes at the distal end of the $\mathrm{OS}^{109}$.

\section{Hypotheses}

Photoreceptor neurons are highly specialized cells that use ubiquitously expressed cilia-related genes to ultimately produce a characteristic organelle called the outer segment $(\mathrm{OS})^{110}$. Our previous studies show that photoreceptors uniquely splice 
pre-mRNA from cilia-related genes to produce photoreceptor-specific protein isoforms ${ }^{101}$. Despite studies implicating the importance of photoreceptor-specific protein isoforms ${ }^{73}$, little is known about the factors that regulate alternative splicing in photoreceptors. This is of clinical significance as there have been several point mutations that have been identified which hinder alternative splicing and subsequently lead to blindness ${ }^{109}$. The abundance of these point mutations that affect alternative splicing in the retina suggests that this mechanism plays a crucial role in vision ${ }^{109}$. One family of proteins that has recently been implicated in regulating alternative splicing in photoreceptors is an RNA binding protein family called Musashi (MSI) ${ }^{101}$. The MSI proteins have previously been shown to regulate translation of several target mRNAs in the cytoplasm ${ }^{95-100}$. However, our recently published work has shown that the MSI proteins are localized at high levels in photoreceptor nuclei ${ }^{101}$, but the importance of this nuclear localization remains unknown. Moreover, several studies have described high expression of MSI protein expression in the retina but almost nothing is known about the function of this protein family in the vertebrate retina ${ }^{101-104}$.

The goal of this work is to examine the biological significance of MSI protein expression in the retina and uncover the mechanisms behind their function. Our in vitro studies led to the hypothesis that the MSI proteins regulate alternative splicing in mammalian photoreceptor nuclei ${ }^{101}$. Through motif enrichment analysis and cell culture assays, we found that the MSI proteins potentially regulate the splicing of many mammalian photoreceptor pre-mRNAs most notably from the Cc2d2a, Cep290, Bbs8, and Prom1 genes ${ }^{101}$. Nonetheless, it is possible that the MSI proteins might have a compound role where they also regulate mRNA translation in the cytoplasm. To 
investigate our predicted role of MSI in photoreceptor-specific alternative splicing, I generated retina- and rod-specific conditional knockout mouse models lacking either MSI1, MSI2, or both MSI1 and MSI2. The central hypothesis of this work is that the MSI proteins regulate pre-mRNA splicing in photoreceptors, and consequently, these proteins are necessary for normal photoreceptor function, morphology, and survival. As a corollary to this hypothesis, in the absence of the MSI proteins, I predict that there will be dysregulation of pre-mRNA splicing (including reduced incorporation of photoreceptor-specific exons) and disrupted photoreceptor function and morphology. This will allow for delineation of the function of the MSI proteins in vertebrate photoreceptors.

We also wanted to examine the molecular mechanisms underlying retinitis pigmentosa which we hope will translate to personalized patient treatment and allow for better mitigation of disease symptoms. Unfortunately, the mechanisms underlying photoreceptor degeneration in retinitis pigmentosa are not well understood ${ }^{111}$. To gain more insight into the signaling pathways underlying photoreceptor cell death in retinitis pigmentosa, we exploited the retinal degeneration-10 (rd10) mouse model, which is one of the premier models used to study retinitis pigmentosa ${ }^{112}$. The rd10 mouse model harbors a mutation in PDE6 which is the effector enzyme of the phototransduction cascade, and the resultant phenotype mimics the phenotype observed in humans ${ }^{112}$. In this model, photoreceptor degeneration occurs when rd10 mice are reared in normal light conditions ${ }^{112}$. Contrarily, photoreceptors are preserved when rd10 mice are reared in dark ${ }^{112}$. Previously, it has been shown that exposure to bright light leads to photoreceptor degeneration in wildtype mice, and this apoptotic signaling is mediated 
through rhodopsin signaling ${ }^{113}$. We hypothesized that a similar signaling cascade is occurring in rd10 mice. To test our hypothesis, we inactivated either transducin or rhodopsin signaling in rd10 mice to dissect the signaling cascades underlying photoreceptor cell death. This will allow us to delineate the signaling pathways that are mediating photoreceptor cell death in the rd10 mouse model of retinitis pigmentosa. 


\section{References}

1. Cote, Rick H. "Photoreceptor phosphodiesterase (PDE6): A G-protein-activated PDE regulating visual excitation in rod and cone photoreceptor cells." (2006).

2. Hsu, Andrew, et al. "Functional architecture of primate cone and rod axons." Vision research 38.17 (1998): 2539-2549.

3. Rieke, Fred. "[12] Mechanisms of single-photon detection in Rod photoreceptors." Methods in enzymology. Vol. 316. Academic Press, 2000. 186202.

4. Purves D, Augustine GJ, Fitzpatrick D, et al., editors. Neuroscience. 2nd edition. Sunderland (MA): Sinauer Associates; 2001. Functional Specialization of the Rod and Cone Systems.

5. Jiang, Liting, Peng Jin, and Peng Lei. "Color discrimination metric based on cone cell sensitivity." Optics express 23.11 (2015): A741-A751.

6. Lamb, Trevor D., and Edward N. Pugh. "Phototransduction, dark adaptation, and rhodopsin regeneration the proctor lecture." Investigative ophthalmology \& visual science 47.12 (2006): 5138-5152.

7. Mannu, Gurdeep S. "Retinal phototransduction." Neurosciences 19.4 (2014): 275.

8. Hu, Guang, and Theodore G. Wensel. "R9AP, a membrane anchor for the photoreceptor GTPase accelerating protein, RGS9-1." Proceedings of the National Academy of Sciences 99.15 (2002): 9755-9760. 
9. Granovsky, Alexey E., and Nikolai O. Artemyev. "A conformational switch in the inhibitory $Y$-subunit of PDE6 upon enzyme activation by transducin." Biochemistry 40.44 (2001): 13209-13215.

10. Hwang, Ji-Young, and Karl-Wilhelm Koch. "Calcium-and myristoyl-dependent properties of guanylate cyclase-activating protein-1 and protein-

2." Biochemistry 41.43 (2002): 13021-13028.

11. Ludwig, Parker E., and Craig N. Czyz. "Embryology, Eye Malformations." StatPearls [Internet]. StatPearls Publishing, 2019.

12. Giger, Florence A., and Corinne Houart. "The Birth of the Eye Vesicle: When Fate Decision Equals Morphogenesis." Frontiers in neuroscience 12 (2018): 87.

13. Stigloher, Christian, et al. "Segregation of telencephalic and eye-field identities inside the zebrafish forebrain territory is controlled by Rx3." Development 133.15 (2006): 2925-2935.

14. Heavner, Whitney, and Larysa Pevny. "Eye development and retinogenesis." Cold Spring Harbor perspectives in biology 4.12 (2012): a008391.

15. Adler, Ruben, and M. Valeria Canto-Soler. "Molecular mechanisms of optic vesicle development: complexities, ambiguities and controversies." Developmental biology 305.1 (2007): 1-13.

16. Park, Byung-Yong, and Jean-Pierre Saint-Jeannet. "Induction and segregation of the vertebrate cranial placodes." Colloquium series on developmental biology. Vol. 1. No. 1. Morgan \& Claypool Life Sciences, 2010.

17. Kowalchuk, Angelica M. Neurogenin2 in the Developing Mammalian Retina. University of California, Davis, 2017. 
18. Javed, Awais, and Michel Cayouette. "Temporal progression of retinal progenitor cell identity: implications in cell replacement therapies." Frontiers in neural circuits 11 (2017): 105.

19. Elliott, Jimmy, et al. "Ikaros confers early temporal competence to mouse retinal progenitor cells." Neuron 60.1 (2008): 26-39.

20. Mattar, Pierre, et al. "A conserved regulatory logic controls temporal identity in mouse neural progenitors." Neuron 85.3 (2015): 497-504.

21. Hafler, Brian P., et al. "Transcription factor Olig2 defines subpopulations of retinal progenitor cells biased toward specific cell fates." Proceedings of the National Academy of Sciences 109.20 (2012): 7882-7887.

22. Swaroop, Anand, Douglas Kim, and Douglas Forrest. "Transcriptional regulation of photoreceptor development and homeostasis in the mammalian retina." Nature Reviews Neuroscience 11.8 (2010): 563.

23. Mears, Alan J., et al. "Nrl is required for rod photoreceptor development." Nature genetics 29.4 (2001): 447.

24. Young, R. W. (1985). Cell differentiation in the retina of the mouse. Anat. Rec. 212, 199-205. doi: 10.1002/ar.1092120215

25. Young, R. W. (1985). Cell proliferation during postnatal development of the retina in the mouse. Brain Res. 353, 229-239. doi: 10.1016/0165-3806(85)90211-1

26. Akimoto, Masayuki, et al. "Targeting of GFP to newborn rods by Nrl promoter and temporal expression profiling of flow-sorted photoreceptors." Proceedings of the National Academy of Sciences 103.10 (2006): 3890-3895. 
27. Oh, Edwin CT, et al. "Rod differentiation factor NRL activates the expression of nuclear receptor NR2E3 to suppress the development of cone photoreceptors." Brain research 1236 (2008): 16-29.

28. $\mathrm{Ng}$, Lily, et al. "Developmental expression of thyroid hormone receptor $\beta 2$ protein in cone photoreceptors in the mouse." Neuroreport 20.6 (2009): 627.

29. Emerson, Mark M., et al. "Otx2 and Onecut1 promote the fates of cone photoreceptors and horizontal cells and repress rod photoreceptors." Developmental cell 26.1 (2013): 59-72.

30. Jung, Cynthia C., et al. "Transcription factor PRDM8 is required for rod bipolar and type 2 OFF-cone bipolar cell survival and amacrine subtype identity." Proceedings of the National Academy of Sciences 112.23 (2015): E3010-E3019.

31. Wu, Fuguo, et al. "Two transcription factors, Pou4f2 and Isl1, are sufficient to specify the retinal ganglion cell fate." Proceedings of the National Academy of Sciences 112.13 (2015): E1559-E1568.

32. Roepman, Ronald, and Uwe Wolfrum. "Protein networks and complexes in photoreceptor cilia." Subcellular Proteomics. Springer, Dordrecht, 2007. 209-235.

33. Besharse, Joseph C., and Cynthia J. Horst. "The photoreceptor connecting cilium A model for the transition zone." Ciliary and flagellar membranes. Springer, Boston, MA, 1990. 389-417.

34. Pearring, Jillian N., et al. "Protein sorting, targeting and trafficking in photoreceptor cells." Progress in retinal and eye research 36 (2013): 24-51. 
35. Berbari, Nicolas F., et al. "The primary cilium as a complex signaling center." Current biology 19.13 (2009): R526-R535.

36. Texier, Yves Stephan. Quantitative analysis of ciliary protein networksCharacterization of the intraflagellar transport complex B. Diss. Technische Universität München, 2013.

37. Spira, Arthur W., and Gordon E. Milman. "The structure and distribution of the cross-striated fibril and associated membranes in guinea pig photoreceptors." American Journal of Anatomy 155.3 (1979): 319-337.

38. Falk, Nathalie, et al. "Specialized cilia in mammalian sensory systems." Cells 4.3 (2015): 500-519.

39. Horst, Cynthia J., Donna M. Forestner, and Joseph C. Besharse. "Cytoskeletalmembrane interactions: a stable interaction between cell surface glycoconjugates and doublet microtubules of the photoreceptor connecting cilium." The Journal of cell biology 105.6 (1987): 2973-2987.

40. Peters, Klaus-Ruediger, et al. "Fine structure of a periciliary ridge complex of frog retinal rod cells revealed by ultrahigh resolution scanning electron microscopy." The Journal of Cell Biology 96.1 (1983): 265-276.

41. Deretic, Dusanka. "From the Golgi to the rod outer segment: Formation, movement, docking and fusion of rhodopsin transport carriers." Photoreceptor cell biology and inherited retinal degenerations. 2004. 29-64.

42. Rana, M. W., and S. R. Taraszka. "Monkey photoreceptor calycal processes and interphotoreceptor matrix as observed by scanning electron microscopy." American journal of anatomy 192.4 (1991): 472-477. 
43. Gilliam, Jared C., et al. "Three-dimensional architecture of the rod sensory cilium and its disruption in retinal neurodegeneration." Cell 151.5 (2012): 1029-1041.

44. Wolfrum, Uwe, Andreas Gießl, and Alexander Pulvermüller. "Centrins, A Novel Group Of Cat2, 2+-Binding Proteins In Vertebrate Photoreceptor Cells." Photoreceptors and Calcium. Springer, Boston, MA, 2002. 155-178.

45. Zhu, Bing, et al. "Functional exploration of the IFT-A complex in intraflagellar transport and ciliogenesis." PLoS genetics 13.2 (2017): e1006627.

46. Rosenbaum, Joel L., and George B. Witman. "Intraflagellar transport." Nature reviews Molecular cell biology 3.11 (2002): 813.

47. Taschner, Michael, Sagar Bhogaraju, and Esben Lorentzen. "Architecture and function of IFT complex proteins in ciliogenesis." Differentiation 83.2 (2012): S12S22.

48. Miller, Mark S., et al. "Mutant kinesin-2 motor subunits increase chromosome loss." Molecular biology of the cell 16.8 (2005): 3810-3820.

49. Pazour, Gregory J., Curtis G. Wilkerson, and George B. Witman. "A dynein light chain is essential for the retrograde particle movement of intraflagellar transport (IFT)." The Journal of cell biology 141.4 (1998): 979-992.

50. Wei, Qing, et al. "The BBSome controls IFT assembly and turnaround in cilia." Nature cell biology 14.9 (2012): 950.

51. Dilan, Tanya L., et al. "Bardet-Biedl syndrome-8 (BBS8) protein is crucial for the development of outer segments in photoreceptor neurons." Human molecular genetics 27.2 (2017): 283-294. 
52. Mourão, André, et al. "Structural basis for membrane targeting of the BBSome by ARL6." Nature structural \& molecular biology 21.12 (2014): 1035.

53. Bertrand, Eric, and Michel Faupel, eds. Subcellular proteomics: from cell deconstruction to system reconstruction. Vol. 43. Springer Science \& Business Media, 2007.

54. Blacque, Oliver E., et al. "Loss of C. elegans BBS-7 and BBS-8 protein function results in cilia defects and compromised intraflagellar transport." Genes \& development 18.13 (2004): 1630-1642.

55. Nakayama, Kazuhisa, and Yohei Katoh. "Ciliary protein trafficking mediated by IFT and BBSome complexes with the aid of kinesin-2 and dynein-2 motors." The Journal of Biochemistry 163.3 (2017): 155-164.

56. Arts, H., Cremers, F., Knoers, N. and Roepman, R., 2009. Focus on molecules: RPGRIP1. Experimental eye research, 88(3), pp.332-333.

57. Hong, Dong-Hyun, et al. "Retinitis pigmentosa GTPase regulator (RPGR)interacting protein is stably associated with the photoreceptor ciliary axoneme and anchors RPGR to the connecting cilium." Journal of Biological Chemistry 276.15 (2001): 12091-12099.

58. Shu, Xinhua, et al. "RPGR ORF15 isoform co-localizes with RPGRIP1 at centrioles and basal bodies and interacts with nucleophosmin." Human Molecular Genetics 14.9 (2005): 1183-1197.

59. Zhao, Yun, et al. "The retinitis pigmentosa GTPase regulator (RPGR)-interacting protein: subserving RPGR function and participating in disk 
morphogenesis." Proceedings of the National Academy of Sciences 100.7 (2003): 3965-3970.

60. Liu, Qin, Jian Zuo, and Eric A. Pierce. "The retinitis pigmentosa 1 protein is a photoreceptor microtubule-associated protein." Journal of Neuroscience 24.29 (2004): 6427-6436.

61. Wensel, Theodore G., et al. "Structural and molecular bases of rod photoreceptor morphogenesis and disease." Progress in retinal and eye research 55 (2016): $32-51$.

62. Roof, Dorothy J., and John E. Heuser. "Surfaces of rod photoreceptor disk membranes: integral membrane components." The Journal of cell biology 95.2 (1982): 487-500.

63. Boesze-Battaglia, Kathleen, et al. "Fusion between retinal rod outer segment membranes and model membranes: a role for photoreceptor peripherin/rds." Biochemistry 37.26 (1998): 9477-9487.

64. Yang, Zhenglin, et al. "Mutant prominin 1 found in patients with macular degeneration disrupts photoreceptor disk morphogenesis in mice." The Journal of clinical investigation 118.8 (2008): 2908-2916.

65. Drivas, Theodore G., and Jean Bennett. "CEP290 and the primary cilium." Retinal Degenerative Diseases. Springer, New York, NY, 2014. 519-525.

66. Gorden, Nicholas T., et al. "CC2D2A is mutated in Joubert syndrome and interacts with the ciliopathy-associated basal body protein CEP290." The American Journal of Human Genetics 83.5 (2008): 559-571. 
67. Chang, Bo, et al. "In-frame deletion in a novel centrosomal/ciliary protein CEP290/NPHP6 perturbs its interaction with RPGR and results in early-onset retinal degeneration in the rd16 mouse." Human molecular genetics 15.11 (2006): 1847-1857.

68. Cideciyan, Artur V., et al. "Centrosomal-ciliary gene CEP290/NPHP6 mutations result in blindness with unexpected sparing of photoreceptors and visual brain: implications for therapy of Leber congenital amaurosis." Human mutation 28.11 (2007): 1074-1083.

69. Kim, Joon, Suguna Rani Krishnaswami, and Joseph G. Gleeson. "CEP290 interacts with the centriolar satellite component PCM-1 and is required for Rab8 localization to the primary cilium." Human molecular genetics 17.23 (2008): 37963805.

70. Knockenhauer, Kevin E., and Thomas U. Schwartz. "Structural characterization of Bardet-Biedl syndrome 9 protein (BBS9)." Journal of Biological Chemistry 290.32 (2015): 19569-19583.

71. Forsythe, Elizabeth, and Philip L. Beales. "Bardet-Biedl syndrome." European journal of human genetics 21.1 (2013): 8 .

72. Sung, Ching-Hwa, and Michel R. Leroux. "The roles of evolutionarily conserved functional modules in cilia-related trafficking." Nature cell biology 15.12 (2013): 1387-1397.

73. Riazuddin, S. Amer, et al. "A splice-site mutation in a retina-specific exon of BBS8 causes nonsyndromic retinitis pigmentosa." The American Journal of Human Genetics 86.5 (2010): 805-812. 
74. Murphy, Daniel, et al. "Alternative splicing shapes the phenotype of a mutation in BBS8 to cause nonsyndromic retinitis pigmentosa." Molecular and cellular biology 35.10 (2015): 1860-1870.

75. Pretorius, Pamela R., et al. "Functional analysis of BBS3 A89V that results in non-syndromic retinal degeneration." Human molecular genetics 20.8 (2011): 1625-1632.

76. Estrada-Cuzcano, Alejandro, et al. "BBS1 mutations in a wide spectrum of phenotypes ranging from nonsyndromic retinitis pigmentosa to Bardet-Biedl syndrome." Archives of ophthalmology 130.11 (2012): 1425-1432.

77. Pretorius, Pamela R., et al. "Identification and functional analysis of the visionspecific BBS3 (ARL6) long isoform." PLoS genetics 6.3 (2010): e1000884.

78. Pretorius, Pamela R., et al. "Functional analysis of BBS3 A89V that results in non-syndromic retinal degeneration." Human molecular genetics 20.8 (2011): 1625-1632.

79. Blencowe, Benjamin J. "Exonic splicing enhancers: mechanism of action, diversity and role in human genetic diseases." Trends in biochemical sciences 25.3 (2000): 106-110.

80. Ram, Oren, and Gil Ast. "SR proteins: a foot on the exon before the transition from intron to exon definition." Trends in Genetics 23.1 (2007): 5-7.

81. Labadorf, Adam, et al. "Genome-wide analysis of alternative splicing in Chlamydomonas reinhardtii." Bmc Genomics 11.1 (2010): 114. 
82. Kornblihtt, Alberto R., et al. "Alternative splicing: a pivotal step between eukaryotic transcription and translation." Nature reviews Molecular cell biology 14.3 (2013): 153.

83. Soergel, David AW, Liana F. Lareau, and Steven E. Brenner. "Regulation of gene expression by coupling of alternative splicing and NMD." Nonsense-mediated mRNA decay (2006): 175-196.

84. Irimia, Manuel, et al. "A highly conserved program of neuronal microexons is misregulated in autistic brains." Cell 159.7 (2014): 1511-1523.

85. Su, Chun-Hao, and Woan-Yuh Tarn. "Alternative splicing in neurogenesis and brain development." Frontiers in Molecular Biosciences 5 (2018): 12.

86. Shi, Yigong. "Mechanistic insights into precursor messenger RNA splicing by the spliceosome." Nature Reviews Molecular Cell Biology 18.11 (2017): 655.

87. Ohyama, Takako, et al. "Structure of Musashi1 in a complex with target RNA: the role of aromatic stacking interactions." Nucleic acids research 40.7 (2011): 32183231.

88. Li, Ning, et al. "The Msi family of RNA-binding proteins function redundantly as intestinal oncoproteins." Cell reports13.11 (2015): 2440-2455.

89. Sutherland, Jessie M., et al. "RNA binding protein Musashi-1 directly targets Msi2 and Erh during early testis germ cell development and interacts with IPO5 upon translocation to the nucleus." The FASEB Journal 29.7 (2015): 2759-2768.

90. Akindahunsi, Akintunde A., Antonella Bandiera, and Giorgio Manzini. "Vertebrate 2xRBD hnRNP proteins: a comparative analysis of genome, mRNA and protein sequences." Computational biology and chemistry 29.1 (2005): 13-23. 
91. Sakakibara, Shin-ichi, et al. "RNA-binding protein Musashi family: roles for CNS stem cells and a subpopulation of ependymal cells revealed by targeted disruption and antisense ablation." Proceedings of the National Academy of Sciences99.23 (2002): 15194-15199.

92. Sakakibara, Shin-ichi, et al. "Rna-binding protein Musashi2: developmentally regulated expression in neural precursor cells and subpopulations of neurons in mammalian CNS." Journal of Neuroscience 21.20 (2001): 8091-8107.

93. Kudinov, Alexander E., et al. "Musashi RNA-binding proteins as cancer drivers and novel therapeutic targets." Clinical Cancer Research 23.9 (2017): 21432153.

94. Fox, Raymond G., et al. "Musashi signaling in stem cells and cancer." Annual review of cell and developmental biology 31 (2015): 249-267.

95. Imai, Takao, et al. "The neural RNA-binding protein Musashi1 translationally regulates mammalian numb gene expression by interacting with its mRNA." Molecular and cellular biology21.12 (2001): 3888-3900.

96. Battelli, Chiara, et al. "The RNA-binding protein Musashi-1 regulates neural development through the translational repression of p21WAF-1." Molecular and Cellular Neuroscience 31.1 (2006): 85-96.

97. Ma, Xianghui, et al. "Msi2 maintains quiescent state of hair follicle stem cells by directly repressing the Hh signaling pathway." Journal of Investigative Dermatology 137.5 (2017): 1015-1024.

98. Cragle, Chad, and Angus M. MacNicol. "Musashi-directed translational activation of target mRNAs is mediated by the poly [A] polymerase, Germline Development- 
2." Journal of Biological Chemistry (2014): jbc-M114.

99. Rutledge, Charlotte E., et al. "Efficient translation of Dnmt1 requires cytoplasmic polyadenylation and Musashi binding elements." PloS one 9.2 (2014): e88385.

100. MacNicol, Melanie C., et al. "Evasion of regulatory phosphorylation by an alternatively spliced isoform of Musashi2." Scientific reports 7.1 (2017): 11503.

101. Murphy, Daniel, et al. "The Musashi 1 controls the splicing of photoreceptor-specific exons in the vertebrate retina." PLoS genetics 12.8 (2016): e1006256.

102. Susaki, Kanako, et al. "Musashi-1, an RNA-binding protein, is indispensable for survival of photoreceptors." Experimental eye research 88.3 (2009): 347-355.

103. Kaneko, Jun, and Chikafumi Chiba. "Immunohistochemical analysis of Musashi-1 expression during retinal regeneration of adult newt." Neuroscience letters 450.3 (2009): 252-257.

104. Nickerson, P. E. B., et al. "Changes in Musashi-1 subcellular localization correlate with cell cycle exit during postnatal retinal development." Experimental eye research 92.5 (2011): 344-352.

105. MacNicol, Angus M., Anna Wilczynska, and Melanie C. MacNicol. "Function and regulation of the mammalian Musashi mRNA translational regulator." (2008): 528-530.

106. Cuadrado, Ana, et al. "Regulation of tau RNA maturation by thyroid hormone is mediated by the neural RNA-binding protein musashi-1." Molecular and Cellular Neuroscience 20.2 (2002): 198-210. 
107. Sterne-Weiler, Timothy, et al. "Loss of exon identity is a common mechanism of human inherited disease." Genome research 21.10 (2011): 15631571.

108. Krawczak, Michael, et al. "Single base-pair substitutions in exon-intron junctions of human genes: nature, distribution, and consequences for mRNA splicing." Human mutation 28.2 (2007): 150-158.

109. Liu, Melissa M., and Donald J. Zack. "Alternative splicing and retinal degeneration." Clinical genetics 84.2 (2013): 142-149.

110. Rachel, Rivka A., Tiansen Li, and Anand Swaroop. "Photoreceptor sensory cilia and ciliopathies: focus on CEP290, RPGR and their interacting proteins." Cilia 1.1 (2012): 22.

111. Kakavand, Kiana. Studies on mechanisms of cell death in retinal degeneration. Diss. 2018.

112. Chang, B., et al. "Two mouse retinal degenerations caused by missense mutations in the $\beta$-subunit of rod cGMP phosphodiesterase gene." Vision research 47.5 (2007): 624-633.

113. Grimm, Christian, et al. "Protection of Rpe65-deficient mice identifies rhodopsin as a mediator of light-induced retinal degeneration." Nature genetics 25.1 (2000): 63 . 


\section{Chapter 2: Manuscript in preparation.}

Title: A critical role for MSI1 and MSI2 in photoreceptor morphogenesis

Authors: Jesse Sundar ${ }^{1}$, Fatimah Matalkah ${ }^{1}$, Bohye Jeong ${ }^{1}$, Peter Stoilov ${ }^{1 *}$, and Visvanathan Ramamurthy $y^{1,2,3, *}$

Affiliations: Departments of Biochemistry ${ }^{1}$, Ophthalmology and Visual Sciences ${ }^{2}$, and Neuroscience ${ }^{3}$; Robert C. Byrd Health Sciences Center, West Virginia University; Morgantown, West Virginia, USA, 26505;

\section{Address for correspondence:}

Peter Stoilov, Department of Biochemistry, West Virginia University School of Medicine;

1 Medical Center Dr. Morgantown, WV, USA, 26505; Email: pstoilov@hsc.wvu.edu;

Telephone: 304-293-6334; Fax: 304-293-6846;

Visvanathan Ramamurthy, Department of Biochemistry, West Virginia University School of Medicine; 1 Medical Center Dr. Morgantown, WV, USA, 26505; Email: ramamurthyv@mix.wvu.edu; Telephone: 304-293-2479; Fax: 304-293-6846;

Keywords: Msi1, Msi2, Musashi. Retina. Photoreceptor. RNA. Binding. Protein. Splicing. 


\section{ABSTRACT}

We previously proposed a role for the Musashi proteins, MSI1 and MSI2, in photoreceptor cell development that is mediated by their ability to control alternative splicing. Simultaneous deletion of Msi1 and Msi2 produced photoreceptors that did not respond to light, displayed severely disrupted OS morphology and axonemal defects. At postnatal day 5, we observed an increase in proliferating retinal progenitor cells in the knockout animals, suggesting delay in photoreceptor development. As expected, loss of Musashi prevented the use of photoreceptor-specific exons in transcripts important for OS morphogenesis, ciliogenesis and synaptic transmission. However, deletion of the photoreceptor-specific exons in Ttc8, Cc2d2a, Cep290, Cacna2d4, and Slc17a7 did not impair retinal development or visual function. We demonstrate a critical role for Musashi in the morphogenesis of terminally differentiated photoreceptor neurons. This role is in stark contrast with the canonical function of the two proteins in maintenance and renewal of stem cells. 


\section{INTRODUCTION}

In eukaryotes, alternative splicing of pre-mRNA is a process that increases protein diversity and controls gene expression. Diversification of proteomes through alternative splicing is a defining characteristic of metazoans and was expanded dramatically in bilaterians ${ }^{1}$. Alternative splicing is particularly prevalent in vertebrate neurons and is critical for the development and function of vertebrate nervous systems ${ }^{2-}$ 6.

We previously showed that photoreceptor neurons exploit a unique splicing program $^{7}$. Motif enrichment analysis suggested that Musashi-1 (MSI1) and Musashi-2 (MSI2), promote the use of photoreceptor specific exons ${ }^{7}$. We further showed that MSI1 is critical for utilization of photoreceptor specific exon in Tetratricopeptide repeat domain protein-8 $(\mathrm{Ttc} 8)^{7}$. In addition, Musashi promotes the splicing of several photoreceptor specific exons when over-expressed in cultured cells ${ }^{7}$. Interestingly, the Musashi proteins are known modulators of mRNA translation in $\mathrm{cytoso}^{8,9}$, where they either block or enhance translation of mRNA depending on signaling of cell ${ }^{10-15}$.

The MSI1 and MSI2 proteins have two highly conserved RNA binding domains (RBDs) in the N-terminal region which show close to $90 \%$ sequence identity and recognize a similar UAG motif in $\mathrm{RNA}^{16}$. The two RBDs of MSI1 and MSI2 are followed by a less conserved $\mathrm{C}$-terminal region which shows approximately $70 \%$ sequence identity ${ }^{17}$. The high degree of sequence identity between the MSI1 and MSI2 results in functional redundancy between the two proteins ${ }^{18,19}$.

Vertebrate photoreceptors are neurons detecting and transducing light stimuli. Photoreceptors are characterized by segment morphology which allows for 
compartmentalization of phototransduction, core cellular functions, and synaptic transmission. The light sensing machinery is confined to outer segment, a stack of membranes that is elaborated by cell's modified primary cilium. The outer segment is dynamic structure that is remade every 7 to 10 days. Consequently, maintenance of the outer segment requires high rate of transport of membranes and proteins through the connecting cilium ${ }^{20}$.

Interestingly, the predicted splicing targets of Musashi in photoreceptors include pre-mRNAs from ciliary (Ttc8, Cep290, Cc2d2a, Prom1) and synaptic-associated genes $\left(\right.$ Cacna2d4, Slc17a7) ${ }^{21-27}$. These genes have been showed to be crucial for photoreceptor development ${ }^{21-27}$. We proposed that production of photoreceptor specific splicing isoforms that is promoted by Musashi is necessary for the development and maintenance of photoreceptor cells in vivo ${ }^{7}$.

To test if Musashi drives photoreceptor development and function, we removed Msi1 and Msi2 in the developing retina and rod photoreceptor cells. We find that Musashi proteins are essential for photoreceptor function, morphogenesis, and survival but not their specification. Specifically, the Musashi proteins are crucial for outer segment (OS) and axoneme development. As expected disruption of the Musashi genes, led to loss of expression of photoreceptor specific splicing isoforms. Surprisingly, deleting the photoreceptor-specific exons of the, Ttc8, Cc2d2a, Cep290, Cacna2d4, and Slc17a7 genes does not produce a detectable phenotype suggesting that the loss of vision in the Musashi mutants is likely independent of the role of the Musashi proteins in controlling alternative splicing. 


\section{MATERIALS AND METHODS}

\section{Generation of mice and genotyping}

Mice carrying floxed alleles for Msi1 and Msi2 were provided by Dr. Christopher Lengner from the University of Pennsylvania. Six3 Cre transgene or Nrl Cre transgenes were used to delete the floxed alleles in developing retina or rod photoreceptors. All mouse lines were devoid of naturally occurring $r d 1$ and $r d 8$ alleles ${ }^{28,29}$. Males hemizygous for the Six3 Cre transgene or Nrl Cre transgene and floxed for either Msi1, Msi2, or both Msi1 and Msi2 were mated with females floxed for either Msi1, Msi2, or both Msi1 and Msi2 to obtain experimental knockout mice and littermate control. The offspring of breeding pairs were genotyped using PCR of DNA derived from ear biopsies. The Msi1 wildtype and floxed alleles were identified using following primers: (5'-CGG ACT GGG AGA GGT TTC TT-3' and 5'-AGC TCC CCT GAT TCC TGG T-3') ${ }^{30}$. The Msi2 wildtype and floxed alleles were identified by using following primers: (5'-GCT CGG CTG ACA AAG AAA GT-3' and 5'-TCT CCT TGT TGC GCT CAG TA-3') ${ }^{30}$. The presence of the Six3 Cre transgene was determined using following primers: (5'-CCC AAA TGT TGC TGG ATA GT-3' and 5'-CCC TCT CCT CTC CCT CCT-3') ${ }^{31}$. The presence of the $\mathrm{Nrl}$ Cre transgene was determined using following primers: (5'-TTT CAC TGG CTT CTG AGT CC-3' and 5'-CTT CAG GTT CTG CGG GAA AC-3') ${ }^{32}$. The presence of Cre recombinase was determined using following primers: (5'-CCT GGA AAA TGC TTC TGT CCG-3' and 5'-CAG GGT GTT ATA AGC AAT CCC-3') ${ }^{33}$. All experiments were executed with the approval of the Institutional Animal Care and Use Committee at West Virginia University. all experiments were carried out with adherence to the principles set forth in the ARVO Statement for the Ethical Use of Animals in 
Ophthalmic and Vision Research which advocates the use of the minimum number of animals per study needed to obtain statistical significance.

\section{Electroretinography, Immunoblotting, and Reverse Transcriptase PCR}

Electroretinography, immunoblotting, and reverse transcriptase PCR were conducted using previously described protocol from our laboratory $7,34,35$.

\section{Immunofluorescence Microscopy}

Immunofluorescence microscopy was carried out using a modified procedure in our laboratory ${ }^{34,35}$. Briefly, eyes were enucleated, and the cornea and lens were discarded. After dissection, eyes were fixed by immersion in $4 \%$ paraformaldehyde in PBS for one hour. After washing the eyes in PBS three times for ten minutes each, they were dehydrated by overnight incubation in 30\% sucrose in PBS. Eyes were then incubated in a 1:1 solution of OCT:30\% sucrose in PBS for one hour and frozen in OCT (VWR, Radnor, PA). The frozen tissues were sectioned using a Leica CM1850 cryostat for collecting serial retinal sections of $16 \mu \mathrm{m}$ thickness. The retinal cross-sections were then mounted onto Superfrost Plus microscope slides (Fisher Scientific, Pittsburgh, PA). Slide sections were then washed and permeabilized with PBS supplemented with $0.1 \%$ Triton X-100 (PBST) and incubated for one hour in a blocking buffer containing 10\% goat serum, $0.3 \%$ Triton $X-100$, and $0.02 \%$ sodium azide in PBS. Retinal sections were then incubated with primary antibody in a dilution buffer containing $5 \%$ goat serum, $0.3 \%$ Triton X-100, $0.02 \%$ sodium azide, and primary antibody at 1:500 dilution in PBS overnight at $4^{\circ} \mathrm{C}$ followed by three 5 minute washes using PBST. Sections were then incubated in the same dilution buffer containing secondary antibody and DAPI at 1:1000 for one hour. Slides were washed with PBST three times for five minutes each before 
treating with Prolong Gold Antifade reagent (ThermoFisher, Waltham, MA) and securing the coverslip. Microscope slides were imaged using a Nikon C2 Confocal Microscope.

\section{Retinal histology of the mouse models}

Following euthanasia, eyes were enucleated using a C-shaped forceps after marking the superior pole and incubated in Z-fixative for $>48$ hours before shipment and tissue processing by Excalibur Pathology Inc. (Norman, OK) ${ }^{34,35}$. The embedding, serial sectioning, mounting, and hematoxylin/eosin (H\&E) staining were performed by Excalibur Pathology. A Nikon C2 Microscope equipped with Elements software was used to image the slides.

\section{Transmission Electron Microscopy}

After euthanasia, a C-shaped forceps was used to enucleate the eye, and the cornea was discarded ${ }^{34,35}$. Eyes were then incubated in a fixative solution containing $2.5 \%$ glutaraldehyde and $2 \%$ paraformaldehyde in $100 \mathrm{mM}$ sodium cacodylate buffer at $\mathrm{pH} 7.5$ for 45 minutes before removal of the lens. After lensectomy, eyes were placed back into fixative for 72 hours before shipment, tissue processing, and imaging at the Robert P. Apkarian Integrated Electron Microscopy Core at Emory University.

\section{Antibodies}

The following primary antibodies were used throughout our studies: rat anti-MSI1 (1:1000; Medical and Biological Laboratories, Woburn, MA), rabbit anti-MSI2 (1:2000; Abcam, Cambridge, MA), mouse anti- $\square$-tubulin (1:10,000; Sigma-Aldrich, St. Louis, MO), rabbit anti-phospho-histone H3 (1:500; Cell Signaling, Danvers, MA), mouse anti-

Ki67 (1:500; BD Biosciences, San Jose, CA), rabbit anti-active Caspase-3 (1:500; Promega, Madison, WI), rhodamine peanut agglutinin (1:1000; PNA: cone OS sheath 
marker, Vector laboratories, Burlingame, CA), rabbit anti-peripherin-2 (1:2000) was a kind gift by Dr. Andrew Goldberg from Oakland University, rabbit anti-PDE6ß (1:2000; ThermoFisher, Waltham, MA), mouse anti-acetylated $\square$-tubulin (1:1000; Santa Cruz, Dallas, TX), guinea pig anti-MAK (1:500; Wako, Richmond, VA), mouse antiglutamylated tubulin (1:500; AdipoGen Life Sciences, San Diego, CA), mouse anti-Ttc8 (1:1000; Santa Cruz, Dallas, TX), rabbit anti-Ttc8 Exon 2A (1:1000; custom made ${ }^{7}$ ), mouse anti-GAPDH (1:10,000; Fitzgerald, Acton, MA), and 4',6-diamidino-2phenylindole (DAPI: nuclear counterstain; 1:1000; ThermoFisher, Waltham, MA). 


\section{RESULTS}

\section{Validation of the conditional knockout mouse models}

To begin, we tested the expression of Musashi proteins in various tissues. Musashi is known to be expressed in stem cell but its expression in adult tissue is not well known. Out of all the tissues we tested, retina had the highest expression of MSI1 and MSI2 proteins (Figure 1A). To test the biological significance of MSI expression in the murine retina, we used Cre-LoxP conditional recombination to knock out either Msi1, Msi2, or both the Msi1 and Msi2 genes throughout the entire retina and ventral forebrain using the Six3 Cre transgene (Supplementary Figure 1) ${ }^{36}$. Throughout this work, we refer to Msi floxed mice which are hemizygous for the Six 3 Cre transgene as ret-Msi-/- mice. The conditional recombination results in the deletion of Msi1's transcription start site, exon 1, and exon 2 (Supplementary Figure 1) ${ }^{19}$. For Msi2, the transcription start site and the first four exons are removed after cre-mediated recombination (Supplementary Figure 1$)^{19}$. The ablation of MSI1 and MSI2 was confirmed by immunoblotting retinal lysates from knockout mice at postnatal day 10 (PN10) (Figure 1B). Immunofluorescence microscopy of retinal cross sections obtained from the knockout mice also affirmed the absence of MSI1 and MSI2 expression in the retina (Figure 1C).

Notably, MSI2 protein levels were moderately but reproducibly upregulated in Msi1 knockout retina (Figure 1B, Supplementary Figure 2). We did not observe the inverse, upregulation of MSI1 protein in Msi2 knockouts (Supplementary Figure 2). These data shows that MSI1 protein regulates the expression of MSI2, and could indicate existence of a homeostatic mechanism for regulation overall Musashi protein 
levels.

\section{The MSI proteins are crucial for photoreceptor function}

To determine if the MSI proteins are required for photoreceptor function, we performed electroretinographic (ERG) recordings of the Msi conditional knockout mice at PN16 and monitored for changes in retinal function up to PN180. Figure 2A shows the scotopic and photopic ERG waveforms of the ret-Msi1-/-, ret-Msi2-/, and ret-Msi1-/:Msi2-/- mice at PN16 immediately after mice open their eyes ${ }^{37}$. When both Msi genes are removed, no scotopic or photopic retinal function remains as shown by absence of conspicuous "a"-waves and "b"-waves (Figure 2A). However, significant retinal function remains in the ret-Msi1-/- and ret-Msi2-/- single knockout mice. We characterized the retinal function of the ret-Msi1-/- and ret-Msi2-/- mice further to see if there was a photoresponse deficit at higher light intensities or as the mice aged (Figure 2B-E). In ret-Msi1-/- mice, there was a statistically significant reduction in photoreceptor "a"-wave amplitudes at almost all light intensities (Figure 2B). This reduction in the photoreceptor "a"-wave amplitude persisted in ret-Msi1-/- mice up to PN180 (Figure 2C). On the other hand, ret-Msi2-/- mice at PN16 had normal photoreceptor function at all of the light intensities we tested (Figure 2D). The "a"-wave amplitude began to decrease progressively in ret-Msi2-/- mice as they aged, and this became significant at PN120 (Figure 2E). Overall, this data shows that the MSI proteins essential for photoreceptor function, and the two proteins are partially redundant.

Intrinsic expression of MSI in photoreceptors is crucial for photoreceptor function

We next sought to determine if the phenotype of the ret-Msi-/- mice was due to 
the absence of MSI expression in photoreceptors or if deletion of MSI in other retinal cell types or retinal progenitors were contributing to the loss of vision. To this end, we generated rod-specific Msi conditional knockouts by crossing Msi floxed mice with mice hemizygous for the $\mathrm{Nrl}$ Cre transgene where the Nrl promoter activates Cre expression in rod photoreceptors ${ }^{38}$. Throughout this work, we refer to the Msi floxed mice which are hemizygous for the $\mathrm{Nrl}$ Cre transgene as rod-Msi-/- mice. After confirming the loss of MSI proteins in rod photoreceptors (Supplementary Figure 3), we collected ERG traces to analyze the retinal function of the knockout mice after ablation of the Msi genes in rods (Supplementary Figure 4A-E). Supplementary Figure 4A shows the scotopic and photopic ERG waveforms of the rod-Msi1-/-, rod-Msi2-/-, and rod-Msi1-/-:Msi2-/- mice at PN16. As observed in the ret-Msi1-/-:Msi2-/- mice, no conspicuous rod function was observed in the rod-Msi1-/-:Msi2-/- mice at PN16 which is demonstrated by absence of conspicuous "a"-wave under scotopic testing conditions (Supplementary Figure 4A). Again, we examined the rod-Msi1-/- and rod-Msi2-/- single knockout mice further to see if the photoresponse phenotype was comparable to that obtained from the ret-Msi1-/and ret-Msi2-/- mice. In rod-Msi1-/- mice at PN16, there was a reduction in photoreceptor "a"-wave amplitudes at several light intensities (Supplementary Figure 4B). This reduction in "a"-wave amplitude persisted as these mice aged up to PN180 (Supplementary Figure 4C). Contrarily, PN16 rod-Msi2-/- mice had no changes in photoreceptor function at all of the light intensities we examined (Supplementary Figure 4D). As observed in the ret-Msi2-/- mice, the "a"-wave amplitude began to decrease progressively as these mice aged, and this decrease became statistically significant at PN90 (Supplementary Figure 4E). The similar phenotypes of the ret-Msi and rod-Msi 
knockout mice shows that the intrinsic expression of MSI in photoreceptors is crucial for their function and that deletion of MSI in other cell types likely does not contribute significantly to the phenotype observed in the ret-Msi-/- mice. Therefore, throughout the rest of our studies, we focus on the ret-Msi1-/-:Msi2-/- mouse model for our experiments since there is a compensation in function occurring between MSI1 and MSI2 in the single knockout mice and to avoid confounding results that might be obtained when Msi1 and Msi2 are deleted only in rod but not cone photoreceptors.

\section{Retinal cell death occurs in the absence of the MSI proteins}

We next wanted to examine the mechanism behind the photoreceptor dysfunction seen in the ret-Msi1-/-:Msi2-/- mouse model. One of the common causes of a reduced ERG is photoreceptor cell death. Therefore, we performed histological analysis of the ret-Msi1-/-:Msi2-/- mice at PN5, PN10, PN16, and PN180 (Figure 3A-D). In ret-Msi1-/-:Msi2-/- mice at PN5, even before the neural retina has differentiated completely, there is a reduction in the neuroblast layer (NBL) thickness which was quantified across the superior-inferior axis (Figure 3A, left and right panels). There is also a more disordered arrangement of NBL nuclei in ret-Msi1-/-:Msi2-/- mice with cells more tightly packed together compared to its littermate control (Figure 3A, left panel). At PN10, the outer nuclear layer (ONL), inner nuclear layer (INL), and ganglion cell layer (GCL) of the retina all form in ret-Msi1-/-:Msi2-/- mice but there is a reduction in the number of layers of photoreceptor nuclei (Figure 3B, left and right panels). At PN16, the number of layers of ONL nuclei continue to decrease suggesting that photoreceptor cell death is occurring (Figure $3 \mathrm{C}$, left and middle panels). However, at this age, there are no statistically significant changes in the number of layers of INL nuclei (Figure 3C, left 
and right panels). By 6 months of age, the retina of ret-Msi1-/- Msi2-/- mice was severely degenerated with a complete loss of ONL nuclei in addition to a significant reduction in the number of layers of INL nuclei (Figure 3D, left, middle, and right panels).

\section{Changes in proliferation during retinal development in the absence of MSI1 and} MSI2

After observing a significant reduction in NBL nuclei in ret-Msi1-/-:Msi2-/- mice even before their retinas had fully differentiated, we wanted to investigate if this phenotype is related to the proliferation or premature death of retinal progenitor cells (RPCs). We collected retinal cross sections of ret-Msi1-/-:Msi2-/- mice at PN5 and probed with antibodies against phospho-histone $\mathrm{H} 3(\mathrm{PHH} 3)$ and Ki67, which are two commonly used markers of proliferation ${ }^{39-41}$. We also examined apoptosis of retinal cells in ret-Msi1-/-:Msi2-/- mice by staining with an antibody against the apoptotic marker anti-active Caspase-3 (CASP3) ${ }^{40,42}$. In ret-Msi1-/-:Msi2-/- mice, we witnessed a substantial increase of both $\mathrm{PHH} 3+$ and Ki67+ cells within the central retina whereas the littermate control had very few $\mathrm{PHH} 3+$ and $\mathrm{Ki67}+$ cells within the central retina (Figure 4A and B). We also noticed a trend toward increase of $\mathrm{PHH} 3+$ and $\mathrm{Ki67}+$ cell in the peripheral retina of ret-Msi1-/-:Msi2-/- mice (Figure 4A and B). No significant changes in proliferation marker staining were witnessed when comparing the superior and inferior retina of ret-Msi1-/-:Msi2-/- mice. CASP3 staining of retinal cross sections from ret-Msi1-/-:Msi2-/- mice showed no significant differences in the number of CASP3+ cells in either the central or peripheral retina (Figure 4C). Our data points to altered proliferation and not increased apoptosis at early stages of retinal development 
as the cause for the reduced number of NBL nuclei at PN5 in the Musashi knockout mice.

\section{The MSI proteins are required for OS development}

Photoreceptor cells are present in the ret-Msi1-/-:Msi2-/- as indicated by the welldefined ONL (Figure 3C). We therefore examined the structure of the OS in ret-Msi1-/:Msi2-/- mice at PN16 by immunofluorescence microscopy using three different OS markers, anti-Peripherin-2 (PRPH2: OS marker), anti-Phosphodiesterase-6 $\square$ (PDE6 $\square$ : rod OS marker), and peanut aglutinin (PNA: cone OS marker). After staining retinal cross sections from ret-Msi1-/-:Msi2-/- mice with PRPH2 and PNA, we observed a severe shortening of the photoreceptor outer segment structure (Figure 5A). This result was not limited to PRPH2, as staining with the rod OS marker PDE6 $\square$ demonstrated the same phenotype (Figure 5B). The outer segment of cone photoreceptors also appears to be severely shortened as shown by the abnormal PNA staining (Figure 5A-B). This defect is likely independent of degeneration since the same phenotype is observed at PN10 before significant degeneration occurs and as the OS begins to elaborate (Supplementary Figure 6). Lastly, no mislocalization of PDE6 $\square$ is found in the ONL or inner segment of ret-Msi1-/-:Msi2-/- mice suggesting that while the MSI proteins are required for outer segment formation they are not regulating trafficking or localization of PDE6 (Figure 5B). No significant changes were observed in the single knockouts (Supplementary Figure 7).

The MSI proteins are crucial for photoreceptor outer segment and axoneme development

Using transmission electron microscopy, we imaged ultrathin retinal sections 
from ret-Msi1-/-:Msi2-/- mice at PN10 when the OS begins to elaborate (Figure 6).

When examining the OS/IS boundary in ret-Msi1-/-Msi2-/- mice by electron microscopy, we observed very little if any conspicuous OS formation (Figure 6A). Instead, the IS of the ret-Msi1-/-:Msi2-/- mice appears to come in direct contact with the RPE (Figure 6AB). At higher magnification, the photoreceptors of ret-Msi1-/-:Msi2-/- mice displayed either no OS formation or formation of aberrant and undersized OS (Figure 6B left, middle, and right panels). The basal body and connecting cilium (CC) appear to be normal in structure and size (Figure 6B, middle panel).

To further examine the structure of the connecting cilium and the axoneme, we stained retinal cross sections from ret-Msi1-/-:Msi2-/- mice at PN10 using antibodies directed against the connecting cilium (glutamylated and acetylated $\square$-tubulin) and axoneme (MAK) markers ${ }^{40,43-45}$. Probing with glutamylated and acetylated $\square$-tubulin antibodies showed that there were no changes in the length of the CC (Figure 7A, C-D). This is in agreement with Figure 5B which revealed a functional connecting cilium due to normal trafficking of PDE6 to OS. Contrarily, staining with the anti-MAK antibody showed a substantial reduction in the length of the axoneme accompanied with punctate staining suggesting a severe structural defect of the axoneme (Figure 7A-B).

\section{The MSI proteins promote splicing of photoreceptor specific exons}

Our previous studies suggested that the MSI proteins are regulating alternative splicing of their target pre-mRNAs in vertebrate photoreceptors ${ }^{7}$. To test if the Musashi proteins are responsible for the inclusion of photoreceptor specific exon, we analyzed the splicing in ret-Msi1-/-:Msi2-/- mice of pre-mRNAs from cilia-and OS-related genes that we previously showed to express photoreceptor specific isoforms (Figure 8). We 
witnessed a drastic reduction in alternative exon inclusion in ret-Msi1-/-:Msi2-/- mice for all of the tested transcripts (Figure 8B). We analyzed isoform expression at the protein level for Ttc8 using two different antibodies, one which recognizes all Ttc8 protein isoforms (Pan-Ttc8) and the other which recognizes the photoreceptor-specific isoform of Ttc8 by binding the epitope encoded by Exon 2A (the photoreceptor-specific exon of Ttc8) (Figure 8A, bottom panel). After probing retinal lysates from the ret-Msi1-/-Msi2-/mice with the pan-Ttc8 antibody, we observed faster migration of the Ttc8 protein compared to the littermate control suggesting that the Exon 2A was not included (Figure 8C). Concordantly, when probing for the photoreceptor-specific isoform of Ttc8 using the Ttc8 Exon 2A antibody, we saw a absence of this isoform in ret-Msi1-/-:Msi2-/- mice (Figure 8C). Taken together these results demonstrate that the Musashi proteins are required for the inclusion of photoreceptor specific alternative exons..

\section{Alternative exons included in photoreceptor mRNAs are not important for their function}

To examine the biological significance of the photoreceptor-specific splicing program that is regulated by the Musashi proteins, we used CRISPR-Cas9 to delete the photoreceptor-specific exons from the Ttc8, Cc2d2a, Cep290, Cacna2d4, and Slc17a7 genes in $C 57 B L 6 / J$ mice. These exons were chosen because: (i) they are located in genes critical for vision; (ii) the exons are used specifically in photoreceptors where

nearly all or nearly all of the transcripts include the exon; (iii) the exons with exception of the Slc17a7 exon are conserved in vertebrates. After validating the exon knockout mice (Figure 9A), we collected ERG traces from the exon knockout mice to determine if these exons were necessary for the function of rod and cone photoreceptor cells. Figure 9B 
shows ERG traces from the Ttc8 exon knockout, Cep290 exon knockout, Cc2d2a exon knockout, Cacna2d4 exon knockout, and Slc17a7 exon knockout compared to wildtype (far left). No significant changes in retinal function were observed in any of exon knockout mice compared to control by five months of age (Figure 9B) suggesting that the inclusion of these photoreceptor-specific exon inclusion is not critical for rod and cone function. 


\section{DISCUSSION}

\section{MSI1 and MSI2 are required for photoreceptor morphogenesis but not specification}

Our data shows a clear requirement for MSI1 and MSI2 in photoreceptor cells. Double knockout of Msi1 and Msi2 in retinal progenitors results in complete loss of vision. Two lines of evidence demonstrate that this loss of vision is due to a defect in photoreceptor morphogenesis, rather than developmental defects due to impairment of the retinal progenitor cells. First, the specification of retinal progenitors to photoreceptor cells was not affected by loss of Musashi. The retina of the knockout mice had clearly defined outer nuclear layer. The rod photoreceptor nuclei retained their characteristic morphology, and the photoreceptor cells expressed cell type specific transcripts such as peripherin and PDE6 $\beta$. Importantly, knockout of Msi1 and Msi2 in rod photoreceptors driven by Nrl-Cre caused loss of scotopic photoresponse. Thus the vision phenotype is not due to impairment of the early stages of retinal development, and is caused by a defect specific to photoreceptor cells.

Morphological examination by electron microscopy and immunofluorescence showed that the outer segment of the knockout photoreceptors is either missing, or is stunted and disorganized. The absence of outer segment is accompanied by a shortened axoneme. In contrast, the connecting cilium has normal length and did not have obvious defects. Trafficking of PDE6 and peripherin through the connecting cilium also appears to be normal and the two proteins localize to the outer segment wherever one is present. Taken together our data demonstrates a requirement for Musashi in the morphogenesis and function of the photoreceptor outer segment that appears not to 
affect transport along the connecting cilium.

\section{Normal photoreceptor function in photoreceptor-specific exon knockout mice}

RT-PCR analysis of alternative splicing in the retina of Msi1 and Msi2 knockout mice shoed that inclusion of photoreceptor specific exons in the mature transcripts is dependent on the Musashi proteins. Even though MSI1 and MSI2 regulate the splicing of the Ttc8, Cc2d2a, Cep290, Cacna2d4, and Slc17a7 pre-mRNAs, knockouts of the photoreceptor specific-exons in these genes revealed that these exons are not crucial for photoreceptor function. The retina of the exon knockout animals developed normally and no adverse phenotype was observed up to 5 months after birth. Thus, our data does not support a mechanisms by which alternative splicing mediates the phenotype of the Musashi knockouts in photoreceptor cells. This is a surprising result considering that four out of the exons are conserved and the genes that host them are critical for vision. Based on the currently available data we cannot completely rule out role for splicing in shaping the phenotype of the Musashi knockouts. Nevertheless, our results point that other mechanism need to be explored, particularly in the light of the documented role for Musashi in control mRNA translation.

\section{Cell proliferation and survival in the Musashi knockout retina}

Morphological examination showed reduced cell number in the neuroblastoid layer at postnatal day 5 in the knockout animals. In the mature retina the outer nuclear layer did not reach the size of the corresponding layers in the wild type animals and progressively degenerated with age. The MSI1 protein was previously reported to be required for photoreceptor survival, but no loss of inner neurons was reported, likely due 
to the presence of the paralogous $\mathrm{MSI}^{46}$. The reduction of the inner nuclear layer that we observe demonstrate that the Musashi proteins are required for the survival of inner retinal neurons in addition to photoreceptors. Interestingly, the reduction of the neuroblastic layer in the Musashi knockout retina at postnatal day 5 was accompanied by increase in the number of proliferating cells that stained positive for $\mathrm{PHH} 3$ and Ki67. Caspase 3 staining did not show differences in the number of apoptotic cells between the wild type and the knockout retina at that stage. These apparently contradictory observations can be explained with the role of the Musashi proteins in supporting stem cell renewal and proliferation through activation of the Notch pathway ${ }^{10,47-50}$. We propose that loss of Musashi in the developing retina reduces the numbers and proliferation rates of the neuronal precursors leading to delayed development of the neuroblastoid layer.

\section{Functional redundancy within the MSI RBP family}

In vertebrates, the Musashi RBP family consists of two paralogues, MSI1 and MSI2, which have high degree of sequence identity, and have arisen from a gene duplication event ${ }^{16,51}$. The RNA binding domains of MSI1 and MSI2 have approximately $90 \%$ sequence identity and recognize the same UAG sequence motif in vitro and in $v i v 0^{52-55}$. The high degree of similarity suggest that the two proteins are likely to be functionally redundant when co-expressed in the same cells. Indeed, we observed only minor reductions in visual function after the loss of either MSI1 or MSI2 alone whereas the combined loss of MSI1 and MSI2 resulted in a complete loss of visual function (Figure 2). Similarly, inclusion of photoreceptor specific exons is promoted by both 
proteins, and the double knockout produces stronger effect on splicing than the knockouts of either Msi1 or Msi2. The functional redundancy in photoreceptor cells that we observe is in agreement with previous reports of redundancy between MSI1 and MSI2 in other cell types ${ }^{18,19}$.

The redundancy between the two Musashi proteins in the retina appear to be partial. Loss of MSI1 produce more severe phenotype than loss of MSI2. Specifically, we observe an early visual defect in the Msi1 knockout mice, which is absent in the Msi2 knockouts. Loss of MSI1 also produced a stronger effect on splicing compared to MSI2. This partial redundancy may reflect intrinsic functional differences between the two proteins, or simply difference in their expression levels in photoreceptor cells. Interestingly, we noticed moderate but reproducible increased in the MSI2 protein levels after knocking out Msi1 (Supplementary Figure 2). Such mutual regulation can contribute to the redundancy between the two proteins and be a part of a homeostatic mechanism that maintains the overall Musashi protein levels.

Our work highlights roles for MSI1 and MSI2 in retinal development, retinal cell survival and photoreceptor morphogenesis. An interesting aspect of the function of the Musashi proteins in retina our their apparently mutually exclusive roles at different stages of development. At early stages of development MSI1 and MSI2 support the renewal and proliferation of retinal precursor cells. At late stages of retinal development and in the adult retina MSI1 and MSI2 are required for morphogenesis of the differentiated photoreceptor cells and survival of mature neurons. These roles are likely executed through translational control of Musashi targets, as knockouts of alternative exons regulated by the Musashi proteins did not recapitulate any of the aspects of the 
phenotype of the Musashi knockout mice. Future studies will be aimed at determining the mechanism(s) by which the absence of Musashi causes a complete loss of vision in mice. 


\section{FUNDING}

This work was supported by the National Institutes of Health [grant numbers RO1 EY028035, R01 EY025536, and R21 EY027707]; the West Virginia Lions Club Foundation; and International Lions Club Foundation. 


\section{ACKNOWLEDGEMENTS}

The authors would like to thank Maxim Sokolov, John Hollander, Ronald Gross, Sundar, and Schmid family for their feedback throughout this work. We would like to thank Dr. Christopher Lengner for the generous donation of the Msi1fl/fl Msi2fl/fl mice. We would like to thank Dr. Goldberg for PRPH2 antibody. 


\section{CONFLICTS OF INTEREST}

The authors have no conflicts of interest. 


\section{REFERENCES}

1. Origin of exon skipping-rich transcriptomes in animals driven by evolution of gene architecture | Genome Biology | Full Text. https://genomebiology.biomedcentral.com/articles/10.1186/s13059-018-1499-9.

2. RBFOX and PTBP1 proteins regulate the alternative splicing of micro-exons in human brain transcripts. https://genome.cshlp.org/content/25/1/1.short.

3. Irimia, M. et al. A Highly Conserved Program of Neuronal Microexons Is Misregulated in Autistic Brains. Cell 159, 1511-1523 (2014).

4. Ule, J. et al. Nova regulates brain-specific splicing to shape the synapse. Nat. Genet. 37, 844-852 (2005).

5. Vuong, J. K. et al. PTBP1 and PTBP2 Serve Both Specific and Redundant Functions in Neuronal Pre-mRNA Splicing. Cell Rep. 17, 2766-2775 (2016).

6. Gehman, L. T. et al. The splicing regulator Rbfox1 (A2BP1) controls neuronal excitation in the mammalian brain. Nat. Genet. 43, 706-711 (2011).

7. Murphy, D., Cieply, B., Carstens, R., Ramamurthy, V. \& Stoilov, P. The Musashi 1 Controls the Splicing of Photoreceptor-Specific Exons in the Vertebrate Retina. PLOS Genet. 12, e1006256 (2016).

8. Kudinov, A. E., Karanicolas, J., Golemis, E. A. \& Boumber, Y. Musashi RNABinding Proteins as Cancer Drivers and Novel Therapeutic Targets. Clin. Cancer Res. 23, 2143-2153 (2017). 
9. Fox, R. G., Park, F. D., Koechlein, C. S., Kritzik, M. \& Reya, T. Musashi Signaling in Stem Cells and Cancer. Annu. Rev. Cell Dev. Biol. 31, 249-267 (2015).

10. Imai, T. et al. The Neural RNA-Binding Protein Musashi1 Translationally Regulates Mammalian numb Gene Expression by Interacting with Its mRNA. Mol. Cell. Biol. 21, 3888-3900 (2001).

11. Battelli, C., Nikopoulos, G. N., Mitchell, J. G. \& Verdi, J. M. The RNA-binding protein Musashi-1 regulates neural development through the translational repression of p21WAF-1. Mol. Cell. Neurosci. 31, 85-96 (2006).

12. Ma, X. et al. Msi2 Maintains Quiescent State of Hair Follicle Stem Cells by Directly Repressing the Hh Signaling Pathway. J. Invest. Dermatol. 137, 1015-1024 (2017).

13. Cragle, C. \& MacNicol, A. M. Musashi Protein-directed Translational Activation of Target mRNAs Is Mediated by the Poly(A) Polymerase, Germ Line Development Defective-2. J. Biol. Chem. 289, 14239-14251 (2014).

14. Rutledge, C. E. et al. Efficient Translation of Dnmt1 Requires Cytoplasmic Polyadenylation and Musashi Binding Elements. PLOS ONE 9, e88385 (2014).

15. MacNicol, M. C. et al. Evasion of regulatory phosphorylation by an alternatively spliced isoform of Musashi2. Sci. Rep. 7, 1-17 (2017).

16. Ohyama, T. et al. Structure of Musashi1 in a complex with target RNA: the role of aromatic stacking interactions. Nucleic Acids Res. 40, 3218-3231 (2012). 
17. Sakakibara, S., Nakamura, Y., Satoh, H. \& Okano, H. RNA-Binding Protein Musashi2: Developmentally Regulated Expression in Neural Precursor Cells and Subpopulations of Neurons in Mammalian CNS. J. Neurosci. 21, 8091-8107 (2001).

18. Sakakibara, S. et al. RNA-binding protein Musashi family: Roles for CNS stem cells and a subpopulation of ependymal cells revealed by targeted disruption and antisense ablation. Proc. Natl. Acad. Sci. 99, 15194-15199 (2002).

19. Li, N. et al. The Msi Family of RNA-Binding Proteins Function Redundantly as Intestinal Oncoproteins. Cell Rep. 13, 2440-2455 (2015).

20. Pearring, J. N., Salinas, R. Y., Baker, S. A. \& Arshavsky, V. Y. Protein sorting, targeting and trafficking in photoreceptor cells. Prog. Retin. Eye Res. 36, 24-51 (2013).

21. Riazuddin, S. A. et al. A Splice-Site Mutation in a Retina-Specific Exon of BBS8 Causes Nonsyndromic Retinitis Pigmentosa. Am. J. Hum. Genet. 86, 805-812 (2010).

22. Murphy, D., Singh, R., Kolandaivelu, S., Ramamurthy, V. \& Stoilov, P. Alternative Splicing Shapes the Phenotype of a Mutation in BBS8 To Cause Nonsyndromic Retinitis Pigmentosa. Mol. Cell. Biol. 35, 1860-1870 (2015).

23. Rachel, R. A., Li, T. \& Swaroop, A. Photoreceptor sensory cilia and ciliopathies: focus on CEP290, RPGR and their interacting proteins. Cilia 1, 22 (2012).

24. Veleri, S. et al. Ciliopathy-associated gene Cc2d2a promotes assembly of subdistal appendages on the mother centriole during cilia biogenesis. Nat. Commun. $\mathbf{5}$, $1-12(2014)$. 
25. Zacchigna, S. et al. Loss of the Cholesterol-Binding Protein Prominin-1/CD133 Causes Disk Dysmorphogenesis and Photoreceptor Degeneration. J. Neurosci. 29, 2297-2308 (2009).

26. Ba-Abbad, R. et al. Mutations in CACNA2D4 Cause Distinctive Retinal Dysfunction in Humans. Ophthalmology 123, 668-671.e2 (2016).

27. Johnson, J. et al. Vesicular Glutamate Transporter 1 Is Required for Photoreceptor Synaptic Signaling But Not For Intrinsic Visual Functions. J. Neurosci. 27, 7245-7255 (2007).

28. A simple polymerase chain reaction assay for genotyping the retinal degeneration mutation (Pdebrd1) in FVB/N-derived transgenic mice. Lab. Anim. 35, 153-156 (2001).

29. Pak, J. S., Lee, E.-J. \& Craft, C. M. The retinal phenotype of Grk1-/- is compromised by a Crb1rd8 mutation. Mol. Vis. 21, 1281-1294 (2015).

30. Yousefi, M. et al. Msi RNA-binding proteins control reserve intestinal stem cell quiescenceControl of intestinal stem cell quiescence by Msi. J. Cell Biol. 215, 401-413 (2016).

31. Jackson, L. STOCK Tg(Six3-cre)69Frty/GcoJ. Genotyping Protocols Database https://www.jax.org/Protocol/UrlAsPDF?stockNumber=019755\&protocollD=28351 (2016). 
32. Jackson, L. C57BL/6J-Tg(Nrl-cre)1Smgc/J. Genotyping Protocols Database https://www.jax.org/Protocol/UrlAsPDF?stockNumber=028941\&protocollD=19558 (2016).

33. Hirrlinger, P. G., Scheller, A., Braun, C., Hirrlinger, J. \& Kirchhoff, F. Temporal control of gene recombination in astrocytes by transgenic expression of the tamoxifeninducible DNA recombinase variant CreERT2. Glia 54, 11-20 (2006).

34. Wright, Z. C. et al. ARL3 regulates trafficking of prenylated phototransduction proteins to the rod outer segment. Hum. Mol. Genet. 25, 2031-2044 (2016).

35. Wright, Z. C. et al. ADP-Ribosylation Factor-Like 2 (ARL2) regulates cilia stability and development of outer segments in rod photoreceptor neurons. Sci. Rep. 8, 1-12 (2018).

36. Furuta, Y., Lagutin, O., Hogan, B. L. M. \& Oliver, G. C. Retina- and ventral forebrain-specific Cre recombinase activity in transgenic mice. genesis 26, 130-132 (2000).

37. Guan, W. et al. Eye opening differentially modulates inhibitory synaptic transmission in the developing visual cortex. eLife 6,.

38. Brightman, D. S., Razafsky, D., Potter, C., Hodzic, D. \& Chen, S. Nrl-Cre transgenic mouse mediates loxP recombination in developing rod photoreceptors. Genes. N. Y. N2000 54, 129-135 (2016).

39. Komitova Mila, Mattsson Bengt, Johansson Barbro B. \& Eriksson Peter S. Enriched Environment Increases Neural Stem/Progenitor Cell Proliferation and 
Neurogenesis in the Subventricular Zone of Stroke-Lesioned Adult Rats. Stroke 36, 1278-1282 (2005).

40. Dilan, T. L. et al. ARL13B, a Joubert Syndrome-Associated Protein, Is Critical for Retinogenesis and Elaboration of Mouse Photoreceptor Outer Segments. J. Neurosci. 39, 1347-1364 (2019).

41. Perou, C. M. et al. Distinctive gene expression patterns in human mammary epithelial cells and breast cancers. Proc. Natl. Acad. Sci. 96, 9212-9217 (1999).

42. Abu-Qare, A. W. \& Abou-Donia, M. B. Biomarkers of apoptosis: release of cytochrome c, activation of caspase-3, induction of 8-hydroxy-2'-deoxyguanosine, increased 3-nitrotyrosine, and alteration of p53 gene. J. Toxicol. Environ. Health B Crit. Rev. 4, 313-332 (2001).

43. Arikawa, K. \& Williams, D. S. Acetylated alpha-tubulin in the connecting cilium of developing rat photoreceptors. Invest. Ophthalmol. Vis. Sci. 34, 2145-2149 (1993).

44. Grau, M. B. et al. Alterations in the balance of tubulin glycylation and glutamylation in photoreceptors leads to retinal degeneration. J. Cell Sci. 130, 938-949 (2017).

45. Omori, Y. et al. Negative regulation of ciliary length by ciliary male germ cellassociated kinase (Mak) is required for retinal photoreceptor survival. Proc. Natl. Acad. Sci. 107, 22671-22676 (2010).

46. Susaki, K. et al. Musashi-1, an RNA-binding protein, is indispensable for survival of photoreceptors. Exp. Eye Res. 88, 347-355 (2009). 
47. Okano, H. et al. Function of RNA-binding protein Musashi-1 in stem cells. Exp. Cell Res. 306, 349-356 (2005).

48. Wuebben, E. L., Mallanna, S. K., Cox, J. L. \& Rizzino, A. Musashi2 Is Required for the Self-Renewal and Pluripotency of Embryonic Stem Cells. PLOS ONE 7, e34827 (2012).

49. de Andrés-Aguayo, L. et al. Musashi 2 is a regulator of the HSC compartment identified by a retroviral insertion screen and knockout mice. Blood 118, 554-564 (2011).

50. Siddall, N. A., McLaughlin, E. A., Marriner, N. L. \& Hime, G. R. The RNA-binding protein Musashi is required intrinsically to maintain stem cell identity. Proc. Natl. Acad. Sci. 103, 8402-8407 (2006).

51. Sutherland, J. M., Siddall, N. A., Hime, G. R. \& McLaughlin, E. A. RNA binding proteins in spermatogenesis: an in depth focus on the Musashi family. Asian J. Androl. 17, 529-536 (2015).

52. Uren, P. J. et al. RNA-Binding Protein Musashi1 Is a Central Regulator of Adhesion Pathways in Glioblastoma. Mol. Cell. Biol. 35, 2965-2978 (2015).

53. Bennett, C. G. et al. Genome-wide analysis of Musashi-2 targets reveals novel functions in governing epithelial cell migration. Nucleic Acids Res. 44, 3788-3800 (2016).

54. Rentas, S. et al. Musashi-2 attenuates AHR signalling to expand human haematopoietic stem cells. Nature 532, 508-511 (2016). 
55. Lan, L. et al. Human oncoprotein Musashi-2 N-terminal RNA recognition motif backbone assignment and identification of RNA-binding pocket. Oncotarget 8, 106587106597 (2017). 


\section{FIGURE 1}
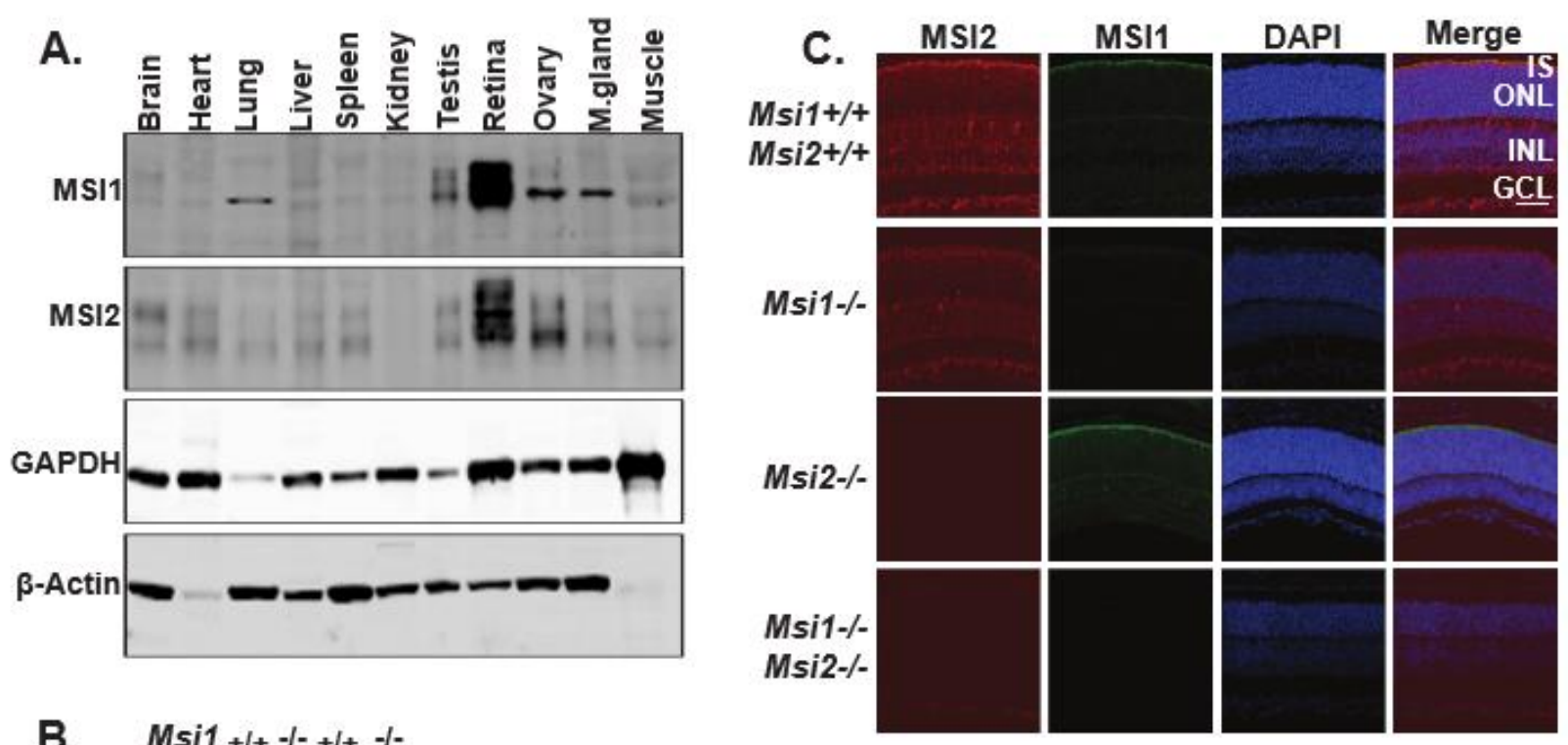

B. Msi1 $+1+-1-+1++-$

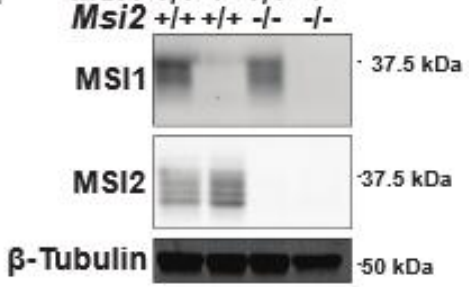




\section{FIGURE 2}

A.

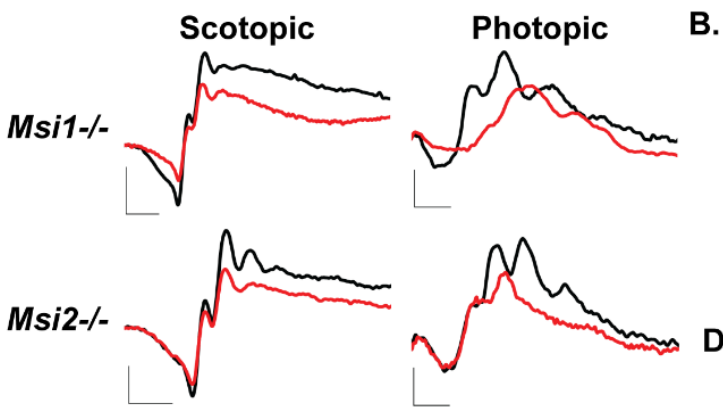

Msi1-\%
B.
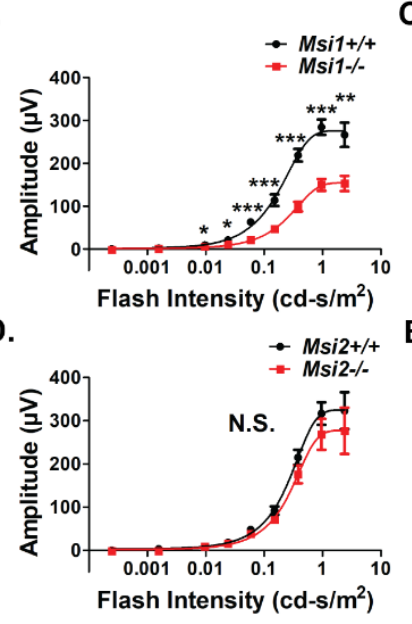

C.

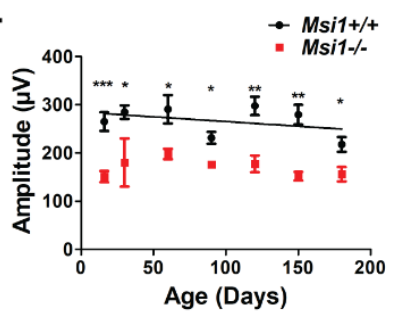

E.

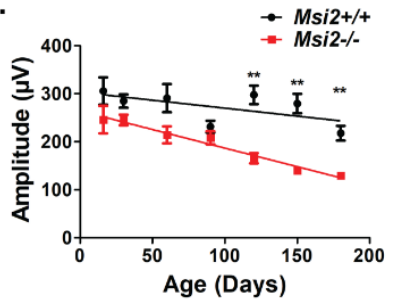




\section{FIGURE 3}
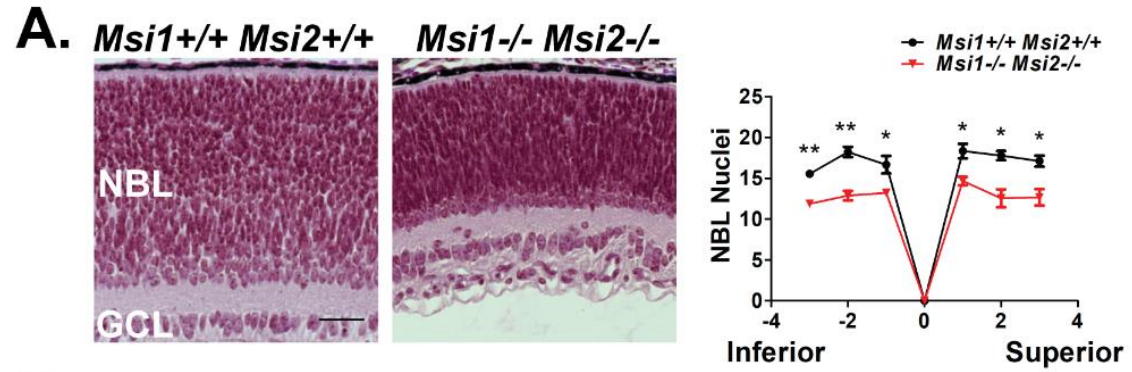

B.
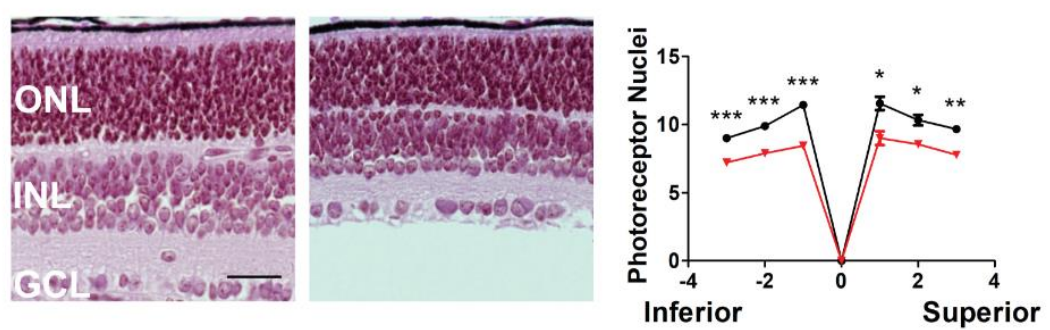

C.
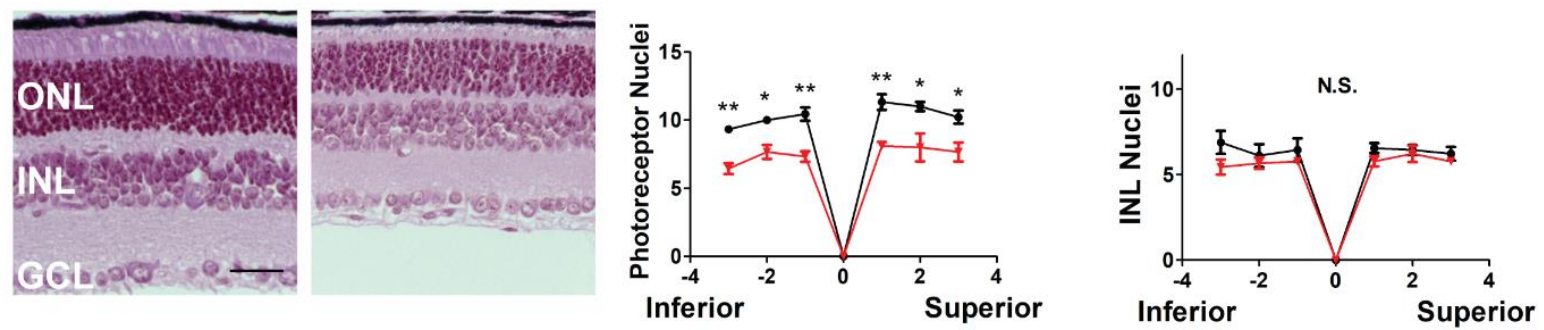

D.
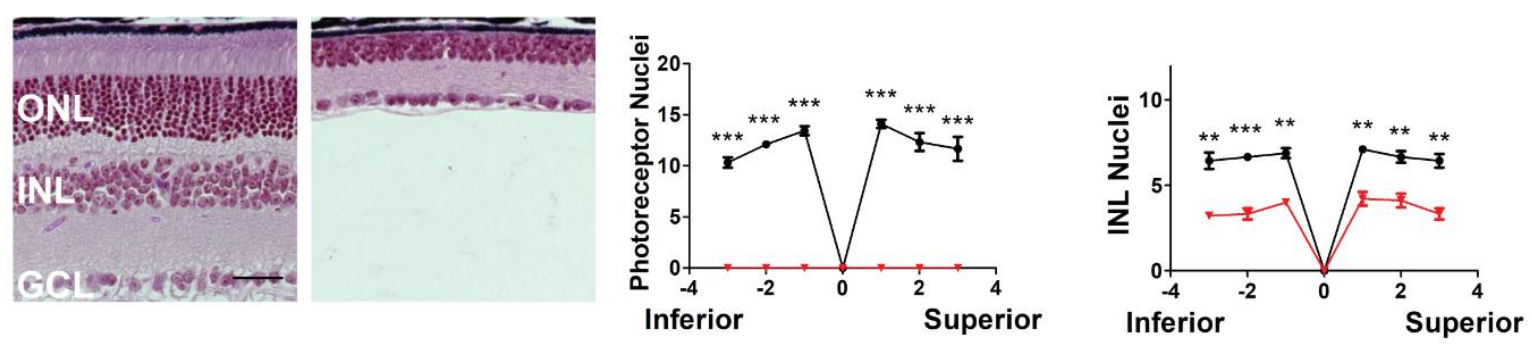


\section{FIGURE 4}

A.
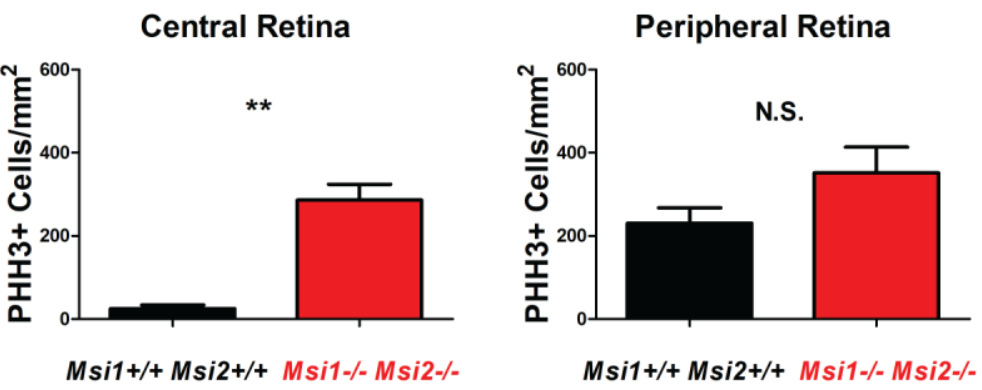

B.

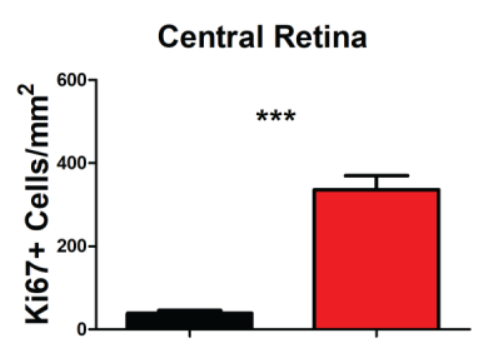

Msi1+/+ Msi2+/+ Msi1-/- Msi2-/-

C.

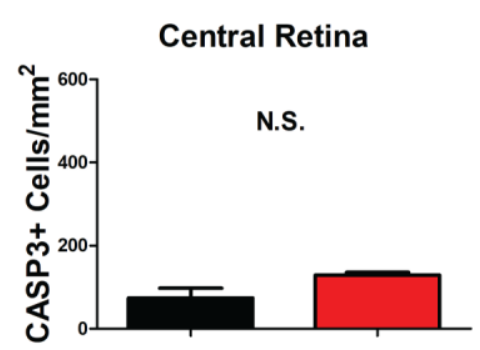

Msi1+/+ Msi2+/+ Msi1-/- Msi2-/-
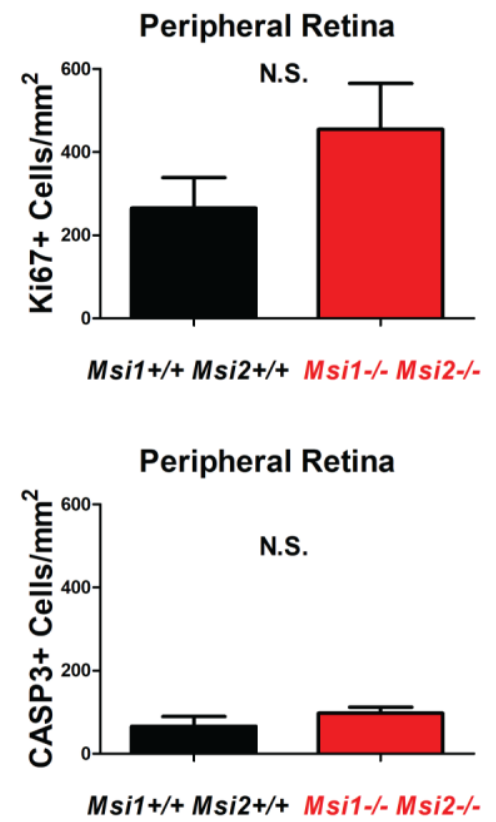
FIGURE 5

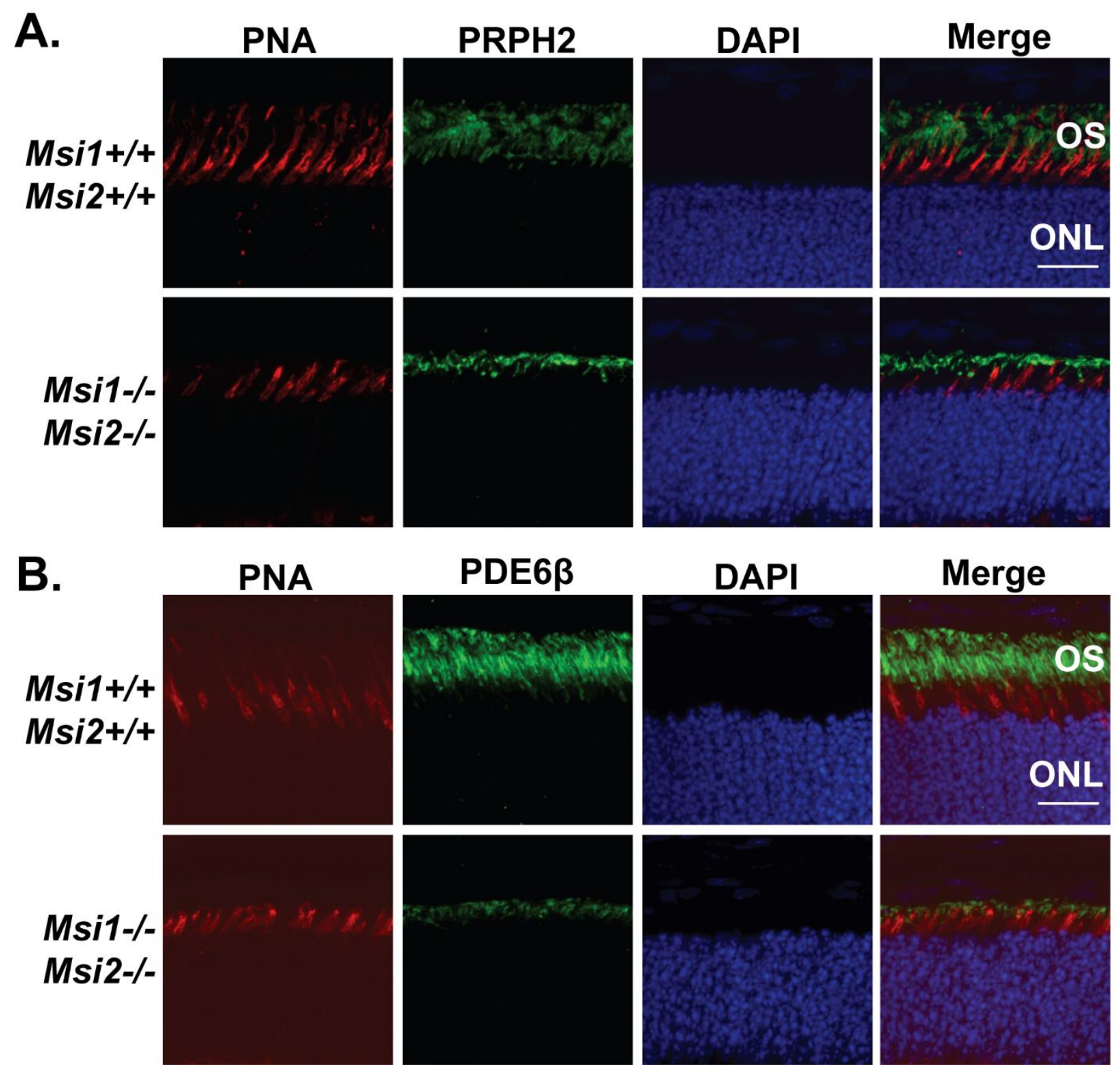


FIGURE 6

A.

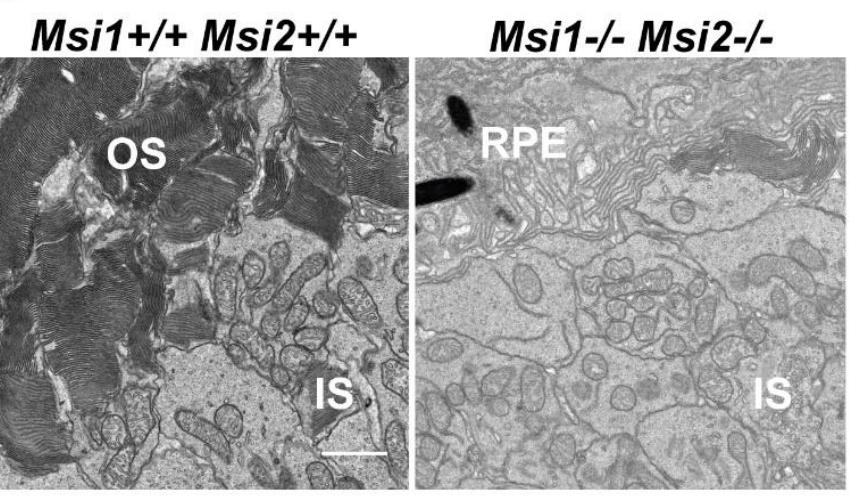

B.

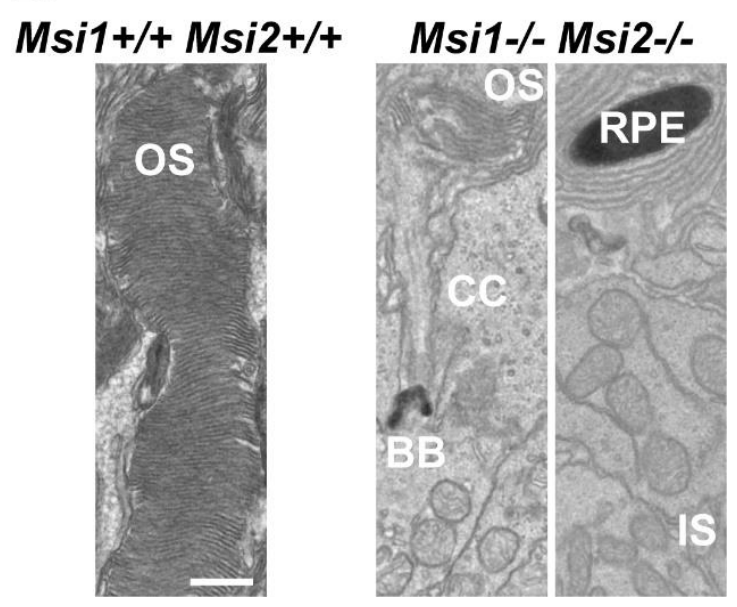




\section{FIGURE 7}

A.

Ac-Tubulin

MAK
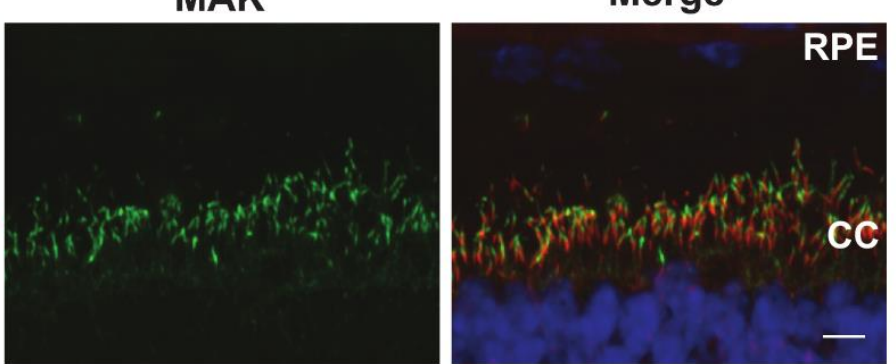

Msi1+/+

Msi2+/+
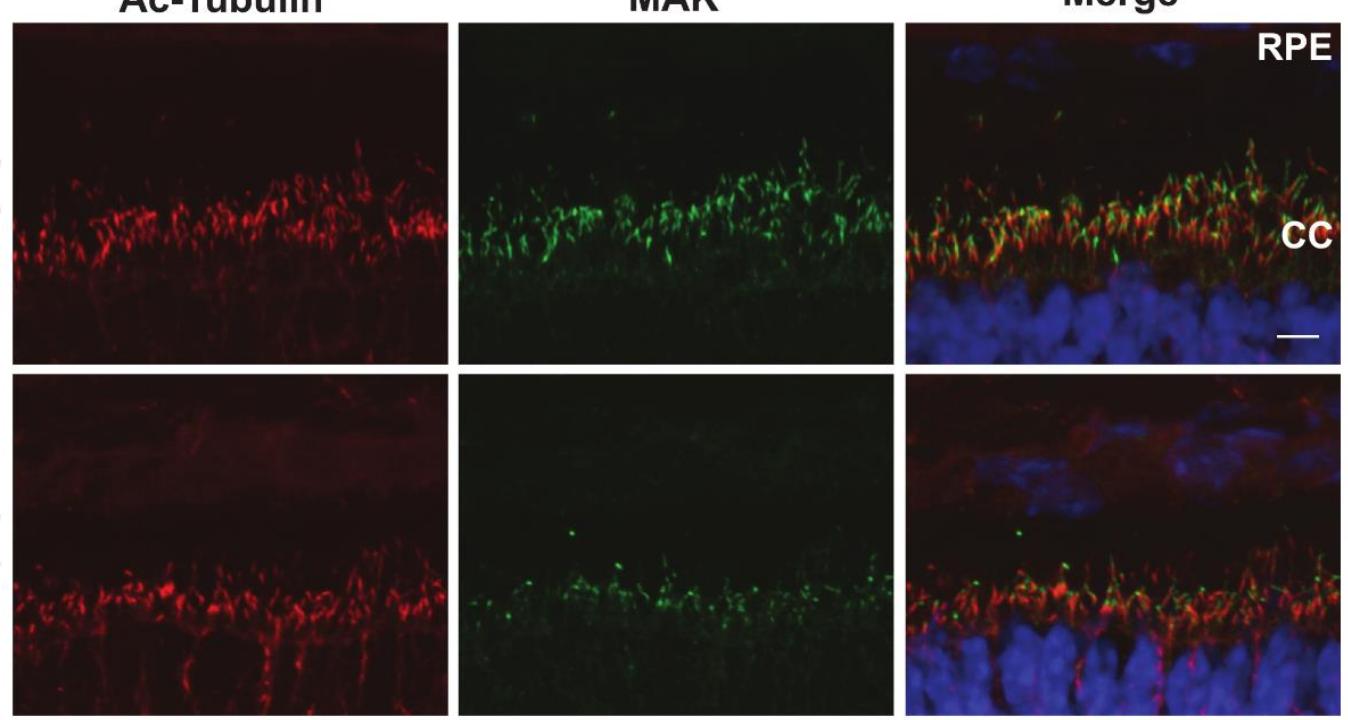

B.

C.

D.
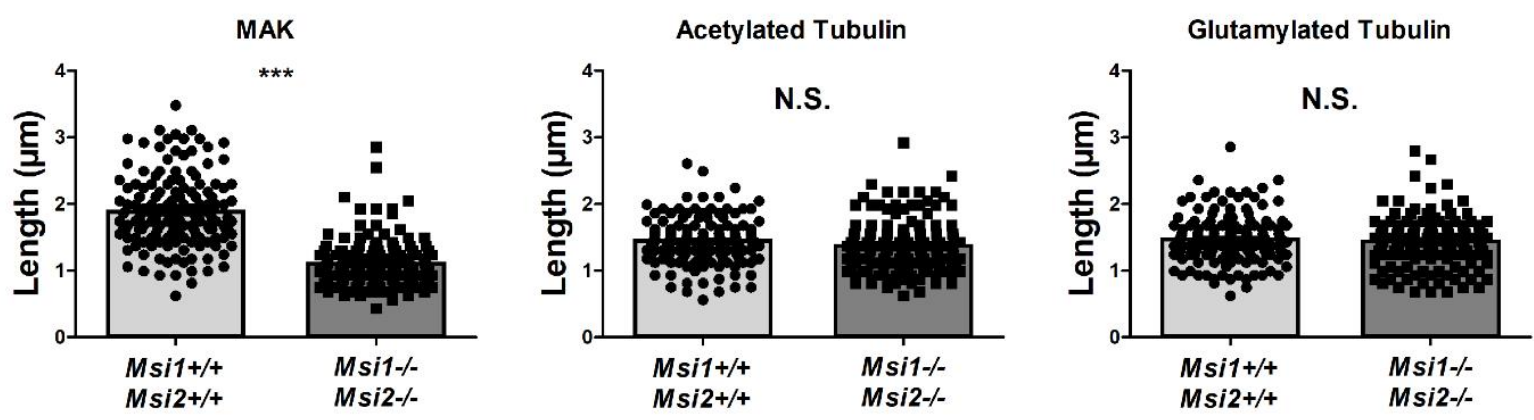


\section{FIGURE 8}

A.

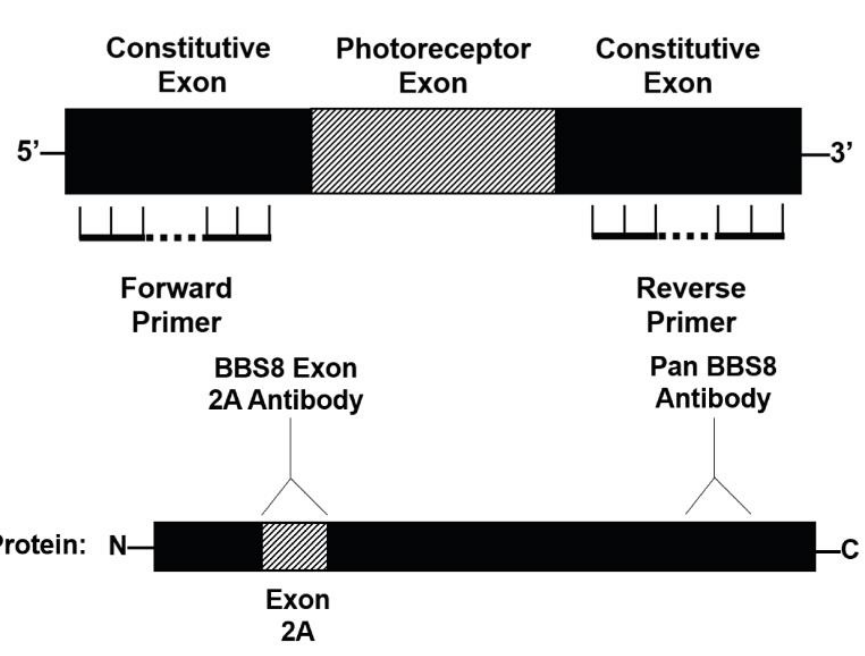

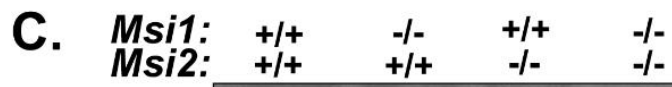

Pan-BBS8

BBS8 E2A

GAPDH
B.

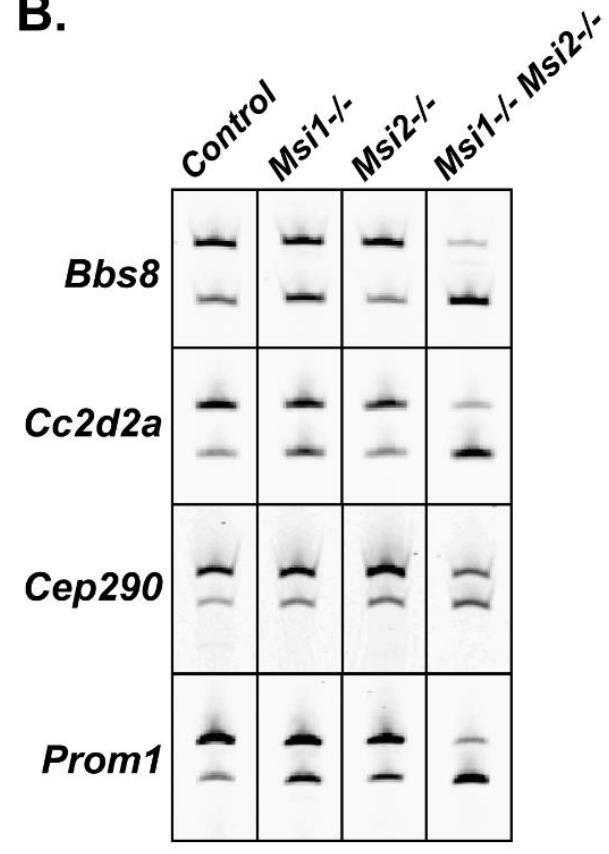




\section{FIGURE 9}

A.

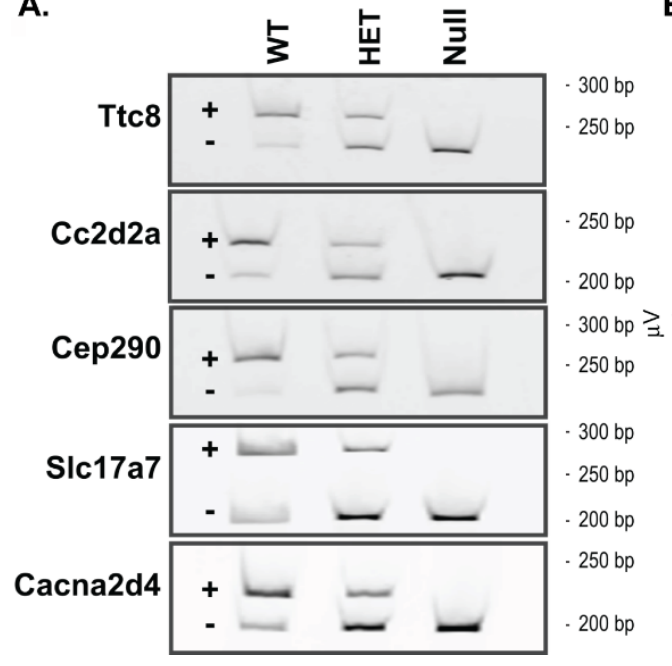

B.

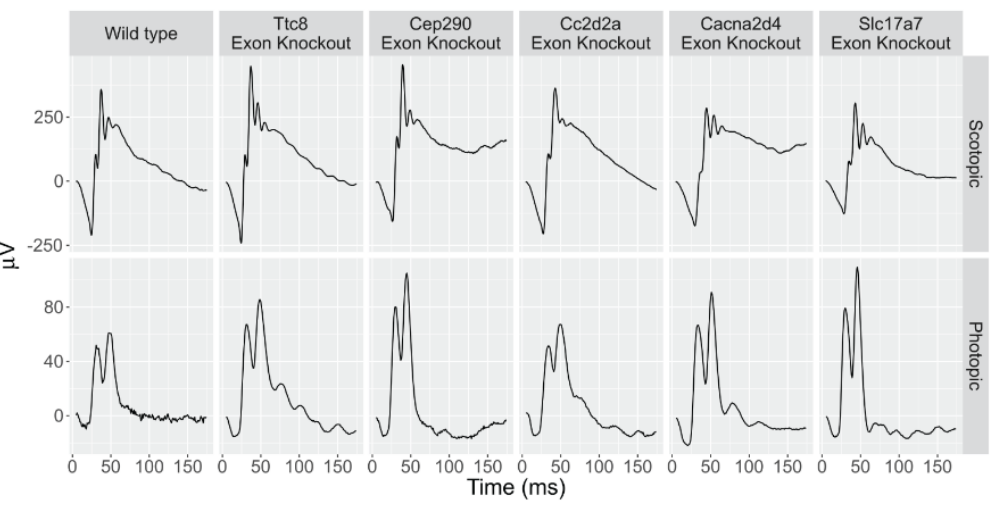


FIGURE LEGENDS

Figure 1: Validation of the conditional knockout mouse models.

A. Immunoblot of various tissues from wildtype mice and subsequently probing with anti-MSI1 and anti-MSI2 antibodies with anti- $\square$-tubulin antibody serving as a loading control.

B. Validation of the ret-Msi1-/-, ret-Msi2-/-, and ret-Msi1-/-: Msi2-/- mice at PN10 by immunoblotting retinal lysates and subsequently probing with anti-MSI1 and anti-MSI2 antibodies with anti- $\square$-tubulin antibody serving as a loading control.

C. Immunofluorescence microscopy images of retinal sections from ret-Msi1-/-, retMsi2-/-, and ret-Msi1-/-: Msi2-/- mice at PN10 probed with anti-MSI1 and anti-MSI2 antibodies along with a DAPI counterstain. (IS: inner segment, ONL: outer nuclear layer, INL: inner nuclear layer, and GCL: ganglion cell layer). Scale bar $=50 \square \mathrm{m}$.

Figure 2: The Musashi proteins are crucial for normal vision as shown by electroretinography.

A. Representative scotopic and photopic electroretinograms (ERGs) from the ret-Msi1-/, ret-Msi2-/-, and ret-Msi1-/-: Msi2-/- mice at PN16. Scotopic ERGs were obtained after overnight dark adaptation using $0.151 \mathrm{~cd}-\mathrm{s} / \mathrm{m}^{2}$ flashes while photopic ERGs were obtained with $7.6 \mathrm{~cd}-\mathrm{s} / \mathrm{m}^{2}$ flashes under light-adapted conditions using a rod-saturating white background light (Scotopic scale bar: $x$-axis $=20 \mathrm{~ms}$, y-axis $=200 \square \mathrm{V}$; Photopic scale bar: $\mathrm{x}$-axis $=20 \mathrm{~ms}, \mathrm{y}$-axis $=20 \square \mathrm{V}$ ).

B. Light stimulus intensity plot of the scotopic "a"-wave response from ret-Msi1-/- mice 
with a maximum amplitude of $276 \pm 10 \square \mathrm{V}$ in control mice and maximum amplitude of $154 \pm 8 \square$ V in the ret-Msi1-/- mice $\left({ }^{*}=\mathrm{P}\right.$-value $<0.05 ;{ }^{* *}=\mathrm{P}$-value $<0.01 ;{ }^{* * *}=\mathrm{P}$-value $<$ $0.001)$.

C. Plot of the rod photoreceptor "a"-wave response from ret-Msi1-/- mice plotted against the age of the mouse during which the ERG was recorded.

D. Light stimulus intensity plot of the scotopic "a"-wave response from ret-Msi2-/- mice with a maximum amplitude of $325 \pm 15 \square \mathrm{V}$ in control mice and maximum amplitude of $278 \pm 18 \square \mathrm{V}$ in the ret-Msi2-/- mice.

E. Plot of the rod photoreceptor "a"-wave response from ret-Msi2-/- mice plotted against the age of the mouse during which the ERG was recorded. All data is shown as the mean \pm the SEM, and statistical analyses were carried out using the homoscedastic unpaired student's t-test $\left({ }^{*}=\mathrm{P}<0.05\right)$.

\section{Figure 3: Retinal cell death occurs in the absence of the Musashiproteins}

A. Left: Brightfield microscopic images of H\&E stained retinal cross sections from the ret-Msi1-/-: Msi2-/- mice at PN5 (NBL: neuroblast layer and GCL: ganglion cell layer). Right: NBL spider plot showing the quantification of the NBL thickness (by neuroblast nuclear layers) at six regions from the inferior to superior retina in the ret-Msi1-/-: Msi2-/mice at PN5 $\left({ }^{*}=\right.$ P-value $<0.05 ;{ }^{* *}=\mathrm{P}$-value $<0.01 ;{ }^{* *}=\mathrm{P}-$ value $\left.<0.001\right)$.

B. Left: Brightfield microscopic images of H\&E stained retinal cross sections from the ret-Msi1-/-: Msi2-/- mice at PN10 (ONL: outer nuclear layer, INL: inner nuclear layer, and GCL: ganglion cell layer). Right: ONL spider plot showing the quantification of the ONL thickness (by photoreceptor nuclear layers) at six regions from the inferior to 
superior retina in the ret-Msi1-/-: Msi2-/- mice at PN10.

C. Left: Brightfield microscopic images of H\&E stained retinal cross sections from the ret-Msi1-/-: Msi2-/- mice at PN16 (ONL: outer nuclear layer, INL: inner nuclear layer, and GCL: ganglion cell layer). Right: ONL and INL spider plots showing the quantification of the ONL and INL thicknesses (by nuclear layers) at six regions from the inferior to superior retina in the ret-Msi1-/-: Msi2-/- mice at PN16.

D. Left: Brightfield microscopic images of H\&E stained retinal cross sections from the ret-Msi1-/-: Msi2-/- mice at PN180 (ONL: outer nuclear layer, INL: inner nuclear layer, and GCL: ganglion cell layer). Right: ONL and INL spider plots showing the quantification of the ONL and INL thicknesses (by nuclear layers) at six regions from the inferior to superior retina in the ret-Msi1-/-: Msi2-/- mice at PN180. All data is shown as the mean \pm the SEM, and statistical analyses were carried out using the homoscedastic unpaired student's t-test $\left({ }^{*}=\mathrm{P}<0.05 ;{ }^{* * *}=\mathrm{P}<0.001\right)$.

\section{Figure 4: Changes in proliferation occur in the absence of MSI1 and MSI2}

A. Quantitation of PHH3+ cells in the central (left) and peripheral (right) regions of the retina in PN5 ret-Msi1-/-: Msi2-/- mice and littermate control mice.

B. Quantitation of Ki67+ cells in the central (left) and peripheral (right) regions of the retina in PN5 ret-Msi1-/-: Msi2-/- mice and littermate control mice.

C. Quantitation of CASP3+ cells in the central (left) and peripheral (right) regions of the retina in PN5 ret-Msi1-/-: Msi2-/- mice and littermate control mice.

Figure 5: The Musashi proteins are required for proper OS development 
A. Immunofluorescence microscopy images of retinal cross sections from the ret-Msi1-/: Msi2-/- mice at PN16 stained with anti-peripherin-2 antibody (PRPH2: OS marker) and peanut agglutinin (PNA: cone OS marker) along with a DAPI counterstain. (OS: outer segment and ONL: outer nuclear layer). Scale bar $=20 \square \mathrm{m}$.

B. Immunofluorescence microscopy images of retinal cross sections from the ret-Msi1-/: Msi2-/- mice at PN16 stained with anti-phosphodiesterase-6 $\square$ antibody (PDE6 $\square$ : rod OS marker) and peanut agglutinin (PNA: cone OS marker) along with a DAPI counterstain. (OS: outer segment and ONL: outer nuclear layer). Scale bar $=20 \square \mathrm{m}$.

\section{Figure 6: The OS rarely develops in the absence of MSI1 and MSI2}

A. Low magnification transmission electron microscopy images of ultrathin retinal sections from ret-Msi1-/-: Msi2-/- mice at PN10 visualizing the boundary between the OS and IS showing a complete lack of typical outer segments in the absence of the Musashi proteins (OS: outer segment, IS: inner segment, and RPE: retinal pigment epithelium). Scale bar $=2 \square \mathrm{m}$.

B. High magnification transmission electron microscopy images of ultrathin retinal sections from ret-Msi1-/-: Msi2-/- mice at PN10 visualizing the boundary between the OS and IS showing that the OS either does not form (far right) or is dysmorphic (middle) in the absence of the Musashi proteins (OS: outer segment, CC: connecting cilium, BB: basal body, RPE: retinal pigment epithelium, and IS: inner segment). Scale bar $=1 \square \mathrm{m}$.

Figure 7: The Musashi proteins are crucial for photoreceptor axoneme development 
A. Immunofluorescence microscopy images of retinal cross sections from the ret-Msi1-/: Msi2-/- mice at PN10 stained with anti-acetylated- $\square$-tubulin antibody (Ac-Tubulin: photoreceptor connecting cilium marker) and anti-male germ cell-associated kinase antibody (MAK: photoreceptor axoneme marker) along with a DAPI counterstain (RPE: retinal pigment epithelium, CC: connecting cilium, and ONL: outer nuclear layer).

B. Scatter bar plot showing the distribution of length measurements for the photoreceptor axoneme of ret-Msi1-/-: Msi2-/- mice at PN10 as assessed by MAK staining.

C. Scatter bar plot showing the distribution of length measurements for the photoreceptor connecting cilium of ret-Msi1-/-: Msi2-/- mice at PN10 as assessed by Actubulin staining.

D. Scatter bar plot showing the distribution of length measurements for the photoreceptor connecting cilium of ret-Msi1-/-: Msi2-/- mice at PN10 as assessed by probing with anti-glutamylated tubulin antibody (Glut-tubulin: photoreceptor connecting cilium marker).

Figure 8: The Musashi proteins regulate alternative splicing of their target transcripts

A. Top: Diagram of the reverse transcriptase PCR splicing assay showing a photoreceptor-specific alternative exon flanked by two constitutive exons. Forward and reverse primers were designed to bind in the flanking constitutive exons upstream and downstream of the photoreceptor-specific exon respectively. When the alternative exon is included in the mature transcript, a longer PCR product is produced which migrates 
more slowly during gel electrophoresis. Bottom: Diagram of the photoreceptor isoform of Ttc8 which has a photoreceptor-specific alternative exon called "2A." Using a custom made antibody that recognizes the peptide encoded by Exon $2 \mathrm{~A}$, the photoreceptor specific isoform of Ttc8 can be detected by immunoblotting. Likewise, using a pan-Ttc8 antibody which recognizes a Ttc8 constitutive peptide sequence, all isoforms of Ttc8 can be detected.

B. Reverse transcriptase PCR splicing assay using total RNA purified from retinal lysates of ret-Msi1-/-, ret-Msi2-/-, and ret-Msi1-/-: Msi2-/- mice. Ttc8, Cc2d2a, Cep290, and Prom1 are four cilia- and OS-related transcripts shown to have reduced photoreceptor-specific exon inclusion in the absence of MSI1 and MSI2.

C. Immunoblot of retinal lysates from ret-Msi1-/-, ret-Msi2-/-, and ret-Msi1-/-: Msi2-/mice. After probing with the pan-Ttc8 antibody (top), a change in the migration of the Ttc8 protein is observed in the absence of MSI1 and MSI2 suggesting that the peptide encoded by Exon 2A was not included. When probing with the Ttc8 E2A antibody (middle), a complete absence of the photoreceptor-specific isoform of Ttc8 is observed in the absence of MSI1 and MSI2.

\section{Figure 9: Exon knockout mice have normal photoreceptor function}
A. Validation of the exon knockout mice by reverse transcriptase PCR.
B. Representative scotopic and photopic electroretinograms (ERGs) from wildtype, Ttc8 exon knockout, Cep290 exon knockout, Cc2d2a exon knockout, Cacna2d4 exon knockout, and S/c17a7 exon knockout mouse models. Scotopic ERGs were obtained after dark adaptation while photopic ERGs were obtained under light-adapted conditions using a rod-saturating white background light. No changes in photoreceptor function are 
observed compared to control. 


\section{SUPPLEMENTARY FIGURE 1}
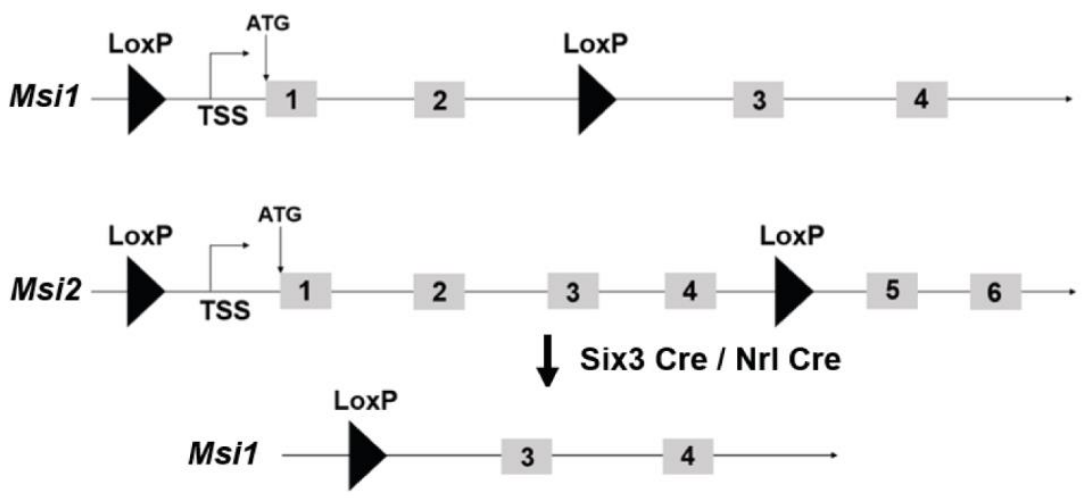

Retina / Rod-specific

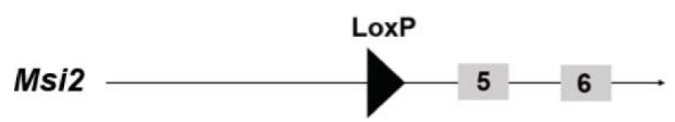
recombination 
A. Msi1 $+/++/++/+-/-=/-=-1-$

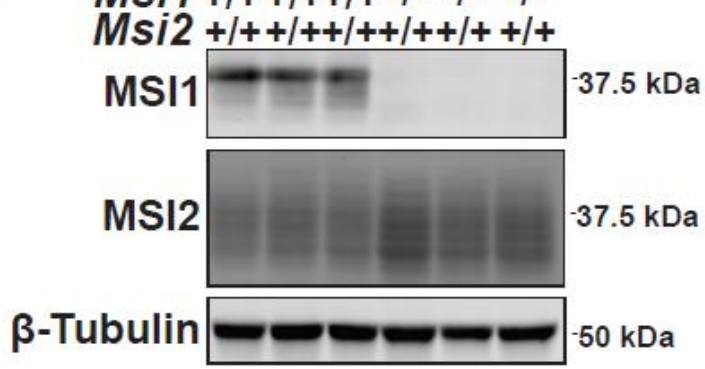

C.

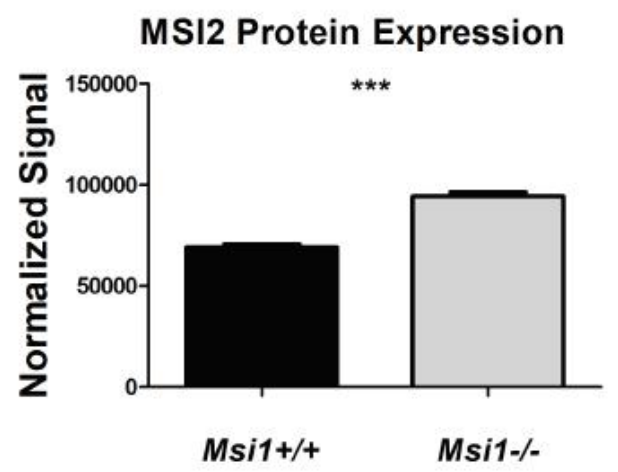

B. Msi1 $+1++/++/++/++/++/+$ Msi2 +/++ $/+++1+-/--/-=-1-$

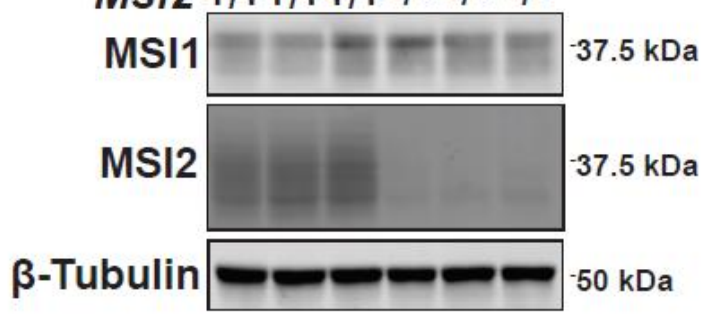

D.

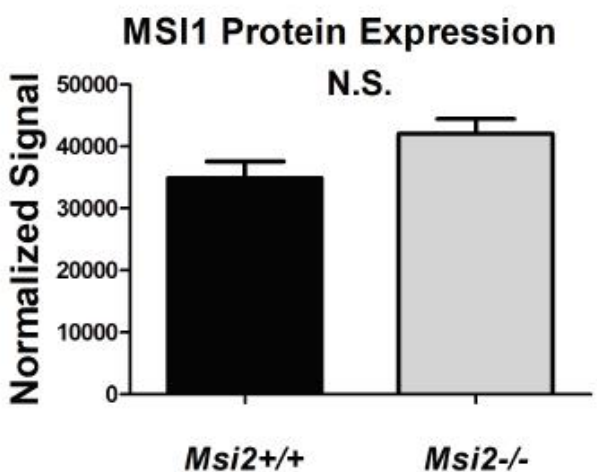


SUPPLEMENTARY FIGURE 3

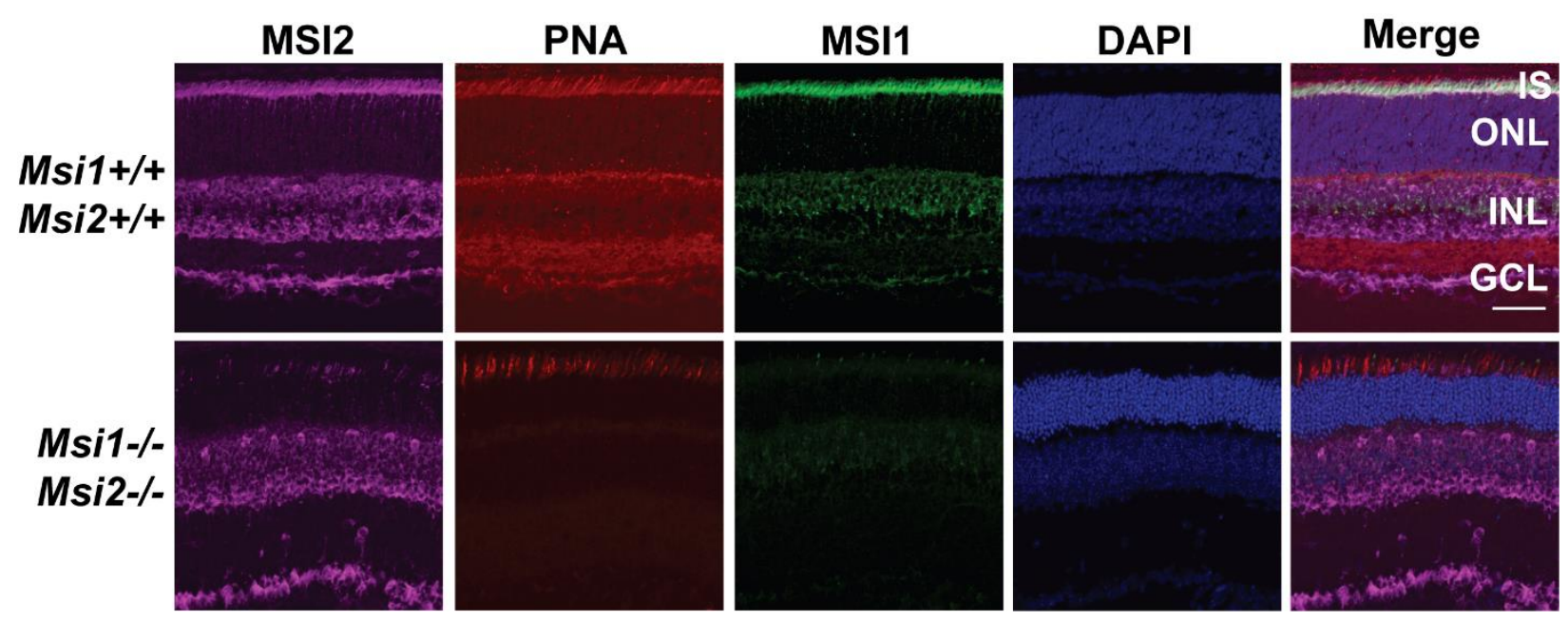




\section{SUPPLEMENTARY FIGURE 4}

A.

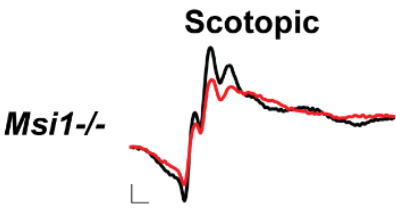<smiles>C=C1C=CN(CCC(C)(C)C)C1</smiles>

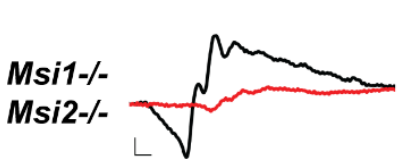

Photopic
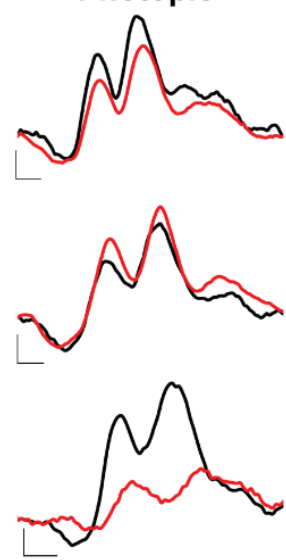

B.

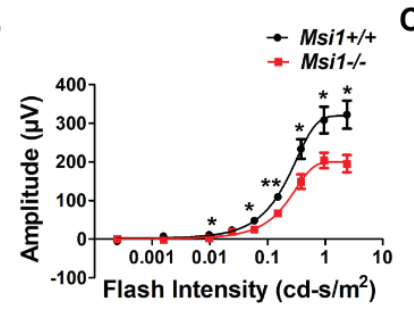

D.

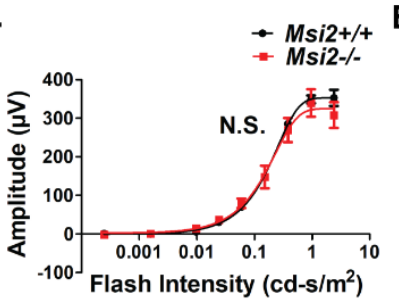

C.

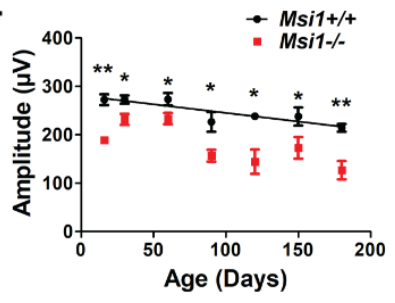

E.

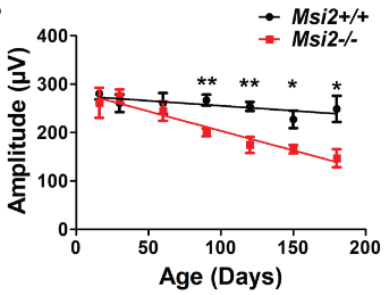


Supplementary Figure 5

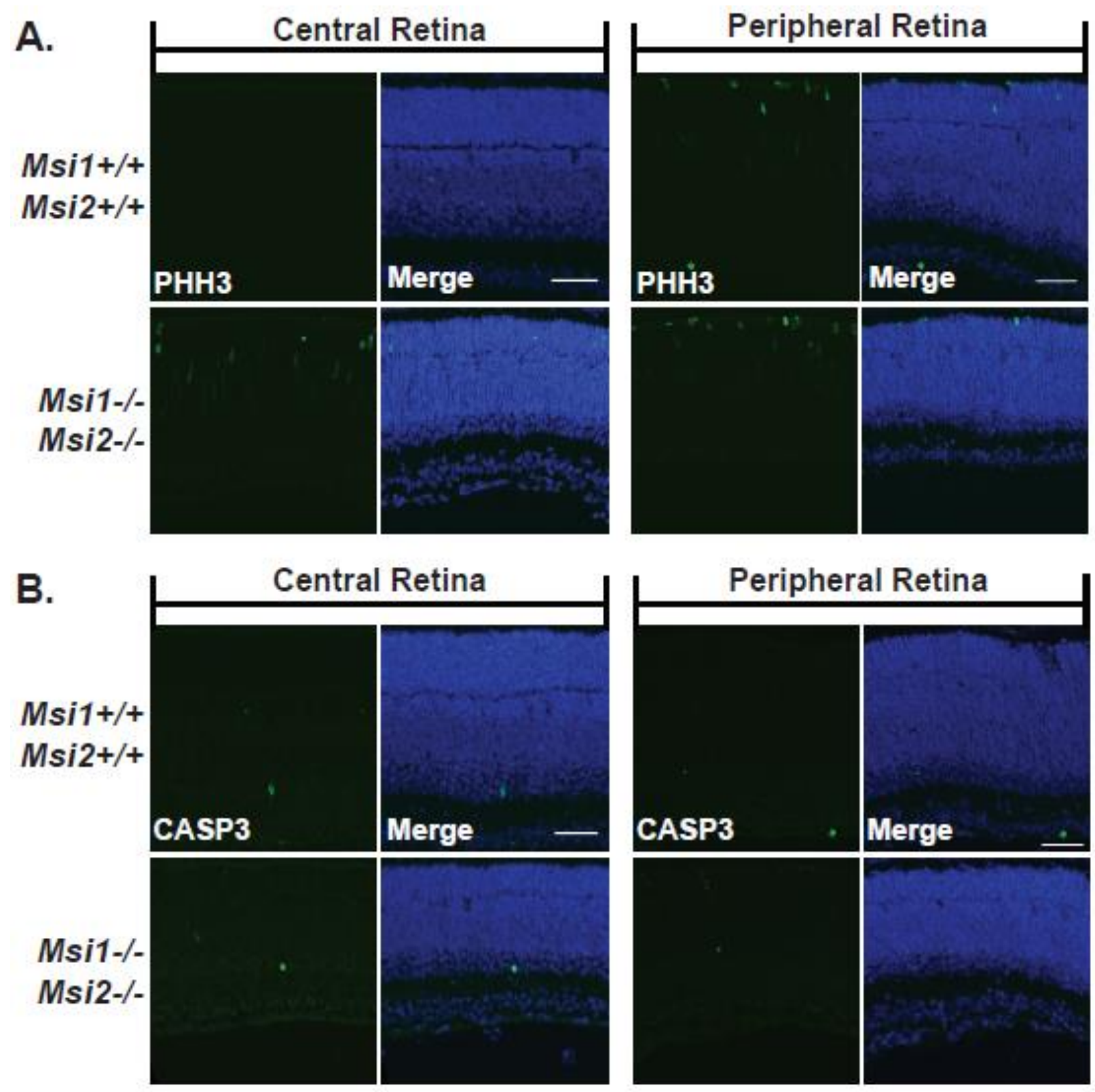


SUPPLEMENTARY FIGURE 6

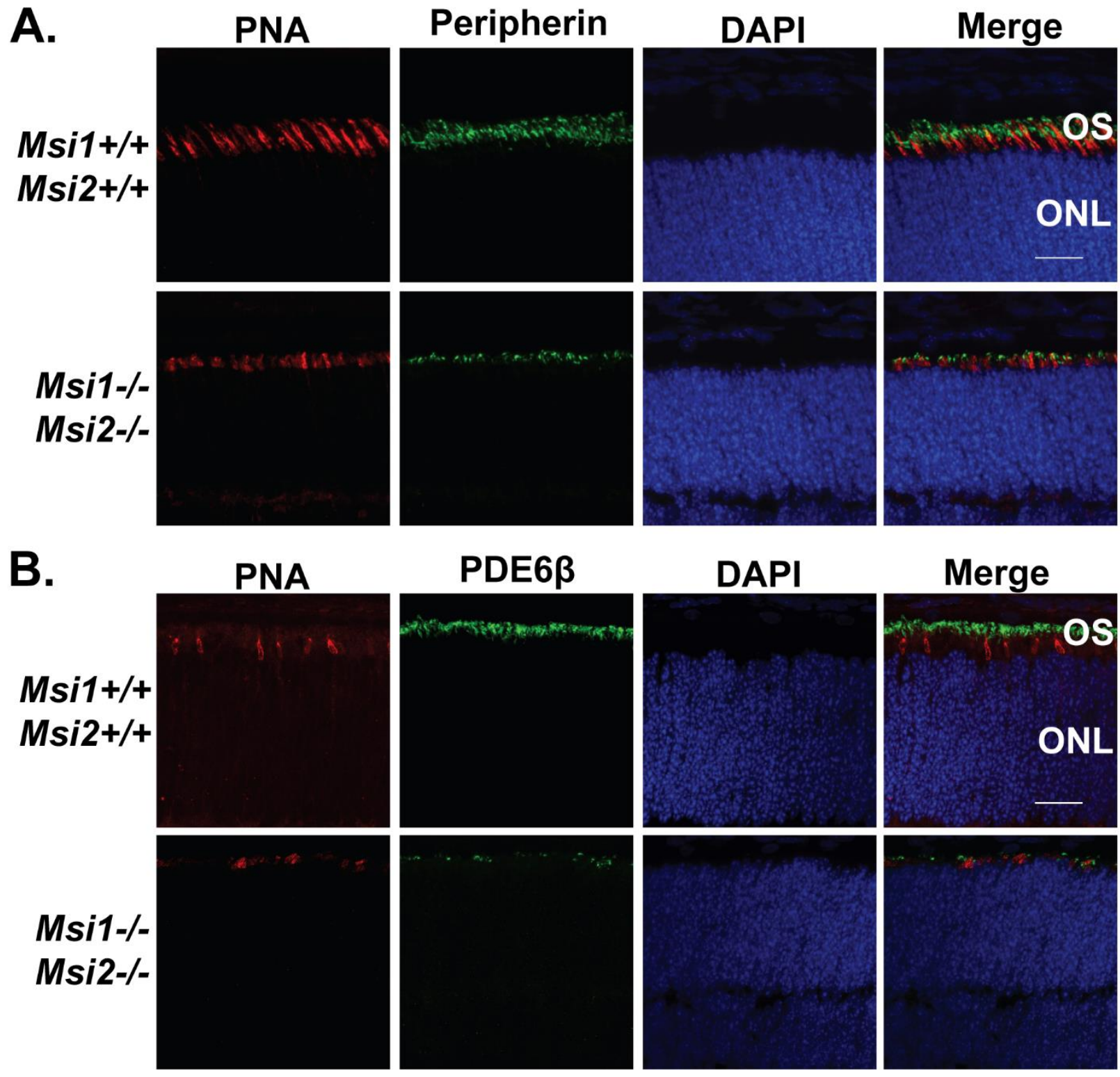




\section{SUPPLEMENTARY FIGURE 7}

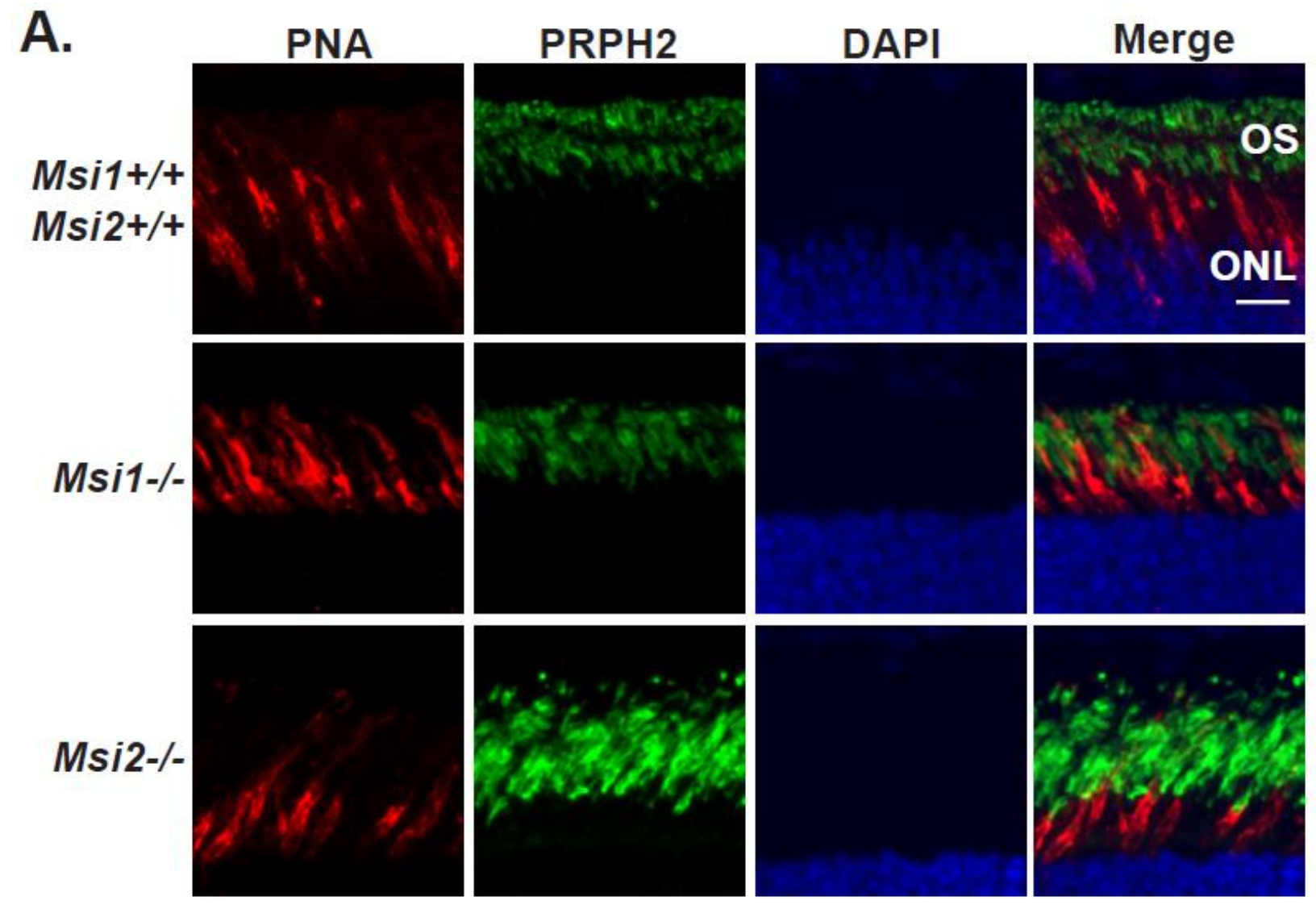




\section{SUPPLEMENTARY FIGURE LEGENDS}

\section{Supplementary Figure 1: Disruption of the Musashi genes by Cre-LoxP}

recombination.

To generate floxed mice for Msi1, a LoxP site was inserted immediately upstream of the Msi1 gene, and a second LoxP site was inserted in parallel with the first LoxP site in the intron between Exons 2 and 3 by homologous recombination. After CRE mediated recombination using either the Six 3 Cre or $\mathrm{Nrl}$ Cre transgenic mice, the transcription start site, Exon 1, and Exon 2 of Msi1 are removed to result in a nonfunctional gene and deletion of the exons that encode part of the N-terminal RNA binding domains of MSI1. To generate floxed mice for Msi2, a LoxP site was inserted immediately upstream of the Msi2 gene, and a second LoxP site was inserted in parallel with the first LoxP site in the intron between Exons 4 and 5 by homologous recombination. After CRE mediated recombination using either the Six $3 \mathrm{Cre}$ or $\mathrm{Nrl}$ Cre transgenic mice, the transcription start site, Exon 1, Exon 2, Exon 3, and Exon 4 of $M s i 2$ are removed to result in a nonfunctional gene and deletion of the exons that encode part of the $\mathrm{N}$-terminal RNA binding domains of MSI2.

\section{Supplementary Figure 2: MSI2 is upregulated in the absence of MSI1.}

A. Immunoblotting of retinal lysates from ret-Msi1-/- mice and littermate controls at PN10 followed by probing with anti-MSI1 and anti-MSI2 antibodies with anti- $\square$-tubulin antibody serving as a loading control. MSI2 is upregulated in the absence of MSI1. B. Immunoblotting of retinal lysates from ret-Msi2-/- mice and littermate controls at 
PN10 followed by probing with anti-MSI1 and anti-MSI2 antibodies with anti- $\square$-tubulin antibody serving as a loading control. MSI1 is not upregulated in the absence of MSI2. C. Quantification of MSI2 protein levels by immunoblotting retinal lysates obtained from Msi1-/- and control mice at PN10. Data is represented as the mean \pm the SEM $\left(^{* * *}: p-\right.$ value $<0.001$ using the homoscedastic unpaired student's t-test).

D. Quantification of MSI1 protein levels by immunoblotting retinal lysates obtained from Msi2-/- and control mice at PN10. Data is represented as the mean \pm the SEM (N.S. : Not statistically significant using the homoscedastic unpaired student's t-test).

\section{Supplementary Figure 3: Validation of the rod-Msi1-/-: Msi2-/- mice by} immunofluorescence microscopy. Immunofluorescence microscopy images of retinal cross sections from the rod-Msi1-/-: Msi2-/- and control mice stained with anti-MSI1 and anti-MSI2 antibodies along with peanut agglutinin (PNA: cone OS marker) and DAPI nuclear counterstain. (IS: inner segment, ONL: outer nuclear layer, INL: inner nuclear layer, and GCL: ganglion cell layer). Scale bar $=50 \square \mathrm{m}$.

\section{Supplementary Figure 4: Intrinsic expression of Musashi in rod photoreceptors is crucial for normal vision as shown by electroretinography.}

A. Representative scotopic and photopic electroretinograms (ERGs) from the rod-Msi1/-, rod-Msi2-/-, and rod-Msi1-/-: Msi2-/- mice at PN16. Scotopic ERGs were obtained after overnight dark adaptation using $0.151 \mathrm{~cd}-\mathrm{s} / \mathrm{m}^{2}$ flashes while photopic ERGs were obtained with $7.6 \mathrm{~cd}-\mathrm{s} / \mathrm{m}^{2}$ flashes under light-adapted conditions using a rod-saturating 
white background light (Scotopic scale bar: $x$-axis $=10 \mathrm{~ms}, y$-axis $=100 \square V$; Photopic scale bar: $\mathrm{x}$-axis $=10 \mathrm{~ms}, \mathrm{y}$-axis $=20 \square \mathrm{V}$ ).

B. Light stimulus intensity plot of the scotopic "a"-wave response from rod-Msi1-/- mice. The data was fitted using regressions with a maximum amplitude of $319 \pm 14 \square \mathrm{V}$ in control mice and maximum amplitude of $201 \pm 8 \square \mathrm{V}$ in the rod-Msi1-/- mice ( ${ }^{*}=\mathrm{P}$-value $<0.05 ;{ }^{* *}=$ P-value $<0.01 ;{ }^{* \star *}=$ P-value $\left.<0.001\right)$

C. Plot of the rod photoreceptor "a"-wave response from rod-Msi1-/- mice plotted against the age of the mouse during which the ERG was recorded.

D. Light stimulus intensity plot of the scotopic "a"-wave response from rod-Msi2-/- mice. The data was fitted using regressions with a maximum amplitude of $353 \pm 7 \square \mathrm{V}$ in control mice and maximum amplitude of $325 \pm 16 \square \mathrm{V}$ in the rod-Msi2-/- mice.

E. Plot of the rod photoreceptor "a"-wave response from rod-Msi2-/- mice plotted against the age of the mouse during which the ERG was recorded. All data is shown as the mean \pm the SEM, and statistical analyses were carried out using the homoscedastic unpaired student's t-test $\left({ }^{*}=\mathrm{P}<0.05\right)$.

\section{Supplementary Figure 5: Changes in proliferation occur in the absence of MSI1 and MSI2}

A. Immunofluorescence microscopy of $\mathrm{PHH} 3+$ cells in the central (left) and peripheral (right) regions of the retina in PN5 ret-Msi1-/-: Msi2-/- mice and littermate control mice. B. Immunofluorescence microscopy of CASP3+ cells in the central (left) and peripheral (right) regions of the retina in PN5 ret-Msi1-/-: Msi2-/- mice and littermate control mice. 
Supplementary Figure 6: Dysmorphic OS architecture in ret-Msi1-/-: Msi2-/- mice at PN10 as shown by immunofluorescence microscopy.

A. Immunofluorescence microscopy images of retinal cross sections from the ret-Msi1-/: Msi2-/- mice at PN10 stained with anti-peripherin-2 antibody (PRPH2: OS marker) and peanut agglutinin (PNA: cone OS marker) along with a DAPI nuclear counterstain. (OS: outer segment and ONL: outer nuclear layer). Scale bar $=20 \square \mathrm{m}$.

B. Immunofluorescence microscopy images of retinal cross sections from the ret-Msi1-/: Msi2-/- mice at PN10 stained with anti-phosphodiesterase-6 $\square$ antibody (PDE6 $\square$ : rod OS marker) and peanut agglutinin (PNA: cone OS marker) along with a DAPI nuclear counterstain. (OS: outer segment and ONL: outer nuclear layer). Scale bar $=20 \square \mathrm{m}$. Supplementary Figure 7: Normal OS architecture in ret-Msi1-/- and ret-Msi2-/mice at PN16 as shown by immunofluorescence microscopy.

A. Immunofluorescence microscopy images of retinal cross sections from the ret-Msi1-/and ret-Msi2-/- mice at PN16 stained with anti-peripherin-2 antibody (PRPH2: OS marker) and peanut agglutinin (PNA: cone OS marker) along with a DAPI nuclear counterstain. (OS: outer segment and ONL: outer nuclear layer). Scale bar $=10 \square \mathrm{m}$. 


\section{Chapter 3: Reprinted with permission from Human Molecular Genetics}

Title: Rhodopsin signaling mediates light-induced photoreceptor cell death in rd10 mice through a transducin-independent mechanism.

Authors: Jesse C. Sundar ${ }^{1}$, Daniella Munezero², Caitlyn Bryan-Haring ${ }^{1}$, Thamaraiselvi Saravanan ${ }^{2}$, Angelica Jacques ${ }^{2}$, and Visvanathan Ramamurthy ${ }^{1,2,3, *}$

Affiliations: Departments of Biochemistry ${ }^{1}$, Ophthalmology and Visual Sciences ${ }^{2}$, and Neuroscience ${ }^{3}$; Robert C. Byrd Health Sciences Center, West Virginia University; Morgantown, West Virginia, USA, 26505;

Address for correspondence: Visvanathan Ramamurthy, Department of Ophthalmology and Visual Sciences, West Virginia University School of Medicine; 1 Medical Center Dr. Morgantown, WV, USA, 26505; Email: ramamurthyv@mix.wvu.edu; Telephone: 304-598-6940; Fax: 304-598-6938; 


\section{ABSTRACT}

Retinitis pigmentosa $(\mathrm{RP})$ is a debilitating blinding disease affecting over 1.5 million people worldwide, but the mechanisms underlying this disease are not well understood. One of the common models used to study RP is the retinal degeneration-10 (rd10) mouse, which has a mutation in Phosphodiesterase-6b (Pde6b) that causes a phenotype mimicking the human disease. In rd10 mice, photoreceptor cell death occurs with exposure to normal light conditions, but as demonstrated in this study, rearing these mice in dark preserves their retinal function. We found that inactivating rhodopsin signaling protected photoreceptors from degeneration suggesting that the pathway activated by this G-protein-coupled receptor is causing light-induced photoreceptor cell death in rd10 mice. However, inhibition of transducin signaling did not prevent the loss of photoreceptors in rd10 mice reared under normal light conditions implying that the degeneration caused by rhodopsin signaling is not mediated through its canonical Gprotein transducin. Inexplicably, loss of transducin in rd10 mice also led to photoreceptor cell death in darkness. Furthermore, we found that the rd10 mutation in Pde6b led to a reduction in the assembled PDE6aßY2 complex, which was corroborated by our data showing mislocalization of the $y$ subunit. Based on our findings and previous studies, we propose a model where light activates a noncanonical pathway mediated by rhodopsin but independent of transducin that sensitizes cyclic nucleotide gated channels to cGMP and causes photoreceptor cell death. These results generate exciting possibilities for treatment of RP patients without affecting their vision or the canonical phototransduction cascade. 


\section{INTRODUCTION}

Retinitis pigmentosa (RP) (OMIM: 268000) is a debilitating genetic disorder characterized by night blindness and decreased visual fields which can progress to complete blindness and is often accompanied by severe photoreceptor cell loss (1). Mutations in more than 50 genes lead to various forms of this disease, and the two most commonly affected genes that lead to autosomal recessive RP are in the Usher syndrome type-2a (Ush2a) and Phosphodiesterase-6 (Pde6) genes with Pde6 mutations accounting for 36,000 cases of RP (2). Current therapies available for hereditary RP symptoms are often insufficient and include vitamin A supplementation and wearing sunglasses $(3,4)$. The biochemical mechanisms underlying photoreceptor cell death and subsequent vision loss in RP are not fully understood and elucidating these mechanisms will aid in the development of more personalized approaches for treating patients with this disease.

One of the commonly used animal models of RP is the retinal degeneration-10 (rd10) mouse where visual function is gradually lost and is accompanied by photoreceptor cell death (5). This phenotype closely mimics the human form of the disease. This mouse model has a missense mutation in the catalytic $\beta$ subunit of the

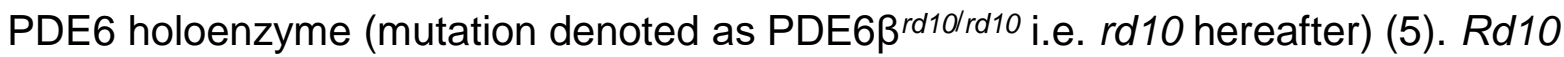
animals raised under normal light conditions in a vivarium with a $12 \mathrm{hr}$ light/12hr dark cycle show complete degeneration of the photoreceptor outer nuclear layer (ONL) by postnatal day 45 (PN45). Intriguingly, our studies show that $r d 10$ mice reared in complete darkness show significant preservation of the ONL at PN45. Elucidating the mechanism behind this light-dependent photoreceptor cell death in the rd10 mouse may 
lead to new insights into the human form of the disease in addition to development of better treatments for autosomal recessive RP.

We hypothesized that the biochemical signaling cascade underlying sensation to light plays a key role in the light-dependent degeneration of photoreceptors in the $r d 10$ mouse model. The phototransduction cascade is fundamental to vision in all mammalian species and begins when the light-sensing G-protein-coupled receptor (GPCR) rhodopsin is activated by the absorption of a photon through its chromophore 11-cis retinal. The subsequent conformational change in rhodopsin leads to activation of the heterotrimeric G-protein transducin. The a subunit of transducin then activates the effector enzyme of the phototransduction cascade PDE6 which leads to closing of cyclic nucleotide gated channels and hyperpolarization of the photoreceptor cell.

After photon absorption, the chromophore 11-cis retinal attached to opsin is isomerized to all-trans retinal in photoreceptors (6). In a series of enzymatic reactions known as the visual cycle, 11 -cis retinal is regenerated in the retinal pigment epithelium (RPE) and returned to photoreceptors to restore rhodopsin's photosensitivity $(6,7)$. The visual cycle begins with the reduction of all-trans retinal to all trans-retinol by NADPH dependent retinol dehydrogenase $(6,8)$. All-trans retinol is then esterified in the RPE by lecithin retinol acyltransferase before being isomerohydrolyzed by the retinal pigment epithelium-specific protein of $65 \mathrm{kDa}$ (RPE65), which catalyzes the production of 11-cis retinol $(6,9)$. The alcohol 11-cis retinol is then oxidized back to the aldehyde 11-cis retinal by 11 -cis retinol dehydrogenase to complete the cycle $(6,8)$. Importantly, the RPE65 enzyme, amongst other critical visual cycle components, becomes necessary for the regeneration of rhodopsin's photosensitivity, and without this enzyme, 
photoreceptors are essentially rhodopsin-deficient (10).

The absence of RPE65 (Rpe65-/-) prevents apoptosis of photoreceptors in mice exposed to high intensity light (15,000 lux) (11). These findings suggest a role for activated rhodopsin in photoreceptor degeneration in response to light exposure. We predicted that a similar signaling cascade is involved in photoreceptor cell death in $r d 10$ mice. We also wanted to know if this rhodopsin signaling requires transducin for apoptotic signaling in rd10 mouse photoreceptors.

To test this hypothesis, mice lacking functional rod transducin- $\alpha$ alleles (Gnat1-/-) and mice lacking functional Rpe65 alleles (Rpe65-/-) were crossed with $r d 10$ mice to generate Gnat1-/- rd10 and Rpe65-/- rd10 experimental mice $(10,12)$. Ablation of RPE65 inactivates rhodopsin signaling since it is required for regeneration of rhodopsin's chromophore 11-cis retinal (10). A rhodopsin knockout mouse could not be used because photoreceptor degeneration is observed, and outer segments fail to develop properly in this mouse model (13).

After validating the Gnat1-/- rd10 and Rpe65-/- rd10 mice, we found that the lack of functional transducin failed to prevent light induced photoreceptor cell death in $r d 10$ mice, and to our surprise, led to degeneration in dark. Indeed, we found that removal of Rpe65 delays photoreceptor cell death in rd10 mice reared under normal light conditions. In addition, we found that the levels of the functional PDE6aßy2 heterotetramer were highly reduced. Lastly, we observed that the levels of each individual subunit of PDE6 were decreased in rd10 mice in addition to mislocalization of PDE6y. 


\section{RESULTS}

\section{Dark rearing rd10 mice delays photoreceptor cell death}

Mice homozygous for the $r d 10$ mutation were raised from birth in either complete darkness or in a vivarium with a $12 \mathrm{hr} \sim 175$ lux light : 12hr dark cycle. At postnatal day 45 (PN45), whole eyes from these mice were collected along with C57BL6/J controls for histological analysis of the retinal outer nuclear layer $(\mathrm{ONL})$ by hematoxylin and eosin (H\&E) staining and immunofluorescence microscopy. $R d 10$ mice raised in normal cyclic light conditions experienced substantial photoreceptor degeneration (Fig. 1A \& B). In contrast, there was significant preservation of the ONL in $r d 10$ mice raised in complete darkness with approximately three to four layers of photoreceptor nuclei remaining at PN45 (Fig. 1A \& B). These findings suggest that the $r d 10$ mutation sensitizes photoreceptors to light and makes them susceptible to cell death. As shown in Fig. 1A, no substantial changes were observed in the retinal pigment epithelium (RPE) or inner retinal layers (INL: inner nuclear layer and GCL: ganglion cell layer) between rd10 mice raised in complete darkness and under normal light conditions. Overall, our findings show significant preservation of photoreceptors in dark reared rd10 animals.

\section{Retinal function is preserved in dark reared rd10 mice}

We next sought to determine if the surviving photoreceptors are functional in dark reared rd10 mice in early adulthood at PN45. One of the commonly used methods for determination of photoreceptor function is electroretinography (ERG) where electrical activity originating from the neural retina is measured after exposure to a light stimulus. This technique allows for analysis of both rod and cone photoreceptor function. Indeed, the preservation of the ONL in rd10 mice raised in complete darkness correlated with increased photoreceptor function compared to $r d 10$ mice raised under cyclic light 
conditions (Fig. 2A-D). ERG traces of the cyclic-light reared $r d 10$ mice revealed a complete absence of "a"- and "b"-waves compared to dark reared rd10 mice and agematched C57BL6/J controls under both scotopic and photopic conditions (Fig. 2A and B). Scotopic ERGs at varying light intensities confirmed the increased "b"-wave amplitude in dark reared $r d 10$ mice compared to $r d 10$ mice raised under cyclic light conditions which suggests that functional rod photoreceptor neurons are preserved in these mice (Fig. 2C). Similarly, photopic ERGs of the cyclic-light and dark reared $r d 10$ mice revealed a significantly increased "b"-wave amplitude in the dark reared $r d 10$ mice implying that dark rearing preserves cone photoreceptors in these mice (Fig. 2D). When compared to age-matched C57BL6/J wildtype controls, we saw a reduction in both "a"wave and "b"-wave amplitudes in the dark reared rd10 mice under scotopic but not photopic testing conditions (Fig. 2A-D). This is likely due to the mutation in the rodspecific PDE6 $\beta$ subunit which affects the levels of the rod-specific PDE6 holoenzyme (Fig. 5).

Inactivating transducin does not prevent light-induced photoreceptor cell death in rd10 mice

To determine if transducin was involved in the mediation of this light dependent photoreceptor cell death in the rd10 mouse, we crossed rd10 mice with the Gnat1-/mouse model. The Gnat1-/- mouse lacks a functional rod transducin- $\alpha$ gene and yet experiences almost no photoreceptor degeneration due to the loss of transducin (12). Gnat1+/- rd10X Gnat1+/- rd10 crosses were used to generate Gnat1-/- rd10 knockout mice and rd10 littermate control mice. The loss of rod transducin- $\alpha$ subunit (GaT1) was validated by western blot. GaT1 was absent in retinal extracts of Gnat1-/- rd10 double 
knockout mice (Fig. 3A). The litters from the heterozygous crosses were raised in either cyclic light or complete darkness for 45 days. H\&E stained retinal sections and immunofluorescence microscopy were used to analyze the retinal morphology. At PN45, photoreceptor cell death is seen in both the normal light reared Gnat1+/+rd10 and Gnat1-/- rd10 animals suggesting that transducin is not mediating the light dependent photoreceptor cell death (Fig. 3B \& D). To our surprise, dark rearing Gnat1-/rd10 mice failed to preserve photoreceptors and caused substantial photoreceptor degeneration with almost no ONL nuclei left at PN45 (Fig. 3C \& E). Overall, these findings suggest that the light-dependent photoreceptor cell death observed in $r d 10$ mice occurs through a transducin-independent mechanism.

\section{Inactivating Rpe65 protects rd10 mice from light-induced photoreceptor cell death}

To determine if the activation of rhodopsin is mediating the light dependent photoreceptor cell death in $r d 10$ animals, we inactivated rhodopsin by blocking the recycling of its chromophore 11-cis retinal with the use of the Rpe65-/- mouse model (10). 11-cis retinal is regenerated from all-trans retinal in part by RPE65, a retinol isomerase encoded by the Rpe65 gene (10). We crossed Rpe65-/- mice with rd10 mice to ultimately develop Rpe65-/- rd10 knockout mice and littermate control rd10 mice. We then validated these mice by immunofluorescence microscopy (Fig. 4A). As expected, RPE65 (green) was absent in the Rpe65-/- rd10 knockouts. Litters from heterozygous crosses were then raised in either normal light or complete darkness for 45 days before mice were sacrificed and whole eyes were collected for histological analysis. H\&E and immunostaining of retinal sections were then imaged to analyze the retinal morphology. 
At PN45, significant photoreceptor cell death is seen in the normal light reared Rpe65+/+ rd10 mice (Fig. 4B \& D). Strikingly, however, standard light reared Rpe65-/rd10 mice experience a slower rate of photoreceptor cell death with approximately three layers remaining at PN45 (Fig. 4B \& D). When these mice were raised in complete darkness, photoreceptor nuclei were preserved to a similar extent between $r d 10$ mice and Rpe65-/- rd10 mice as seen by similar ONL thickness (Fig. 4C \& E). Altogether, these findings suggest that rhodopsin is signaling independently of transducin to mediate the light dependent photoreceptor cell death in the $r d 10$ mouse.

\section{The functional PDE6 holoenzyme is reduced and mis-assembled}

We next wanted to test how the rd10 mutation in the $\beta$ subunit of PDE6 affects the assembly of the holoenzyme. To this end, we immunoprecipitated the PDE6 complex with ROS1 antibody, which specifically detects the assembled functional PDE6 holoenzyme (14), in $r d 10$ and $C 57 B L 6 / J$ control retinal lysates at PN15 before the onset of photoreceptor degeneration (Fig. 5A). We then immunoblotted the fractions from the immunoprecipitation and probed with antibodies directed against PDE6a, PDE6 $\beta$, and PDE6y to check for the assembly of each subunit to the complex. Interestingly, in rd10 mice, the levels of all three PDE6 subunits are considerably reduced in the bound (assembled) fraction compared to age-matched $C 57 B L 6 / J$ controls suggesting that there is a decrease in the amount of assembled, functional PDE6 (Fig. 5A). Furthermore, significant amounts of the PDE6y subunit are present in the unbound (unassembled) fraction in rd10 mice with no enrichment of PDE6y in the bound (assembled) fraction as seen in the age-matched C57BL6/J controls (Fig. 5A). This data 
suggests that the PDE6 holoenzyme is mis-assembled, and there is a likely dysregulation of PDE6 if the $\gamma$ subunit is unable to interact with the $\alpha$ and $\beta$ subunits.

\section{The rd10 mutation alters levels of the PDE6 subunits}

We next wanted to determine if the reduction in the assembled PDE6 holoenzyme in rd10 mice was due to an instability of the complex or a reduction in the steady state protein levels of the individual subunits. Immunoblotting of retinal lysates from $r d 10$ mice revealed that the levels of the PDE6 $\beta$ subunit are dramatically reduced prior to photoreceptor degeneration (Fig. 5B). The drastic loss in PDE6 $\beta$ levels is accompanied by a significant decrease in its cognate partner catalytic PDE6 $\alpha$ subunit (Fig. 5B) implying that the ability for cGMP hydrolysis and consequently phototransduction efficiency is greatly reduced. Lastly, the levels of the inhibitory $Y$ subunit are also decreased (Fig. 5B). The reduction in PDE6 $\beta$ levels was confirmed by immunofluorescence microscopy of retinal sections from the $r d 10$ mice before the onset of photoreceptor degeneration (Fig. 5C). Overall, the rd10 mutation substantially affects the levels of each individual PDE6 subunit.

\section{PDE6y but not PDE6a is mislocalized in both standard light and dark reared rd10 mice}

After finding PDE6y in the unassembled fraction of our pulldown experiment, we predicted that the PDE6 subunits may not be properly localized in $r d 10$ mice. To test this hypothesis, we used immunofluorescence microscopy to examine retinal sections from normal light and dark reared rd10 mice for PDE6a, PDE6 $\beta$, and PDE6y localization before the onset of photoreceptor degeneration. Retinal sections were first stained with anti-PDE6 $\beta$ antibody, wheat germ agglutinin (WGA, a rod outer segment marker), and 
counterstained with DAPI to see how the Pde6b mutation affects PDE6 $\beta$ localization. The reduction in PDE6 $\beta$ observed in Fig. 5B was confirmed by immunofluorescence microscopy (Fig. 5C), but its localization remained obscure (Fig. 5C). We found PDE6a to be properly localized to the outer segment in both normal light and dark reared $r d 10$ mice (Fig. 6A), and its levels were severely reduced in agreement with Fig. 5B. On the contrary, we observed substantial mislocalization of PDE6y in both normal light and dark reared $r d 10$ mice compared to the $C 57 B L 6 / J$ control prior to the onset of photoreceptor degeneration (Fig. 6B). This data suggests that the rd10 mutation could alter the regulation of the PDE6 holoenzyme through mislocalization of the inhibitory PDE6y subunit. 


\section{DISCUSSION}

Our studies reveal that dark-rearing prolongs survival and function of rod and cone photoreceptors in the rd10 mouse model (Fig. $1 \& 2$ ). We also examined the signaling pathways underlying the light-dependent photoreceptor cell death and the protection afforded by dark-rearing $r d 10$ mice. Our findings show that the light-induced photoreceptor degeneration caused by the rd10 mutation is mediated by rhodopsin signaling (Fig. 4). However, the degeneration is independent of the canonical rhodopsin-transducin signaling cascade (Fig. 3). Intriguingly, the protection afforded by dark-rearing was lost when transducin signaling was abolished (Fig. 3). However, inhibition of rhodopsin signaling had no substantial effect on photoreceptor survival in dark-reared rd10 mice (Fig. 4). The rd10 mutation also caused a significant reduction in the levels of the functional PDE6aßץ2 heterotetramer in addition to a possible misassembly of PDE6 and a reduction in each of the individual subunits (Fig. 5). Corroborating the mis-assembly of PDE6, PDE6y but not PDE6a was mislocalized in both light and dark reared $r d 10$ mice (Fig. 6). It has been shown that photoreceptor degeneration caused by mutations in PDE6 such as $r d 1$ and $r d 10$ can be genetically rescued by inactivating cyclic nucleotide-gated channels $(15,16)$, but this approach has limited clinical applicability since the phototransduction cascade becomes arrested. Our study reveals that a rhodopsin mediated signaling event that is independent of transducin is causing cell death in rd10 mice. Novel therapies can be designed to target this pathway that modulates photoreceptor viability and thus treat patients with RP while not affecting their vision.

The $r d 10$ mouse model is a widely used mouse model of RP, which carries a 
missense mutation in exon 13 of the $P d e 6 b$ gene that leads to a substitution of arginine for cysteine (Arg560Cys) in the $\beta$ subunit of the PDE6 holoenzyme (5). We found that this mutation causes a significant reduction in levels of the functional PDE6aßy2 holoenzyme in addition to a probable mis-assembly of PDE6. We found the majority of PDE6y in the unassembled fraction of $r d 10$ mice, and PDE6y was mislocalized in the inner segments of $r d 10$ mice. Similarly, we witnessed a reduction in all three subunits of PDE6 with PDE6 $\alpha$ and PDE6 $\beta$ being most dramatically affected. These findings are similar to a recently published study showing that the $r d 10$ mutation causes an instability of the PDE6 holoenzyme and a subsequent reduction in basal and maximal PDE6 activity (15). Interestingly, inactivation of cyclic nucleotide-gated channels protects $\mathrm{rd} 10$ mice from photoreceptor degeneration implicating $\mathrm{Ca}^{2+}$ ion influx as one factor driving cell death (15). Altogether, these findings point to altered regulation of the PDE6 holoenzyme as a cause of degeneration in rd10 mice.

Interestingly, mice lacking the inhibitory PDE6y subunit have dysregulation of the PDE6 holoenzyme and undergo rapid photoreceptor cell death even in the presence of PDE6a $\beta$ (17). This absence of PDE6y leads to a paradoxical decrease in PDE6a $\beta$ activity, which causes high cGMP concentrations that likely keeps the cGMP-gated cation channels open continuously leading to an excessive cation influx and photoreceptor degeneration (17-18). Alternatively, it is possible that the rd10 mutation and subsequent PDE6y mislocalization could lead to protein misfolding and aggregation that can overload the proteasome (19). This idea is supported by findings that show an overload of the proteasome is a common underlying mechanism in many forms of hereditary retinal disease, especially when the causative mutations are in 
phototransduction genes (19).

After inactivating rhodopsin signaling, we found that photoreceptors were protected in normal light conditions suggesting that rhodopsin is mediating lightaccelerated photoreceptor cell death in rd10 mice. Strikingly, our data also revealed that photoreceptor degeneration in $r d 10$ mice raised under normal light conditions is independent of transducin- $\alpha$ which is rhodopsin's canonical interactor. Altogether, these findings lead us to conclude that rhodopsin can signal through other Gi/o-family members besides transducin $(T)$. This conclusion is supported by several other studies which have suggested that rhodopsin can couple to other members of the Gi/o family (20-24). For instance, one report showed that activated rhodopsin expressed in cell culture inhibited adenylyl cyclase activity through a Gi signaling cascade (20). Another study using primary retinal cell culture found that activation of rhodopsin in the plasma membrane altered the adenylate cyclase cascade to cause photoreceptor cell death (24). Yet another study found that Gißy can replace T $\beta y$ to restore the rhodopsinstimulated GTPase activity of Ta, and they also found that Gia exhibited rhodopsinstimulated GTPase activity when reconstituted with Gißy or TßY (23). If rhodopsin's noncanonical G-protein interactor can be identified in vivo, it may be possible to treat RP patients without affecting their vision or the canonical phototransduction cascade by targeting this noncanonical subunit. Remarkably, inhibitory drugs targeting G-protein subunits have already been developed and are showing strong efficacy in preclinical models (25).

Likewise, transducin-independent signaling in photoreceptors is well-documented (26-29). For example, deletion of Grk1 led to photoreceptor degeneration, even in the 
absence of transducin (26). A previous report also showed that photoreceptor cell death caused by bright light is independent of transducin (27). Likewise, transducin signaling was found to not play a direct role in the light-dependent dephosphorylation of GRK1 (29). Another study found that activation of rhodopsin leads to phosphorylation of the insulin receptor and this is independent of transducin implying that other pathways can be activated through rhodopsin signaling (30). Interestingly, the insulin receptor has been shown to play a neuroprotective role when mice are exposed to light (31). The activated insulin receptor is thought to desensitize cyclic nucleotide-gated channels to the effects of cGMP (32). This would likely result in increased closure of these ion channels and less $\mathrm{Ca}^{2+}$ entry into the cell.

When we compared our mechanistic findings to other studies of $r d 10$ mice, we found that the signaling pathways underlying the photoreceptor degeneration observed in rd10 mice may be complex and multifactorial. For instance, one report found that inhibition of MCP-1 signaling increased photoreceptor viability in rd10 mice (33). Another study found that inhibition of ceramide mediated apoptotic signaling reduced photoreceptor cell death in rd10 mice (34). Interestingly, activation of adenosine monophosphate-activated protein kinase (AMPK) signaling protected photoreceptors in rd10 mice (35). Likewise, activation of Wnt signaling rescued photoreceptors in rd10 mice from undergoing severe photoreceptor degeneration (36). A previous report also found that inhibition of $p 75^{\mathrm{NTR}}$ signaling reduced photoreceptor cell death in $r d 10$ mice (37). Remarkably, inhibition of TNFa signaling also reduced photoreceptor cell death in rd10 mice (38). Inhibition of AMPA/Kainate signaling was found to increase photoreceptor survival in rd10 mice as well (39). Perhaps tying multiple pathways 
together, one group observed that calcium overload and calpain activation occurred in rd10 mice before the onset of photoreceptor degeneration in addition to an increased permeability of lysosomal membranes (40). Lastly, Nakao et al. found that adenylyl cyclase caused photoreceptor cell death in rd10 mice (41). Altogether, these findings suggest that the mechanisms underlying neurodegeneration in $r d 10$ mice are complex and multifactorial.

Similarly, multiple studies have shown that various treatment regimens can mitigate the photoreceptor degeneration seen in the $r d 10$ mouse model. For example, it has been shown that injection of pro-insulin or IGF1 has a neuroprotective effect in rd10 mice (42-43). Inhibition of microglial phagocytosis by treatment with cRGD also increased photoreceptor survival in rd10 mice (44). In a similar manner, Granulocyte Colony-Stimulating Factor (G-CSF) and Erythropoietin delayed neurodegeneration in rd10 mice (45). Interestingly, treatment with either tamoxifen, tauroursodeoxycholic acid, carnosic acid, or Norgestrel reduced photoreceptor cell death in rd10 mice (46-49). Implicating oxidative stress as one factor driving photoreceptor cell death, treatment with antioxidants such as $\alpha$ tocopherol and ascorbic acid preserved photoreceptor function in rd10 mice (50). Suggestive of a dysregulation of iron, injection of transferrin protected $r d 10$ mice from undergoing severe photoreceptor degeneration (51). This was complemented by another study which found that treating rd10 mice with zincdesferrioxamine had a neuroprotective effect (52). Lastly, Valosin-containing protein inhibitors and continuous environmental enrichment provided some degree of neuroprotection in rd10 mice (53-55).

Surprisingly, our findings also reveal that transducin is critical for photoreceptor 
survival in rd10 mice reared in complete darkness. It is important to note that the photoreceptor degeneration in the Gnat1-/- rd10 mice was not caused by the removal of the rod transducin- $\alpha$ gene since the Gnat1-/- mouse model exhibits minimal changes in retinal ONL thickness up to one year of age, and no mRNA is produced from the knockout gene (12). Likewise, this cell death is unlikely to be a gene dosage effect since Gnat1+/- rd10 mice undergo photoreceptor cell death at the same rate as Gnat1-/- rd10 mice in light (unpublished data). The ONL thickness is also indistinguishable between Gnat1 $+/-r d 10$ and littermate $r d 10$ mice when they are reared in the dark (unpublished data). Moreover, double and triple knockouts have been generated in previous studies without any noticeable effects on photoreceptor viability $(26-27,56)$. Most notably, Fan et al. showed that the Rpe65-/- Grk1-/- Gnat1-/- triple knockout mouse model had increased photoreceptor survival compared to their Rpe65-/- Grk1-/- mouse model (26).

Future experiments will be needed to address the mechanisms underlying the neurodegeneration observed in the dark reared Gnat1-/- rd10 mice. We suspect that some basal activity between transducin and PDE6 is required for photoreceptor survival to modulate the high intracellular $\mathrm{Ca}^{2+}$ levels observed in darkness (57). Interestingly, transducin is known to translocate to different subcellular locations of the photoreceptor cell depending on lighting conditions (58). In complete darkness, transducin is found in the outer segments of rod photoreceptors, but upon exposure to light, it translocates and diffuses throughout the rod photoreceptor (58). Its sequestration to the outer segment only in darkness may allow for some basal activity that modulates high intracellular $\mathrm{Ca}^{2+}$ levels observed in darkness (57). Similarly, arrestin and Grb14 translocate from the inner segment in darkness to the outer segment upon light 
exposure, and this process is dependent upon rhodopsin signaling yet independent of transducin signaling (59-60). Alternatively, in Gnat1-/- mice, intracellular $\mathrm{Ca}^{2+}$ concentrations do not undergo light-dependent reductions and prolonged exposure to high $\mathrm{Ca}^{2+}$ levels may become toxic to photoreceptors (61). Another study also showed that oxidative stress is increased in Gnat1-/- mice, and this could be responsible for the underlying neurodegeneration observed (62). Future experiments addressing the intracellular $\mathrm{Ca}^{2+}$ concentrations and oxidative stress in Gnat1-/- rd10 mice will provide more insight into the mechanisms underlying the neurodegeneration observed.

In conclusion, this work shows for the first time that the signaling cascade responsible for the light-accelerated photoreceptor cell death in $r d 10$ mice relies on the rhodopsin GPCR but is independent of its G-protein transducin. However, future studies will be necessary to identify the transducin-independent signaling pathway and whether or not rhodopsin is mediating light-induced photoreceptor cell death through an increased ion flux mechanism (15). It is tempting to speculate that if a protein downstream of rhodopsin can be identified and targeted for drug-mediated inhibition, patients with photoreceptor cell loss caused by light exposure can be treated while preserving their visual function. 


\section{MATERIALS AND METHODS \\ Generation of mice and genotyping}

Rd10 mice were obtained from The Jackson Laboratory in the C57BL6/J background. These mice were confirmed to be homozygous for the rd10 allele and were bred with Gnat1-/- mice and Rpe65-/- mice that were kindly provided by Dr. Vladimir Kefalov from Washington University with the approval of Dr. Janis Lem from Tufts University. Gnat1+/-rd10 and Rpe65+/-rd10 strains were then separately crossed to generate Rpe65-/-rd10 and Gnat1-/-rd10 experimental mice, which were raised in rooms either in complete darkness or with a standard 12hr 175 lux light : 12hr dark cycle. Littermate rd10 mice from these crosses were used as controls. The mouse models used for experimentation had no confounding $r d 1$ and $r d 8$ alleles (63-64). The genotype of offspring from breeding pairs was determined by polymerase chain reaction (PCR) amplification of genomic DNA derived from ear biopsies. The Rpe65 wildtype and null alleles were identified using the following primers (5'- TCA TGG TCT AGC CAT GTC TG -3', 5'- CAC TTG TGT AGC GCC AAG TG -3', and 5'- AAT CCC TAC CAG ATG CCA TC -3') (65). The Gnat1 wildtype and null alleles were identified by using the following primers (5'- TAT CCA CCA GGA CGG GTA TTC -3', 5'- GCG GAG TCA TTG AGC TGG TAT -3', and 5'- GGG AAC TTC CTG ACT AGG GGA GG -3') (66). All experiments were conducted with the approval of the West Virginia University Institutional Animal Care and Use Committee, and all work was performed with adherence to the principles set forth in the ARVO Statement for the Ethical Use of Animals in Ophthalmic and Vision Research which advocates minimum use of animals per study needed to obtain statistical significance. 


\section{Electroretinography}

The ERG photoresponse was measured as previously described (67) using the UTAS BigShot LED Ganzfield System with UBA-4204 amplifier, and EM for Windows (LKC Technologies). After overnight dark adaptation, mice were placed under anesthesia using $1.5 \%$ isoflurane mixed with oxygen at 2 liters/minute. Electroretinograms from each eye were measured simultaneously from the corneal surface using electrodes after pupillary dilation with a $1: 1$ solution of $8 \%$ tropicamide : $1.5 \%$ phenylephrine hydrochloride. The electrodes were referenced to a needle electrode placed on the scalp between the ears. Hydroxypropyl methylcellulose (Novartis Pharmaceuticals) was added to facilitate contact between electrodes and the cornea while maintaining the integrity of the cornea. The mouse's body temperature was maintained at a temperature of $37^{\circ} \mathrm{C}$ using a regulated heating pad. Scotopic responses were obtained in complete darkness using single LED white light flashes of intensities varying from $2.45 \cdot 10^{-4} \mathrm{~cd}-\mathrm{s} / \mathrm{m}^{2}$ to $2.4 \mathrm{~cd}-\mathrm{s} / \mathrm{m}^{2}$. Photopic responses were obtained with single LED white light flashes after light adaptation using $30 \mathrm{~cd}-\mathrm{s} / \mathrm{m}^{2} \mathrm{rod}$ photoreceptor-saturating white light. The photoresponse vs. flash intensity data was modeled using the Naka-Rushton fit as described previously (68).

\section{Immunoblotting}

Immunoblotting was performed using a protocol adapted from our laboratory (67). Briefly, mice were sacrificed using $\mathrm{CO}_{2}$ followed by cervical dislocation, and retinas or whole eyes were frozen on dry ice for protein studies. Retinas or whole eyes were homogenized, and cells were lysed in PBS supplemented with protease inhibitor and 
0.1\% CHAPS (3-[(3-cholamidopropyl) dimethylammonio]-1-propanesulfonate) detergent by sonication. Cellular debris was cleared at $4^{\circ} \mathrm{C}$ by centrifugation for 10 minutes at $12,000 \mathrm{X}$ g. The samples were placed into Laemmli buffer (2\% SDS, 10\% glycerol, 5\% 2-mercaptoethanol, $0.002 \%$ bromophenol blue, and $62.5 \mathrm{mM}$ Tris- $\mathrm{HCl} \mathrm{pH} \mathrm{6.8)} \mathrm{and}$ boiled for 10 minutes before western blotting analysis. These lysates were loaded into standard SDS PAGE gels and fractionated by size. The proteins were transferred onto PVDF membranes (Millipore) and subsequently blocked for one hour with Odyssey Blocking Buffer (LICOR Biosciences) before incubation with primary antibody. The membranes were washed three times for five minutes in $0.1 \%$ Tween-20 in PBS, and secondary antibodies conjugated to infrared dye (Thermo-Fisher) were used to detect the primary antibody at 1:50,000 dilution. The membranes were then washed three times for five minutes in $0.1 \%$ Tween-20 in PBS and then scanned using an Odyssey Infrared Imaging System (LICOR Biosciences).

\section{Immunofluorescence Microscopy}

Immunofluorescence microscopy was performed as previously described in our laboratory (67). Briefly, mice were sacrificed using $\mathrm{CO}_{2}$ before secondary cervical dislocation. After enucleation of the eyes, the lens and cornea were removed. Eyes were immediately fixed by incubation in $4 \%$ paraformaldehyde in PBS for 1.5 hours. Eyes were then incubated in $20 \%$ sucrose in PBS overnight after washing them three times in PBS for five minutes each. After placing the eyes in a 1:1 solution of OCT:20\% sucrose in PBS for two hours, they were flash frozen in OCT (VWR). A Leica CM1850 cryostat was used to cryosection eyes at $16 \mu \mathrm{m}$ thickness and collect retinal cross- 
sections. The sections were placed on Superfrost Plus slides (Fisher Scientific). Slides were then permeabilized with PBST (0.1\% Triton X-100 in PBS) and incubated for 30 minutes in a blocking buffer containing $0.05 \%$ sodium azide, $0.5 \%$ Triton $X-100$, and $10 \%$ goat serum in PBS. Retinal sections were incubated with primary antibody overnight at $4^{\circ} \mathrm{C}$ followed by three 5 minute washes with PBST before incubation with secondary antibody and DAPI. After three five minute washes in PBST and coverslip placement, a Nikon C2 Confocal Microscope was used to image slides.

\section{Retinal histology of the rd10 mice}

Knockout and control mice were euthanized, and whole eyes were enucleated before marking the superior pole with a red tissue dye (Marketlab), and eyes were then fixed for 48 hours using Alcohol Z-fixative (Excalibur Pathology). Samples were then shipped to Excalibur Pathology for tissue processing and preparation of hematoxylin and eosin (H\&E) stained slides. Images of stained slides were collected on a Nikon C2 Microscope using Elements software (Nikon). Images were processed using ImageJ software (National Institutes of Health).

\section{PDE6 assembly assay by ROS1 pulldown}

After euthanasia, retinas were isolated and frozen on dry ice before homogenization by sonication in co-immunoprecipitation buffer $(20 \mathrm{mM}$ Tris- $\mathrm{HCl} \mathrm{pH} 8$, $137 \mathrm{mM} \mathrm{NaCl}, 2 \mathrm{mM}$ EDTA, $0.1 \%$ Triton $\mathrm{X}-100,0.02 \%$ sodium azide, protease inhibitor cocktail, and $10 \mathrm{mM}$ iodoacetamide). Samples were centrifuged at $13,000 \mathrm{Xg}$ for $10 \mathrm{~min}$ at $4^{\circ} \mathrm{C}$ to remove debris. Lysates were then precleared by tumble incubation with protein $\mathrm{A} / \mathrm{G}$ beads for 30 minutes at $4^{\circ} \mathrm{C}$ before centrifugation at $13,000 \mathrm{Xg}$ for $10 \mathrm{~min}$. A total fraction was collected before tumble incubating samples with ROS1 monoclonal 
antibody for four hours at $4^{\circ} \mathrm{C}$. Samples were centrifuged at $13,000 \mathrm{Xg}$ for 10 minutes at $4^{\circ} \mathrm{C}$. The supernatant was tumble incubated with protein $A / G$ beads for 60 minutes at $4^{\circ} \mathrm{C}$ before centrifugation at $13,000 \mathrm{Xg}$ for 30 seconds. After collecting the unbound fraction, bead pellets were washed three times with washing buffer $(10 \mathrm{mM}$ Tris- $\mathrm{HCl} \mathrm{pH}$ 7.4, $150 \mathrm{mM} \mathrm{NaCl}, 1 \mathrm{mM}$ EDTA, $0.1 \%$ Triton $\mathrm{X}-100,0.02 \%$ sodium azide, and protease inhibitor cocktail). Laemmli buffer (2\% SDS, 10\% glycerol, 5\% 2-mercaptoethanol, $0.002 \%$ bromophenol blue, and $62.5 \mathrm{mM}$ Tris- $\mathrm{HCl} \mathrm{pH} \mathrm{6.8)} \mathrm{was} \mathrm{then} \mathrm{added} \mathrm{to} \mathrm{the} \mathrm{beads}$ and samples were boiled for 5 minutes, lightly vortexed and subjected to centrifugation at $13,000 \mathrm{Xg}$ for 30 seconds. Samples from the total, unbound, and bound fractions were then size fractionated on SDS-PAGE gels before immunoblotting as described earlier.

\section{Antibodies}

Throughout this work, the following primary antibodies were used at 1:1000 dilutions: rabbit anti-PDE6y (Thermo-Fisher), rabbit anti-PDE6 $\beta$ (Thermo-Fisher), rabbit anti-PDE6 $\alpha$ (Thermo-Fisher), anti-assembled PDE6 (i.e. ROS1) was a kind gift from Dr. Ted Wensel from Baylor College and Rick Cote from University of New Hampshire, rabbit anti-rod-Transducin- $\alpha$ (Santa Cruz), rabbit anti-RPE65 was a kind gift from Dr. Michael Redmond from the National Eye Institute, mouse anti-GAPDH (Fitzgerald), rhodamine peanut agglutinin (PNA: cone OS sheath marker, Vector laboratories), and fluorescein wheat germ agglutinin (WGA: rod OS sheath marker, Vector laboratories). 


\section{ACKNOWLEDGEMENTS}

This work was supported by the National Institutes of Health [grant numbers RO1 EY028035, R01 EY025536, and R21 EY027707]; the West Virginia Lions Club Foundation; and International Lions Club Foundation.

We thank Dr. Michael Redmond for kindly providing us with an aliquot of antiRPE65 antibody and Drs. Vladimir Kefalov and Janis Lem for kindly providing us with the Gnat1-/- and Rpe65-/-knockout mice. We also thank Dr. Ted Wensel and Dr. Rick Cote for providing us with the ROS1 antibody. 


\section{CONFLICT OF INTEREST}

The authors have no conflicts of interest. 


\section{REFERENCES}

1. Fahim, A.T., Daiger, S.P. and Weleber, R.G. (2017) Nonsyndromic retinitis pigmentosa overview. In GeneReviews $\AA$ [Internet], University of Washington, Seattle.

2. Ferrari, S., Di lorio, E., Barbaro, V., Ponzin, D., S Sorrentino, F. and Parmeggiani, F. (2011) Retinitis pigmentosa: genes and disease mechanisms. Current Genom., 12, pp.238-249.

3. Hartong, D.T., Berson, E.L. and Dryja, T.P. (2006) Retinitis pigmentosa. The Lancet, 368, pp.1795-1809.

4. Geruschat, D. and Turano, K. (2002) Connecting research on retinitis pigmentosa to the practice of orientation and mobility. J. of Vis. Impair. \& Blind., 96, pp.69-85.

5. Chang, B., Hawes, N.L., Pardue, M.T., German, A.M., Hurd, R.E., Davisson, M.T., Nusinowitz, S., Rengarajan, K., Boyd, A.P., Sidney, S.S. et al. (2007) Two mouse retinal degenerations caused by missense mutations in the $\beta$-subunit of rod cGMP phosphodiesterase gene. Vis. Res., 47, pp.624-633.

6. Kiser, P.D. and Palczewski, K. (2010) Membrane-binding and enzymatic properties of RPE65. Prog. in Ret. and Eye Res., 29, pp.428-442.

7. Huang, J., Possin, D.E. and Saari, J.C. (2009) Localizations of visual cycle components in retinal pigment epithelium. Mol. Vis., 15, p.223.

8. Parker, R.O. and Crouch, R.K. (2010) Retinol dehydrogenases (RDHs) in the visual cycle. Exp. Eye Res., 91, pp.788-792. 
9. Moiseyev, G., Chen, Y., Takahashi, Y., Wu, B.X. and Ma, J.X. (2005) RPE65 is the isomerohydrolase in the retinoid visual cycle. Proc. of the Nat. Acad. of Sci., 102, pp.12413-12418.

10. Redmond, T.M., Yu, S., Lee, E., Bok, D., Hamasaki, D., Chen, N., Goletz, P., Ma, J.X., Crouch, R.K. and Pfeifer, K. (1998) Rpe65 is necessary for production of 11-cis-vitamin A in the retinal visual cycle. Nat. Genet., 20, p.344.

11.Grimm, C., Wenzel, A., Hafezi, F., Yu, S., Redmond, T.M. and Remé, C.E. (2000) Protection of Rpe65-deficient mice identifies rhodopsin as a mediator of light-induced retinal degeneration. Nat. Genet., 25, p.63.

12. Calvert, P.D., Krasnoperova, N.V., Lyubarsky, A.L., Isayama, T., Nicolo, M., Kosaras, B., Wong, G., Gannon, K.S., Margolskee, R.F., Sidman, R.L. et al. (2000) Phototransduction in transgenic mice after targeted deletion of the rod transducin a-subunit. Proc. of the Nat. Acad. of Sci., 97, pp.13913-13918.

13. Humphries, M.M., Rancourt, D., Farrar, G.J., Kenna, P., Hazel, M., Bush, R.A., Sieving, P.A., Sheils, D.M., Creighton, P., Erven, A. et al. (1997) Retinopathy induced in mice by targeted disruption of the rhodopsin gene. Nat. Genet., 15, p.216.

14. Kolandaivelu, S., Huang, J., Hurley, J.B. and Ramamurthy, V. (2009) AIPL1, a protein associated with childhood blindness, interacts with a-subunit of rod phosphodiesterase (PDE6) and is essential for its proper assembly. J. of Biol. Chem., 284, pp.30853-30861.

15. Wang, T., Reingruber, J., Woodruff, M.L., Majumder, A., Camarena, A., Artemyev, N.O., Fain, G.L. and Chen, J. (2018) The PDE6 mutation in the rd10 
retinal degeneration mouse model causes protein mislocalization and instability and promotes cell death through increased ion influx. J. of Biol. Chem., 293, pp.15332-15346.

16. Paquet-Durand, F., Beck, S., Michalakis, S., Goldmann, T., Huber, G., Mühlfriedel, R., Trifunović, D., Fischer, M.D., Fahl, E., Duetsch, G. et al. (2010) A key role for cyclic nucleotide gated (CNG) channels in cGMP-related retinitis pigmentosa. Hum. Mol. Genet., 20, pp.941-947.

17.Tsang, S.H., Gouras, P., Yamashita, C.K., Kjeldbye, H., Fisher, J., Farber, D.B. and Goff, S.P. (1996) Retinal degeneration in mice lacking the $y$ subunit of the rod cGMP phosphodiesterase. Science, 272, pp.1026-1029.

18. Dvir, L., Srour, G., Abu-Ras, R., Miller, B., Shalev, S.A. and Ben-Yosef, T. (2010) Autosomal-recessive early-onset retinitis pigmentosa caused by a mutation in PDE6G, the gene encoding the gamma subunit of rod cGMP phosphodiesterase. The Am. J. of Hum. Genet., 87, pp.258-264.

19. Lobanova, E.S., Finkelstein, S., Skiba, N.P. and Arshavsky, V.Y. (2013) Proteasome overload is a common stress factor in multiple forms of inherited retinal degeneration. Proc. of the Nat. Acad. of Sci., 110, pp.9986-9991.

20.Weiss, E.R., Heller-Harrison, R.A., Diez, E., Crasnier, M., Malbon, C.C. and Johnson, G.L. (1990) Rhodopsin expressed in Chinese hamster ovary cells regulates adenylyl cyclase activity. J. of Mol. Endocrine., 4, pp.71-79.

21. Weiss, E.R., Hao, Y., Dickerson, C.D., Osawa, S., Shi, W., Zhang, L.R. and Wong, F. (1995) Altered cAMP levels in retinas from transgenic mice expressing a rhodopsin mutant. Biochem. and Biophys. Res. Comm., 216, pp.755-761. 
22.Li, X., Gutierrez, D.V., Hanson, M.G., Han, J., Mark, M.D., Chiel, H., Hegemann, P., Landmesser, L.T. and Herlitze, S. (2005) Fast noninvasive activation and inhibition of neural and network activity by vertebrate rhodopsin and green algae channelrhodopsin. Proc. of the Nat. Acad. of Sci., 102, pp.17816-17821.

23. Kanaho, Y., Tsai, S.C., Adamik, R., Hewlett, E.L., Moss, J. and Vaughan, M. (1984) Rhodopsin-enhanced GTPase activity of the inhibitory GTP-binding protein of adenylate cyclase. J. of Biol. Chem., 259, pp.7378-7381.

24. Alfinito, P.D. and Townes-Anderson, E. (2002) Activation of mislocalized opsin kills rod cells: a novel mechanism for rod cell death in retinal disease. Proc. of the Nat. Acad. of Sci., 99, pp.5655-5660.

25. Campbell, A.P. and Smrcka, A.V. (2018) Targeting G protein-coupled receptor signalling by blocking G proteins. Nat. Rev. Drug Discov., 17, pp.789-803.

26. Fan, J., Sakurai, K., Chen, C.K., Rohrer, B., Wu, B.X., Yau, K.W., Kefalov, V. and Crouch, R.K. (2010) Deletion of GRK1 causes retina degeneration through a transducin-independent mechanism. J. of Neurosci., 30, pp.2496-2503.

27. Hao, W., Wenzel, A., Obin, M.S., Chen, C.K., Brill, E., Krasnoperova, N.V., Eversole-Cire, P., Kleyner, Y., Taylor, A., Simon, M.I. et al. (2002) Evidence for two apoptotic pathways in light-induced retinal degeneration. Nat. Genet., 32, p.254.

28. Brockerhoff, S.E., Rieke, F., Matthews, H.R., Taylor, M.R., Kennedy, B., Ankoudinova, I., Niemi, G.A., Tucker, C.L., Xiao, M., Cilluffo, M.C. et al. (2003) Light stimulates a transducin-independent increase of cytoplasmic $\mathrm{Ca} 2+$ and 
suppression of current in cones from the zebrafish mutant nof. J. of Neurosci., 23, pp.470-480.

29. Osawa, S., Jo, R., Xiong, Y., Reidel, B., Tserentsoodol, N., Arshavsky, V.Y., luvone, P.M. and Weiss, E.R. (2011) Phosphorylation of G protein-coupled receptor kinase 1 (GRK1) is regulated by light but independent of phototransduction in rod photoreceptors. J. of Biol. Chem., 286, pp.20923-20929.

30. Rajala, A., Anderson, R.E., Ma, J.X., Lem, J., Al-Ubaidi, M.R. and Rajala, R.V. (2007) G-protein-coupled receptor rhodopsin regulates the phosphorylation of retinal insulin receptor. J. of Biol. Chem., 282, pp.9865-9873.

31. Rajala, A., Tanito, M., Le, Y.Z., Kahn, C.R. and Rajala, R.V. (2008) Loss of neuroprotective survival signal in mice lacking insulin receptor gene in rod photoreceptor cells. J. of Biol. Chem., 283, pp.19781-19792.

32. Gupta, V.K., Rajala, A. and Rajala, R.V. (2012) Insulin receptor regulates photoreceptor CNG channel activity. Am. J. of Phys.-Endocrine. and Metab., 303, pp.E1363-E1372.

33. Guo, C., Otani, A., Oishi, A., Kojima, H., Makiyama, Y., Nakagawa, S. and Yoshimura, N. (2012) Knockout of ccr2 alleviates photoreceptor cell death in a model of retinitis pigmentosa. Exp. Eye Res., 104, pp.39-47.

34. Strettoi, E., Gargini, C., Novelli, E., Sala, G., Piano, I., Gasco, P. and Ghidoni, R. (2010) Inhibition of ceramide biosynthesis preserves photoreceptor structure and function in a mouse model of retinitis pigmentosa. Proc. of the Nat. Acad. of Sci., 107, pp.18706-18711. 
35. Xu, L., Kong, L., Wang, J. and Ash, J.D. (2018) Stimulation of AMPK prevents degeneration of photoreceptors and the retinal pigment epithelium. Proc. of the Nat. Acad. of Sci., 115, pp.10475-10480.

36. Patel, A.K., Surapaneni, K., Yi, H., Nakamura, R.E., Karli, S.Z., Syeda, S., Lee, T. and Hackam, A.S. (2015) Activation of Wnt/ $\beta$-catenin signaling in Muller glia protects photoreceptors in a mouse model of inherited retinal degeneration. Neuropharmacology, 91, pp.1-12.

37. Platón-Corchado, M., Barcelona, P.F., Jmaeff, S., Marchena, M., HernándezPinto, A.M., Hernández-Sánchez, C., Saragovi, H.U. and De La Rosa, E.J. (2017) p75 NTR antagonists attenuate photoreceptor cell loss in murine models of retinitis pigmentosa. Cell Death \& Dis., 8, p.e2922.

38. de la Cámara, C.M.F., Hernández-Pinto, A.M., Olivares-González, L., CuevasMartín, C., Sánchez-Aragó, M., Hervás, D., Salom, D., Cuezva, J.M., Enrique, J., Millán, J.M. et al. (2015) Adalimumab reduces photoreceptor cell death in a mouse model of retinal degeneration. Sci. Rep., 5, p.11764.

39. Xiang, Z., Bao, Y., Zhang, J., Liu, C., Xu, D., Liu, F., Chen, H., He, L., Ramakrishna, S., Zhang, Z. et al. (2018) Inhibition of non-NMDA ionotropic glutamate receptors delays the retinal degeneration in rd10 mouse. Neuropharmacology, 139, pp.137-149.

40. Rodriguez-Muela, N., Hernandez-Pinto, A.M., Serrano-Puebla, A., Garcia-Ledo, L., Latorre, S.H., De La Rosa, E.J. and Boya, P. (2015) Lysosomal membrane permeabilization and autophagy blockade contribute to photoreceptor cell death in a mouse model of retinitis pigmentosa. Cell Death and Diff., 22, p.476. 
41. Nakao, T., Tsujikawa, M., Notomi, S., Ikeda, Y. and Nishida, K. (2012) The role of mislocalized phototransduction in photoreceptor cell death of retinitis pigmentosa. PLoS One, 7, p.e32472.

42. Isiegas, C., Marinich-Madzarevich, J.A., Marchena, M., Ruiz, J.M., Cano, M.J., de la Villa, P., Hernández-Sánchez, C., Enrique, J. and de Pablo, F. (2016) Intravitreal injection of proinsulin-loaded microspheres delays photoreceptor cell death and vision loss in the rd10 mouse model of retinitis pigmentosa. Invest. Ophthalmol. Vis. Sci., 57, pp.3610-3618.

43. Arroba, A.I., Álvarez-Lindo, N., Van Rooijen, N. and Enrique, J. (2011) Microgliamediated IGF-I neuroprotection in the rd10 mouse model of retinitis pigmentosa. Invest. Ophthalmol. Vis. Sci., 52, pp.9124-9130.

44.Zhao, L., Zabel, M.K., Wang, X., Ma, W., Shah, P., Fariss, R.N., Qian, H., Parkhurst, C.N., Gan, W.B. and Wong, W.T. (2015) Microglial phagocytosis of living photoreceptors contributes to inherited retinal degeneration. EMBO Mol. Med., 7, pp.1179-1197.

45. Sasahara, M., Otani, A., Oishi, A., Kojima, H., Yodoi, Y., Kameda, T., Nakamura, H. and Yoshimura, N. (2008) Activation of bone marrow-derived microglia promotes photoreceptor survival in inherited retinal degeneration. The Am. J. of Path., 172, pp.1693-1703.

46. Wang, X., Zhao, L., Zhang, Y., Ma, W., Gonzalez, S.R., Fan, J., Kretschmer, F., Badea, T.C., Qian, H.H. and Wong, W.T. (2017) Tamoxifen provides structural and functional rescue in murine models of photoreceptor degeneration. J. of Neurosci., 37, pp.3294-3310. 
47. Phillips, M.J., Walker, T.A., Choi, H.Y., Faulkner, A.E., Kim, M.K., Sidney, S.S., Boyd, A.P., Nickerson, J.M., Boatright, J.H. and Pardue, M.T. (2008) Tauroursodeoxycholic acid preservation of photoreceptor structure and function in the rd10 mouse through postnatal day 30. Invest. Ophthalmol. Vis. Sci., 49, pp.2148-2155.

48. Kang, K., Tarchick, M.J., Yu, X., Beight, C., Bu, P. and Yu, M. (2016) Carnosic acid slows photoreceptor degeneration in the Pde6b rd10 mouse model of retinitis pigmentosa. Sci. Rep., 6, p.22632.

49. Doonan, F., O’Driscoll, C., Kenna, P. and Cotter, T.G. (2011) Enhancing survival of photoreceptor cells in vivo using the synthetic progestin Norgestrel. J. of Neurochem., 118, pp.915-927.

50. Komeima, K., Rogers, B.S. and Campochiaro, P.A. (2007) Antioxidants slow photoreceptor cell death in mouse models of retinitis pigmentosa. J. of Cell. Phys., 213, pp.809-815.

51.Picard, E., Jonet, L., Sergeant, C., Vesvres, M.H., Behar-Cohen, F., Courtois, Y. and Jeanny, J.C. (2010) Overexpressed or intraperitoneally injected human transferrin prevents photoreceptor degeneration in rd10 mice. Mol. Vis., 16, p.2612.

52. Obolensky, A., Berenshtein, E., Lederman, M., Bulvik, B., Alper-Pinus, R., Yaul, R., Deleon, E., Chowers, I., Chevion, M. and Banin, E. (2011) Zincdesferrioxamine attenuates retinal degeneration in the rd10 mouse model of retinitis pigmentosa. Free Radical Bio. and Med., 51, pp.1482-1491. 
53. Ikeda, H.O., Sasaoka, N., Koike, M., Nakano, N., Muraoka, Y., Toda, Y., Fuchigami, T., Shudo, T., Iwata, A., Hori, S. et al. (2014) Novel VCP modulators mitigate major pathologies of rd10, a mouse model of retinitis pigmentosa. Sci. Rep., 4, p.5970.

54. Barone, I., Novelli, E., Piano, I., Gargini, C. and Strettoi, E. (2012) Environmental enrichment extends photoreceptor survival and visual function in a mouse model of retinitis pigmentosa. PloS One, 7, p.e50726.

55. Barone, I., Novelli, E. and Strettoi, E. (2014) Long-term preservation of cone photoreceptors and visual acuity in rd10 mutant mice exposed to continuous environmental enrichment. Mol. Vis., 20, p.1545.

56. Hattar, S., Lucas, R.J., Mrosovsky, N., Thompson, S., Douglas, R.H., Hankins, M.W., Lem, J., Biel, M., Hofmann, F., Foster, R.G. et al. (2003) Melanopsin and rod-cone photoreceptive systems account for all major accessory visual functions in mice. Nature, 424, p.75.

57. Krizaj, D. and Copenhagen, D.R. (2002) Calcium regulation in photoreceptors. Front. in Biosci.: A J. and Virt. Lib., 7, p.d2023.

58. Sokolov, M., Lyubarsky, A.L., Strissel, K.J., Savchenko, A.B., Govardovskii, V.I., Pugh Jr, E.N. and Arshavsky, V.Y. (2002) Massive light-driven translocation of transducin between the two major compartments of rod cells: a novel mechanism of light adaptation. Neuron, 34, pp.95-106.

59. Mendez, A., Lem, J., Simon, M. and Chen, J. (2003) Light-dependent translocation of arrestin in the absence of rhodopsin phosphorylation and transducin signaling. J. of Neurosci., 23, pp.3124-3129. 
60. Rajala, A., Daly, R.J., Tanito, M., Allen, D.T., Holt, L.J., Lobanova, E.S., Arshavsky, V.Y. and Rajala, R.V. (2009) Growth factor receptor-bound protein 14 undergoes light-dependent intracellular translocation in rod photoreceptors: functional role in retinal insulin receptor activation. Biochemistry, 48, pp.55635572.

61. Woodruff, M.L., Sampath, A.P., Matthews, H.R., Krasnoperova, N.V., Lem, J. and Fain, G.L. (2002) Measurement of cytoplasmic calcium concentration in the rods of wild-type and transducin knock-out mice. The J. of Phys., 542, pp.843854.

62. Berkowitz, B.A., Lewin, A.S., Biswal, M.R., Bredell, B.X., Davis, C. and Roberts, R. (2016) MRI of retinal free radical production with laminar resolution in vivo. Invest. Ophthalmol. Vis. Sci., 57, pp.577-585.

63. Gimenez, E. and Montoliu, L. (2001) A simple polymerase chain reaction assay for genotyping the retinal degeneration mutation (Pdebrd1) in FVB/N-derived transgenic mice. Lab. Animals, 35, pp.153-156.

64.Pak, J.S., Lee, E.J. and Craft, C.M. (2015) The retinal phenotype of Grk1-/- is compromised by a Crb1rd8 mutation. Mol. Vis., 21, p.1281.

65. Cottet, S., Jüttner, R., Voirol, N., Chambon, P., Rathjen, F.G., Schorderet, D.F. and Escher, P. (2013) Retinal pigment epithelium protein of 65 kDA gene-linked retinal degeneration is not modulated by chicken acidic leucine-rich epidermal growth factor-like domain containing brain protein/Neuroglycan $\mathrm{C} /$ chondroitin sulfate proteoglycan 5. Mol. Vis., 19, p.2312. 
66. Tracy, C.M., Kolesnikov, A.V., Blake, D.R., Chen, C.K., Baehr, W., Kefalov, V.J. and Willardson, B.M. (2015) Retinal cone photoreceptors require phosducin-like protein 1 for G protein complex assembly and signaling. PloS One, 10, p.e0117129.

67. Wright, Z.C., Singh, R.K., Alpino, R., Goldberg, A.F., Sokolov, M. and Ramamurthy, V. (2016) ARL3 regulates trafficking of prenylated phototransduction proteins to the rod outer segment. Hum. Mol. Genet., 25, pp.2031-2044.

68. Severns, M.L. and Johnson, M.A. (1993) The care and fitting of Naka-Rushton functions to electroretinographic intensity-response data. Doc. Ophthalmol., 85, pp.135-150. 


\section{LEGENDS:}

Figure 1: Dark rearing delays photoreceptor cell death in rd10 animals. A. Brightfield images of hematoxylin and eosin (H\&E) stained retinal cross sections from the PN45 rd10 mice reared under standard light conditions and in darkness (OS: outer segment, IS: inner segment, ONL: outer nuclear layer, INL: inner nuclear layer, and GCL: ganglion cell layer). Scale bar $=30 \mu \mathrm{m}$. B. Spider diagram showing the quantification of the ONL thickness at six regions from the inferior to superior retina in the light and dark reared rd10 mice at PN45 $(n=3)$. Data is shown as the mean \pm the SEM with statistical significance calculated using the two tailed homoscedastic unpaired student's t-test $\left({ }^{*}=\mathrm{P}<0.05 ;{ }^{* *}=\mathrm{P}<0.01\right)$.

Figure 2: Preservation of retinal function in dark reared rd10 mice. A. Representative scotopic $\left(0.151 \mathrm{~cd}-\mathrm{s} / \mathrm{m}^{2}\right)$ electroretinograms (ERGs) of the standard light (red) and dark (green) reared rd10 mice at PN45 along with age-matched C57BL6/J controls (black) after overnight dark adaptation (Scotopic scale bar: $x$-axis $=20 \mathrm{~ms}, y$-axis $=200 \mu \mathrm{V}$ ). B. Representative photopic $\left(7.6 \mathrm{~cd}-\mathrm{s} / \mathrm{m}^{2}\right)$ ERGs of the standard light (red) and dark (green) reared rd10 mice along with age-matched C57BL6/J controls (black) under lightadapted conditions using a $30 \mathrm{~cd}-\mathrm{s} / \mathrm{m}^{2}$ rod-saturating white background light at PN45 (Photopic scale bar: $x$-axis $=20 \mathrm{~ms}, y$-axis $=40 \mu \mathrm{V}$ ). C. Light stimulus intensity plot of the scotopic "b"-wave response from the standard light and dark reared rd10 mice along with age-matched C57BL6/J controls at PN45 ( $n=3)$. The dose response relationship was modeled using the Naka-Rushton fit with maximum amplitudes determined to be $833 \pm 64 \mu \mathrm{V}, 479 \pm 31 \mu \mathrm{V}$, and $50 \pm 5 \mu \mathrm{V}$ for the wildtype, dark and light reared rd10 mice respectively. D. Light stimulus intensity plot of the photopic "b"-wave response from the 
dark and standard light reared rd10 mice along with age-matched C57BL6/J controls at PN45 ( $n=3)$. The dose response relationship was modeled using the Naka-Rushton fit with maximum amplitudes determined to be $153 \pm 20 \mu \mathrm{V}, 129 \pm 19 \mu \mathrm{V}$, and $22 \pm 4 \mu \mathrm{V}$ for the wildtype, dark and light reared rd10 mice respectively. Data is shown as the mean \pm the SEM with statistical significance calculated using the two tailed homoscedastic unpaired student's t-test $\left({ }^{*}=\mathrm{P}<0.05 ;{ }^{* *}=\mathrm{P}<0.01 ;{ }^{* *}=\mathrm{P}<0.001\right)$.

Figure 3: Light-dependent photoreceptor cell death in rd10 mice is not mediated by transducin signaling. A. Validation of the Gnat1-/- rd10 mice by immunoblotting retinal lysates and subsequently probing with an antibody against rod transducin-a (GaT1). Glyceraldehyde 3-phosphate dehydrogenase (GAPDH) serves as a loading control. Molecular weight in kilodaltons $(\mathrm{kDa})$ is indicated on the right. $\mathrm{B}$. H\&E stained retinal cross sections from the standard light reared Gnat1-/- rd10 mice along with littermate rd10 controls at PN45. (OS: outer segment, IS: inner segment, ONL: outer nuclear layer, INL: inner nuclear layer, and GCL: ganglion cell layer). Scale bar $=30 \mu \mathrm{m} . \mathrm{C} . \mathrm{H} \& \mathrm{E}$ stained retinal cross sections from the dark reared Gnat1-/- rd10 mice along with littermate rd10 controls at PN45. Scale bar $=30 \mu \mathrm{m}$. D. Spider plot showing the quantification of the photoreceptor nuclei at six regions from the inferior to superior retina in the standard light reared Gnat1-/- rd10 mice and littermate rd10 controls at PN45. E. Quantification of photoreceptor nuclei at six regions from the inferior to superior retina in the dark reared Gnat1-/- rd10 mice and littermate rd10 controls at PN45. Data is shown as the mean \pm the SEM ( $n=3$, two tailed homoscedastic unpaired student's t-test; ${ }^{*}=\mathrm{P}<0.05 ;{ }^{* *}=\mathrm{P}<0.01 ;$ N.S. $=$ Not Significant). 
Figure 4: Inactivating Rpe65 protects rd10 mice from light-induced photoreceptor cell death. A. Validation of the Rpe65-/- rd10 mice at PN15 before the onset of photoreceptor degeneration by immunofluorescence microscopy of retinal cross sections stained with RPE65 antibody (Green), peanut agglutinin (PNA: cone photoreceptor OS marker, Red), and DAPI nuclear counterstain (Blue). Scale bar =

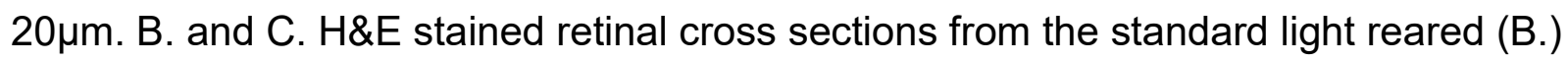
and dark-reared (C.) Rpe65-/- rd10 mice along with littermate rd10 controls at PN45. (OS: outer segment, IS: inner segment, ONL: outer nuclear layer, INL: inner nuclear layer, and GCL: ganglion cell layer). Scale bar $=30 \mu \mathrm{m}$. D. ONL spider plot showing the quantification of the ONL thickness at six regions from the inferior to superior retina in the light reared Rpe65-/- rd10 mice and littermate rd10 controls at PN45. E. ONL spider plot from the inferior to superior retina in the dark reared Rpe65-/- rd10 mice and littermate rd10 controls at PN45. Data is shown as the mean \pm the SEM $(n=3$, two tailed homoscedastic unpaired student's t-test, ${ }^{*}=\mathrm{P}<0.05 ;{ }^{* *}=\mathrm{P}<0.01 ;$ N.S. $=$ Not Significant).

Figure 5: The rd10 mutation causes a reduction in the levels of the functional PDE6 complex and its individual subunits. A. PN15 C57BL6/J (left) and rd10 (right) retinal lysates were used for immunoprecipitation by incubation with ROS1 antibody which recognizes the assembled PDE6aßy2 complex. Following immunoprecipitation, total (T), unbound $(U)$, and bound $(B)$ fractions were subjected to size separation by gel electrophoresis and then electroblotted onto PVDF membranes before probing with antibodies directed against either PDE6a, PDE6 $\beta$, or PDE6y to check for the assembly of each subunit to the complex. B. Immunoblot of retinal lysates from PN15 C57BL6/J wildtype control mice $(n=3)$ and rd10 mice $(n=3)$ probed with antibodies directed against 
PDE6a, PDE6ß, PDE6y, and Glyceraldehyde 3-phosphate dehydrogenase (GAPDH: loading control). C. Immunofluorescence microscopy images of retinal cross sections from C57BL6/J wildtype control mice and light and dark reared rd10 mice after probing with an antibody directed against PDE6 $\beta$ (red), wheat germ agglutinin (WGA: rod photoreceptor OS marker shown in green), and DAPI (blue) counterstain. Scale bar = $10 \mu \mathrm{m}$.

Figure 6: PDE6y but not PDE6a is mislocalized in both light and dark reared rd10 mice. A. Immunofluorescence microscopy images of retinal cross sections from the light and dark reared rd10 mice along with a C57BL6/J wildtype control after probing with antibody directed against PDE6a (red), wheat germ agglutinin (WGA: rod photoreceptor OS marker shown in green), and DAPI (blue) nuclear counterstain. Scale bar $=10 \mu \mathrm{m}$. B. Immunofluorescence microscopy images of retinal cross sections from the light and dark reared rd10 mice along with a C57BL6/J wildtype control after probing with antibody against PDE6y (red), WGA (green), and DAPI (blue). Scale bar $=10 \mu \mathrm{m}$. 


\section{ABBREVIATIONS}

1. B: Bound

2. CHAPS: 3-[(3-cholamidopropyl)dimethylammonio]-1-propanesulfonate

3. DAPI: 4',6-diamidino-2-phenylindole

4. ERG: Electroretinography

5. GAPDH: Glyceraldehyde 3-phosphate dehydrogenase

6. GCL: Ganglion cell layer

7. Gnat1: Rod transducin-a gene

8. GPCR: G-protein-coupled receptor

9. H\&E: Hemoxylin and eosin stain

10. INL: Inner nuclear layer

11. IS: Inner segment

12. OCT: Optimal cutting temperature compound

13. ONL: Outer nuclear layer

14. OS: Outer segment

15.PBS: Phosphate buffered saline

16. PBST: Phosphate buffered saline supplemented with $0.1 \%$ Triton $X-100$

17.PCR: Polymerase chain reaction

18. PDE6: Phosphodiesterase-6

19.PDE6 $\beta$ : Phosphodiesterase- $6 \beta$ subunit

20.PN45: Postnatal day 45

21. PNA: Peanut agglutinin

22. rd10: Retinal degeneration-10 
23. RP: Retinitis pigmentosa

24. RPE: Retinal pigment epithelium

25. Rpe65: Gene encoding the retinal pigment epithelium-specific protein of $65 \mathrm{kDa}$ (RPE65)

26. SEM: Standard error of the mean

27. T: Total

28. U: Unbound

29. Ush2a: Usher syndrome type-2a

30. WGA: Wheat germ agglutinin 
Figure 1

A.
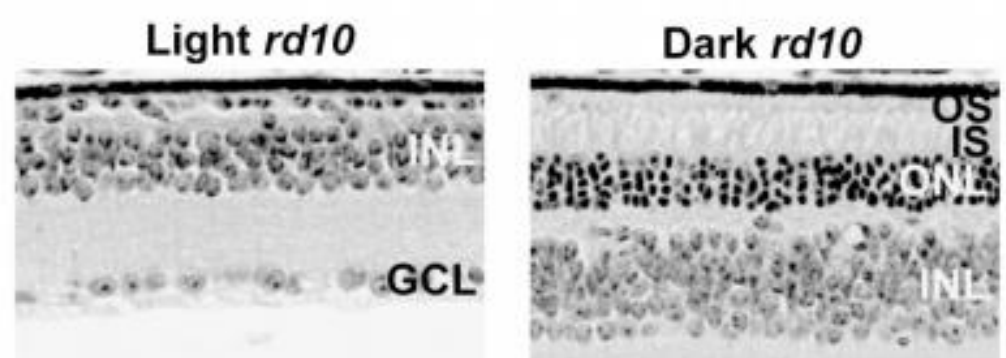

$200900 \mathrm{vi} \cdot \mathrm{GCL}$

B.

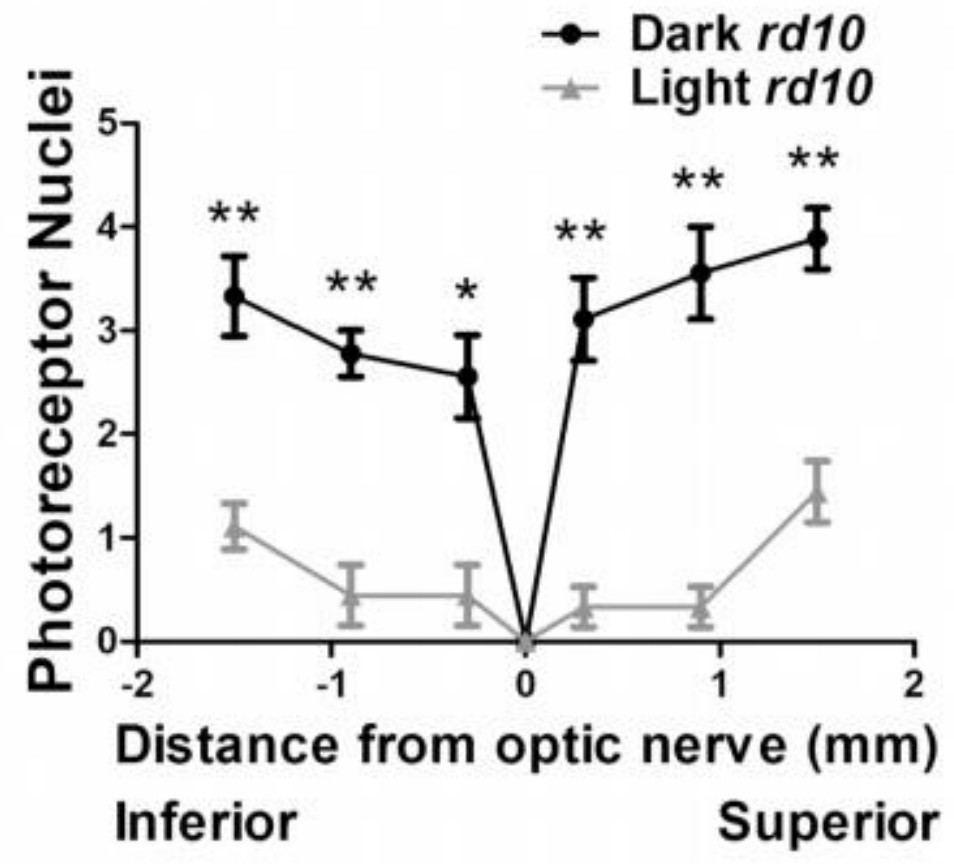


Figure 2

A.

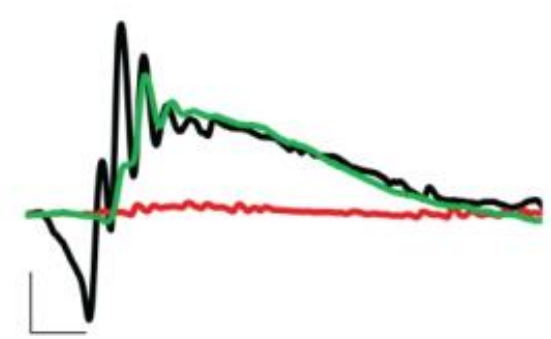

c.

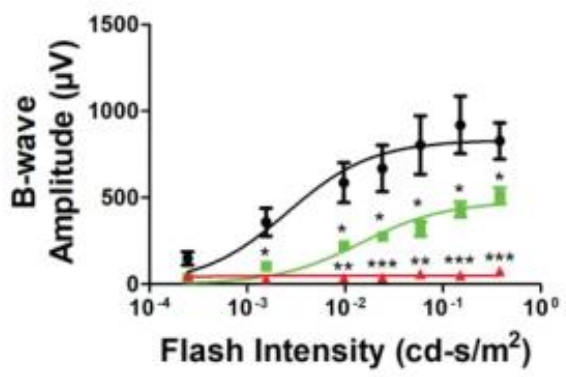

B.

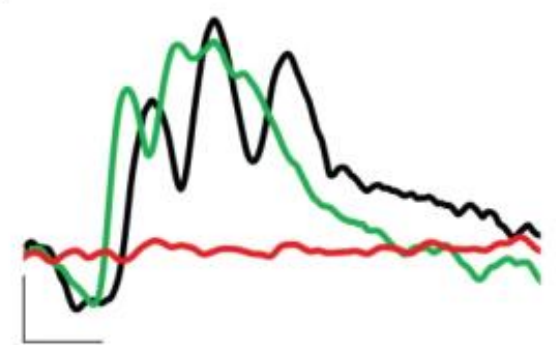

D.

$\rightarrow C 57 B L 6 / J$

-- Dark rd10

- Light rd10

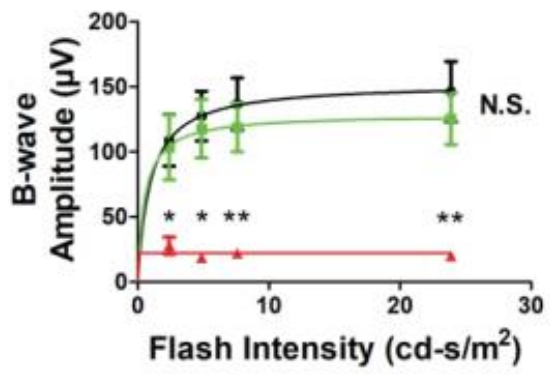


Figure 3

A. Gnat1: +/+ - $-/$

B.
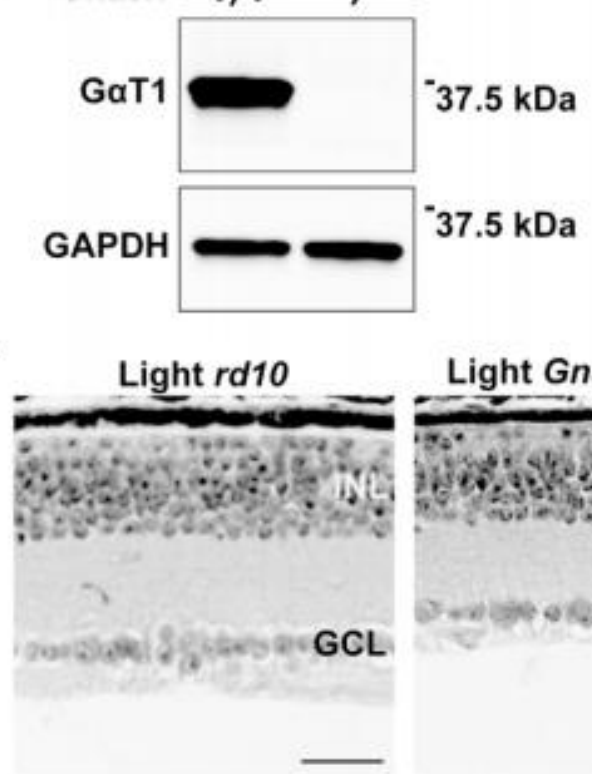

Light Gnat1-/- rd10

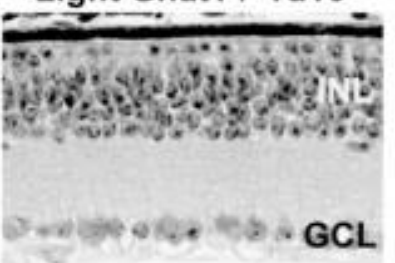

c.

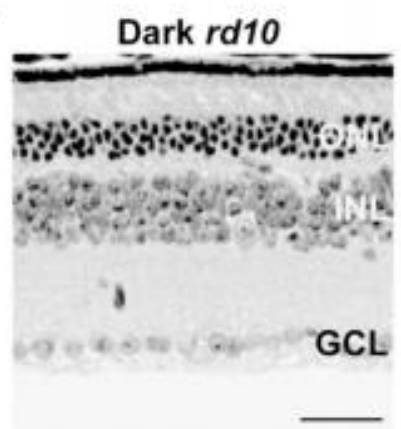

Dark Gnat1\%/-rd10

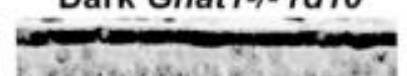

D.

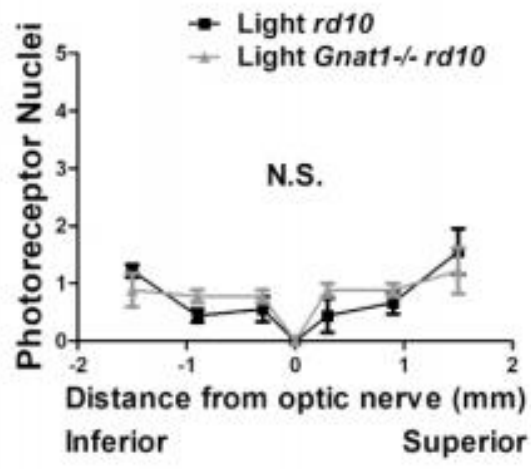

E.

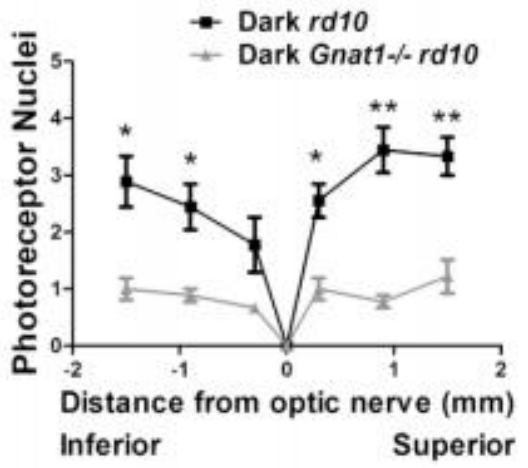




\section{Figure 4}

A.
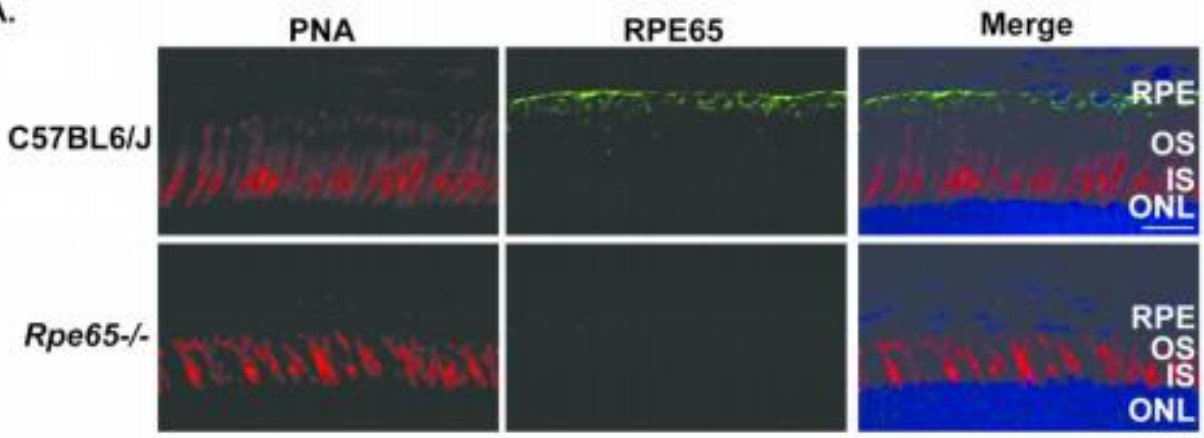

B.

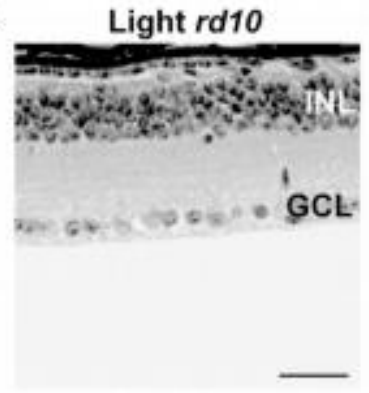

Light Rpe65-/ rd10

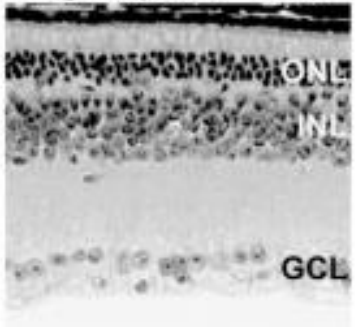

C.

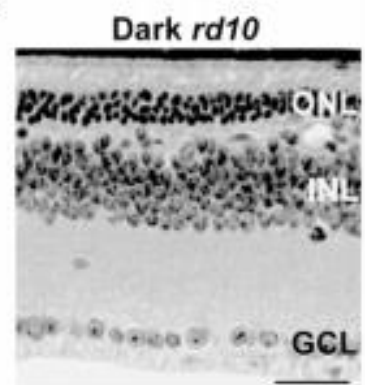

Dark Rpe65-/ rd10
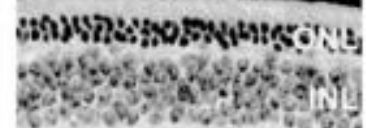

$600 \times 40,7,0009 \mathrm{GCL}$
D.

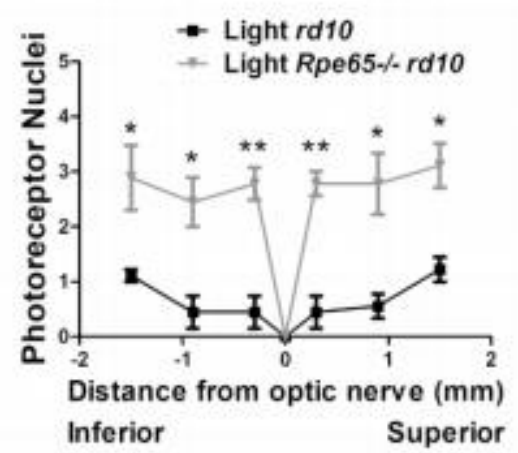

E.

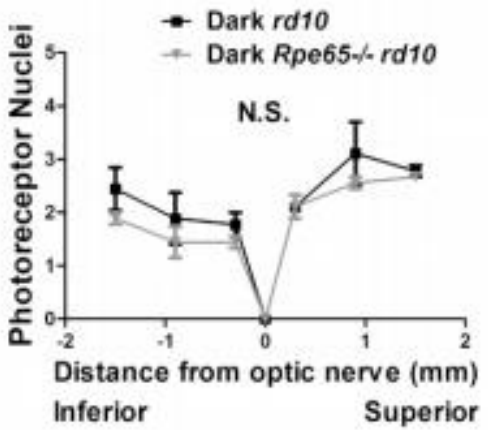


Figure 5

A.

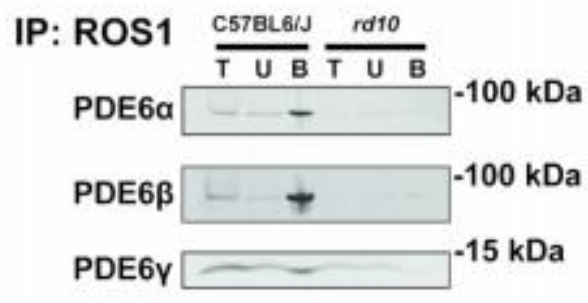

B.

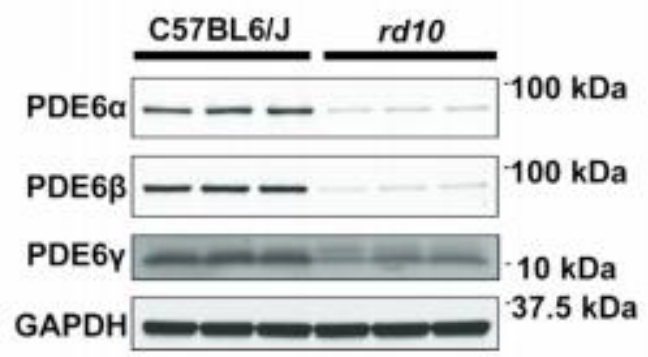

c.

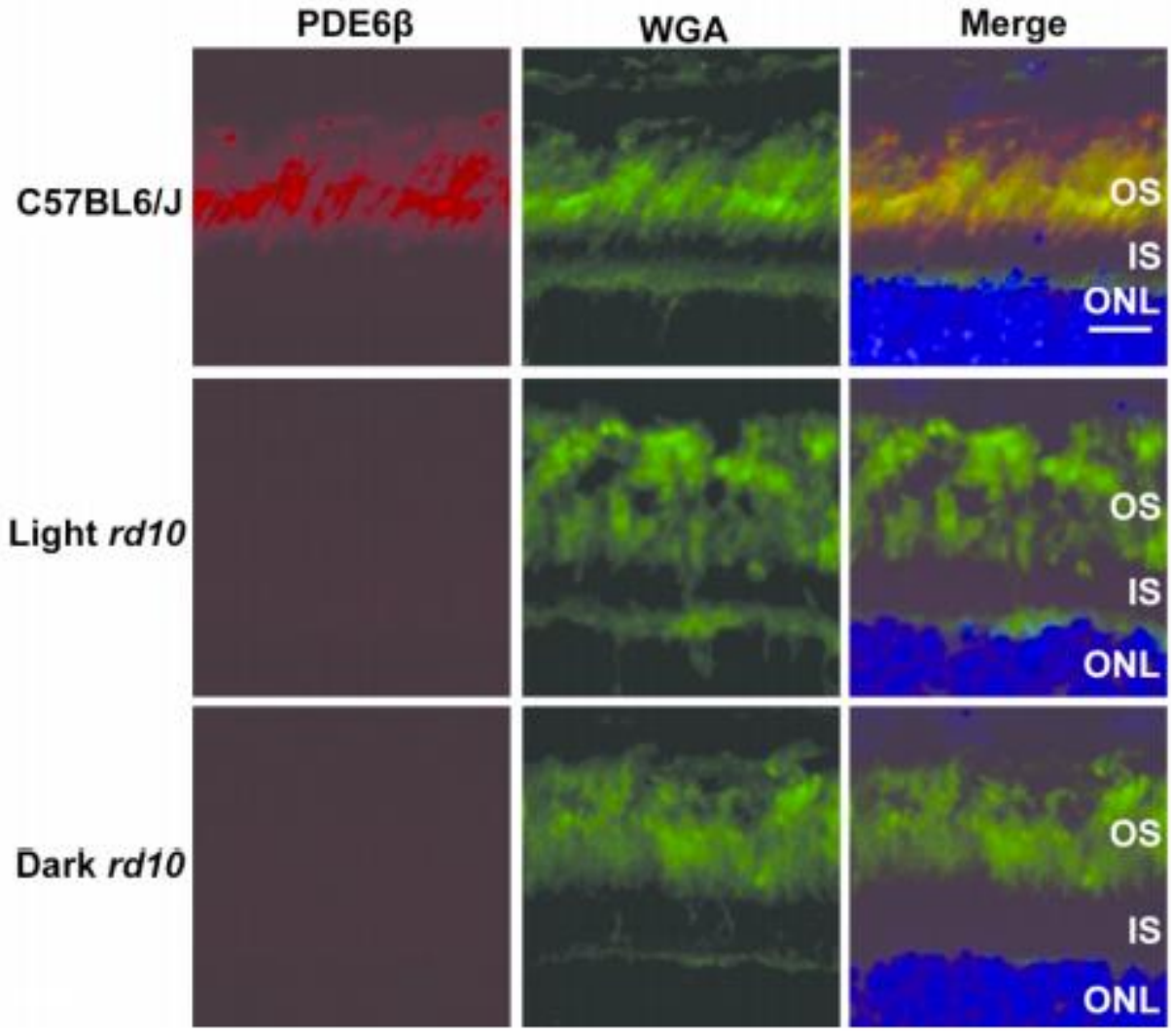


Figure 6
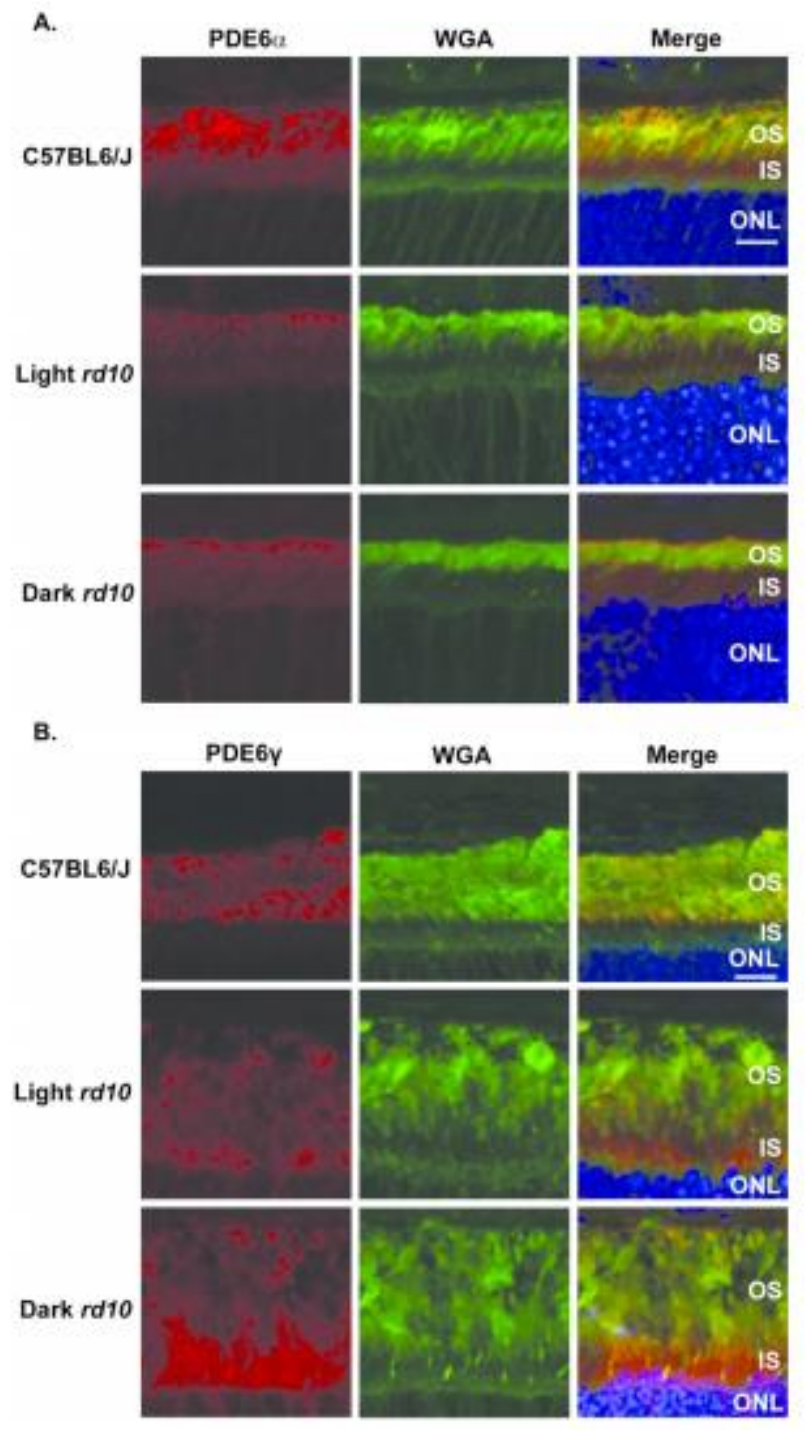


\section{Chapter 4: Discussion and Future Directions}

Previous reports have observed high expression of MSI in the retina ${ }^{1-4}$. However, the biological significance of this expression and the function of MSI in the retina remains largely unknown. To gain mechanistic insight into the function of the MSI RBPs in vivo, we generated knockout mouse models using Cre-LoxP recombination to knock out either Msi1, Msi2, or both Msi1 and Msi2 in the retina and ventral forebrain using the Six3 Cre transgene. We found that there is cross-regulation between the MSI proteins in the retina and that MSI1 and MSI2 can partially compensate for the other's function in photoreceptors. Furthermore, the MSI proteins are essential for vision and retinal cell survival. Interestingly, we found that the MSI proteins are necessary for normal proliferation of RPCs. The MSI proteins also appear to be regulating OS and axoneme development in photoreceptors. Lastly, we show that the MSI proteins regulate alternative splicing of their target transcripts in murine photoreceptor cells, but the effect seen in ret-Msi1-/-: Msi2-/- mice may be additive due to the altered splicing of all MSl's target pre-mRNAs or due to a mechanism other than splicing.

The MSI RBP family consists of two paralogues in vertebrates, MSI1 and MSI2, which have a high degree of sequence identity, and this is thought to have arisen from a gene duplication event ${ }^{5-6}$. Intriguingly, the RNA binding domains of MSI1 and MSI2 have approximately $90 \%$ sequence identity raising the possibility that they can bind similar and/or identical RNA targets ${ }^{5}$. This information suggests that MSI1 and MSI2 have the potential to partially compensate for the loss of the other. Indeed, we observed only minor reductions in visual function after the loss of either MSI1 or MSI2 alone whereas the combined loss of MSI1 and MSI2 resulted in a complete loss of visual function, and this agrees with other studies which have reported a functional redundancy between 
MSI1 and $\mathrm{MSI}^{7-8}$. Moreover, autoregulation and cross-regulation amongst RBPs have emerged as a common mechanism to modulate protein expression at the posttranscriptional level9-10. However, cross-regulation between MSI1 and MSI2 has not been previously reported in the retina, and our studies suggest that MSI1 negatively cross-regulates the other member of its RBP family, MSI2.

The MSI RBPs appear to be crucial for not only photoreceptor cell survival but also inner retinal neuron survival as well. Our findings agree with a previously published study which showed that MSI1 is required for photoreceptor survival ${ }^{2}$. The limiting factor of this study is that it focused on the biological significance of retinal MSI1 expression alone but not MSI2 expression. It is likely that the effects reported by Susaski et. al are not as severe due to the functional redundancy between MSI1 and MSI2 which would account for the intermediate phenotype that they observed.

Our data also revealed changes in RPC proliferation in the absence of MSI (Figure 4). Surprisingly, we found that the number of PHH3-positive and KI67-positive RPCs was increased in the absence of MSI1 and MSI2 even though the number of NBL nuclei in the retina was less than the littermate control. We suspect that MSI1 and MSI2 are regulating differentiation of RPCs, which would account for the increase in proliferation marker staining in the absence of MSI if RPC differentiation was delayed or impeded. Moreover, we found putative MSI binding sites on several mRNAs necessary for proper retinal cell differentiation including Nrl, Nr2e3, Crx, and Pax6 raising the possibility that the MSI RBP family may be regulating transcription factors necessary for retinal cell development at the posttranscriptional level. Likewise, another study has reported that the MSI RBP family may be necessary for the proper differentiation of 
inner root sheath cells in the hair follicle ${ }^{11}$.

In agreement with our hypothesis, the MSI proteins appear to be essential for OS and axoneme development. In the absence of MSI, dysmorphic OS developed, and the axoneme stained in a punctate manner with very little elongation as seen in the littermate control. This is in agreement with Susaki et. al who reported alterations in OS structure in the absence of $\mathrm{MSI}^{2}$. We suspect that the MSI proteins are posttranscriptionally regulating RNA targets that are important for the OS structure. More work will be required to find which RNA targets the MSI proteins are binding and directly regulating. Strikingly, however, the CC of photoreceptors in ret-Msi1-/-: Msi2-/- mice seems to be normal as shown by transmission electron microscopy in addition to normal $\mathrm{CC}$ length measurements and normal trafficking of the phototransduction protein PDE6 through the CC and into the dysmorphic OS. After observing that the MSI proteins are regulating the photoreceptor-specific splicing of several cilia-related transcripts in vivo, we suspect that the alternative exons within these transcripts are not necessary for proper CC formation.

We observed that the MSI proteins regulate a unique alternative splicing program in murine photoreceptors. Strikingly, we found a common theme where the MSI proteins are required for the inclusion of photoreceptor-specific exons into multiple cilia- and OSrelated transcripts in photoreceptors. These include mRNAs from the Bbs8, Cc2d2a, Cep290, and Prom1 genes which encode ubiquitously expressed proteins necessary for ciliogenesis, yet their mRNAs are spliced uniquely in photoreceptors. This photoreceptor-specific splicing occurs through a unique mechanism which we delineated in our previous work ${ }^{1}$. Using Bbs8 as a model RNA target for MSI, we 
showed by RNA pulldown that MSI binds to the downstream intron of the photoreceptorspecific Exon 2A $\mathrm{A}^{1}$. This downstream binding is necessary for Bbs8 Exon $2 \mathrm{~A}$ inclusion which we showed through the use of wildtype and mutated reporter minigenes ${ }^{1}$. Using the reporter minigene with the wildtype intronic sequence downstream of Exon $2 \mathrm{~A}$, we found that MSI1 promoted inclusion of Exon $2 \mathrm{~A}$ into the mature transcript ${ }^{1}$. On the contrary, when the MSI binding sites in the intron downstream of Exon $2 \mathrm{~A}$ were mutated, Exon 2A inclusion was hindered substantially ${ }^{1}$. Intriguingly, our data is in agreement with Cuadrado et al. who reported that MSI may regulate the splicing of Tau $\mathrm{mRNA}^{12}$.

Even though MSI regulates the splicing of the Bbs8, Cc2d2a, Cep290, Cacna2d4, and Slc17a7 pre-mRNAs, knockout of these photoreceptor specific-exons in C57BL6/J mice revealed that these exons are not crucial for photoreceptor function. This suggests that the phenotype witnessed in ret-Msi1-/-: Msi2-/- mice is either cumulative due to the altered splicing of all of MSI's target transcripts together or that another mechanism is responsible for the photoreceptor degeneration. Most notably, the MSI RBP family is highly concentrated in the inner segment, yet the importance of this cytoplasmic localization in photoreceptors remains largely unknown.

These findings provide a strong groundwork for future studies. Most notably, the cumulative list of RNA targets that are regulated by the MSI proteins is still unknown in the vertebrate retina. Through CLIP-sequencing analysis, the in vivo RNA targets of the MSI proteins can be identified by cross linking the RNA to the MSI proteins via ultraviolet light exposure before pulling down the MSI proteins and sequencing the bound $\mathrm{RNA}^{13}$. This will provide insight into not only which RNAs the MSI proteins are 
regulating but also what location on the RNA these proteins are bound to possibly providing clues to their function in the vertebrate retina ${ }^{13}$.

This experiment will also provide insight into mechanisms by which the MSI proteins regulate RPC proliferation and photoreceptor survival and may reveal an essential role for MSI protein expression in retinal development. It will be interesting to see which RNAs are regulated by the MSI proteins that are involved in the modulation of RPC proliferation. Previous studies have shown that the MSI proteins can activate the Wnt and Notch pathways providing a possible explanation for the alterations that we observed in RPC proliferation ${ }^{14,15}$. In addition, the expression of the MSI proteins appear to be essential for not only photoreceptor survival but also inner retinal neuron survival as well. This is supported by other studies which have confirmed that MSI has important antiapoptotic functions $\mathbf{s}^{2,16,17}$.

The findings obtained in rd10 mice have important implications for the future treatment of patients. We discovered that rhodopsin can activate signaling pathways independently of transducin that ultimately lead to light-induced photoreceptor cell death in rd10 mice. Not surprisingly, the next major scientific hurdle that needs to be addressed is identifying the non-canonical G-protein that couples to rhodopsin in vivo. Future experiments will be needed to identify this novel signaling interactor of rhodopsin perhaps through coimmunoprecipitation and mass spectrometry. Crosslinking assays can also be conducted to detect transient or weak interactions. If this non-canonical Gprotein can be identified, it may be possible to treat retinitis pigmentosa patients exhibiting light-induced photoreceptor cell death without affecting their vision or the phototransduction cascade. Remarkably, inhibitory drugs targeting G-protein subunits 
have already been developed and are showing excellent efficacy in preclinical models. In conclusion, we have shown that the Musashi proteins are essential posttranscriptional regulators of photoreceptor morphogenesis and alternative splicing and that mechanisms underlying photoreceptor cell death in retinitis pigmentosa may involve pathological signaling due to light exposure. Future experiments will be needed to address the mechanisms underlying Musashi's functions which we have found to be critical for photoreceptor survival and to address the signaling pathways that underlie transducin-independent rhodopsin signaling in vertebrate photoreceptors. 


\section{References}

1. Murphy, Daniel, et al. "The Musashi 1 controls the splicing of photoreceptorspecific exons in the vertebrate retina." PLoS genetics 12.8 (2016): e1006256.

2. Susaki, Kanako, et al. "Musashi-1, an RNA-binding protein, is indispensable for survival of photoreceptors." Experimental eye research 88.3 (2009): 347-355.

3. Kaneko, Jun, and Chikafumi Chiba. "Immunohistochemical analysis of Musashi-1 expression during retinal regeneration of adult newt." Neuroscience letters 450.3 (2009): 252-257.

4. Nickerson, P. E. B., et al. "Changes in Musashi-1 subcellular localization correlate with cell cycle exit during postnatal retinal development." Experimental eye research 92.5 (2011): 344-352.

5. Ohyama, Takako, et al. "Structure of Musashi1 in a complex with target RNA: the role of aromatic stacking interactions." Nucleic acids research 40.7 (2011): 32183231.

6. Sutherland, Jessie M., et al. "RNA binding proteins in spermatogenesis: an in depth focus on the Musashi family." Asian journal of andrology 17.4 (2015): 529.

7. Li, Ning, et al. "The Msi family of RNA-binding proteins function redundantly as intestinal oncoproteins." Cell reports13.11 (2015): 2440-2455.

8. Sakakibara, Shin-ichi, et al. "RNA-binding protein Musashi family: roles for CNS stem cells and a subpopulation of ependymal cells revealed by targeted disruption and antisense ablation." Proceedings of the National Academy of Sciences99.23 (2002): 15194-15199.

9. Rossbach, Oliver, et al. "Auto-and cross-regulation of the hnRNP L proteins by 
alternative splicing." Molecular and cellular biology 29.6 (2009): 1442-1451.

10. Jangi, Mohini, et al. "Rbfox2 controls autoregulation in RNA-binding protein networks." Genes \& development 28.6 (2014): 637-651.

11. Sugiyama-Nakagiri, Yoriko, et al. "Expression of RNA-binding protein Musashi in hair follicle development and hair cycle progression." The American journal of pathology 168.1 (2006): 80-92.

12. Cuadrado, Ana, et al. "Regulation of tau RNA maturation by thyroid hormone is mediated by the neural RNA-binding protein musashi-1." Molecular and Cellular Neuroscience 20.2 (2002): 198-210.

13. Murigneux, Valentine, et al. "Transcriptome-wide identification of RNA binding sites by CLIP-seq." Methods 63.1 (2013): 32-40.

14. Rezza, Amelie, et al. "The overexpression of the putative gut stem cell marker Musashi-1 induces tumorigenesis through Wnt and Notch activation." J Cell Sci 123.19 (2010): 3256-3265.

15. Takahashi, Tetsufumi, et al. "Musashi-1 post-transcriptionally enhances phosphotyrosine-binding domain-containing $\mathrm{m}$-Numb protein expression in regenerating gastric mucosa." PLoS One 8.1 (2013): e53540.

16. Nikpour, Parvaneh, et al. "The RNA binding protein Musashi1 regulates apoptosis, gene expression and stress granule formation in urothelial carcinoma cells." Journal of cellular and molecular medicine 15.5 (2011): 1210-1224.

17. Szabat, M., et al. "Musashi expression in $\beta$-cells coordinates insulin expression, apoptosis and proliferation in response to endoplasmic reticulum stress in diabetes." Cell death \& disease 2.11 (2011): e232. 
18. Campbell, Adrian P., and Alan V. Smrcka. "Targeting G protein-coupled receptor signaling by blocking G proteins." Nature Reviews Drug Discovery 17.11 (2018): 789-803. 